\title{
ADEQUAÇÃO DE RECIPIENTES, PARA CRIAÇÃO EM DIETAS ARTIFICIAIS, DE PRAGAS COM COMPORTAMENTOS VARIÁVEIS
}

\author{
ANa Maria de Lima Souza
}

Bióloga

Orientador: Prof. Dr. JOSÉ ROBERTO POSTALI PARRA

Dissertação apresentada à Escola

Superior de Agricultura "Luiz de Queiroz", Universidade de São Paulo, para obtenção do título de Mestre em Ciências, Área de Concentração: Entomologia.

\author{
P IR A C I C A B A \\ Estado de São Paulo - Brasil \\ Março - 1999
}


Dados Internacionais de Catalogação na Publicação (CIP) DIVISÃO DE BIBLIOTECA E DOCUMENTAÇÃO - Campus "Luiz de Queiroz"/USP

Souza, Ana Maria de Lima

Adequação de recipientes, para criaçăo em dietas artificiais, de pragas com comportamentos variáveis / Ana Maria de Lima Souza. - - Piracicaba, 1999.

$95 \mathrm{p.}:$ il.

Dissertação (mestrado) - E Escola Superior de Agricultura Luiz de Queiroz, 1999. Bibliografia.

1. Biologia 2. Broca-da-cana-de-açúcar 3. Canibalismo 4. Consumo alimentar 5. Dieta artificial 6. Lagarta-da-maçã-do-algodoeiro 7. Lagarta-da-cartucho-do-milho I. Titulo 
Aos meus queridos pais, Thereza e josé Honório pelo apoio, respeito e dedicação de suas vidas na minha formação pessoal e profissional

Paulo Henrique, Crébio e Lais com muito amor 


\section{AGRADECIMENTOS}

Ao Prof. Dr. José Roberto Postali Parra, Professor Associado do Departamento de Entomologia, Fitopatologia e Zoologia Agrícola da Escola Superior de Agricultura "Luiz de Queiroz", Universidade de São Paulo (ESALQ/USP), pela orientação, amizade e inestimável apoio.

Aos Professores do Curso de Pós-Graduação em Entomologia do Departamento de Entomologia, Fitopatologia e Zoologia Agrícola da Escola Superior de Agricultura "Luiz de Queiroz", Universidade de São Paulo (ESALQ/USP), que transmitiram seus conhecimentos, experiências profissionais e de vida.

Ao Engenheiro Agrônomo Crébio José Ávila (Embrapa/CPAO - Dourados - MS), pela orientação quanto às análises estatísticas, exemplo profissional, apoio nos momentos dificeis e amizade.

Aos Professores Celso Omoto, Evôneo Berti Filho e José Djair Vendramim, pelo apoio durante a realização da pesquisa e amizade.

Ao Conselho Nacional de Desenvolvimento Científico e Tecnológico - CNPq pela concessão de bolsa de estudo durante a realização do curso.

Ao Engenheiro Agrônomo Luiz Antonio Alves José (Cyanamid Química do Brasil Ltda.) pelo fornecimento das bandejas Bio-RT-32 para a realização da pesquisa e amizade.

Ao Engenheiro Agrônomo Sérgio Zambom (Rhône-Poulenc Agro Brasil) pela colaboração durante a realização da pesquisa. 
Ao Engenheiro Agrônomo Nilton Piccinato (Dupont do Brasil S.A.) pela colaboração durante a realização da pesquisa e amizade.

À Bióloga Rosa Maria da Silva Molina, pela inestimável colaboração e apoio durante a realização da pesquisa, pela amizade, estímulo e constante companheirismo.

À Neide Graciano Zério, pela colaboração, apoio durante a execução do trabalho e principalmente amizade.

Ao Biólogo Heraldo Negri de Oliveira, pelo auxílio na parte fotográfica, estímulo e amizade.

Ao Amigo Alexandre de Sene Pinto, pela inestimável colaboração na arte final das fotos, estímulo, amizade e constante companheirismo.

Aos Amigos Cyrene C. Valente, Paulo H. Valente, Carlos H. Miguel, José C. Correa, Éder L. Ribeiro, Olga Saranholi, Fernanda Bacellar, José H. Soares, pelo estímulo e amizade.

Aos Amigos Maria Aparecida Leão Bittencourt, Eliana A. Magrini, Paulo Sérgio Machado Botelho, pela amizade e constante companheirismo.

Aos Amigos e Colegas Alfredo, Miguel, Rossi, Bete, Maria Tereza, Marcos, Denise, Elton, Jairo, pelo convívio fraterno durante o curso.

À Patricia Milano pela amizade e colaboração durante a execução da pesquisa.

Aos Amigos da Biologia, Silvia, Teresinha, Laila, Rosmarina, Marcone, Peter, Alessandra, Mauro, Adriana, Márcia, pelo carinho e amizade. 
Aos Bibliotecários da Prefeitura do Campus de Piracicaba da ESALQ/USP, pela dedicação e em particular à Eliana Maria Garcia Sabino e Kátia Maria de Andrade Ferraz.

A Todos aqueles que, direta ou indiretamente, colaboraram para a execução deste trabalho. 


\section{SUMÁRIO}

PÁGINA

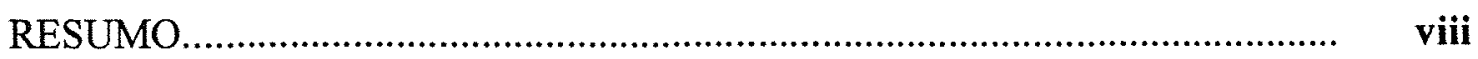

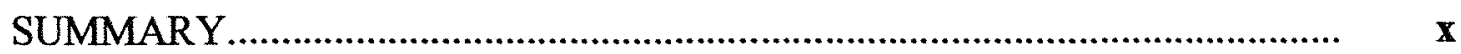

1 INTRODUÇÃO.................................................................................

2 REVISÃO DE LITERATURA...........................................................

2.1 Criação e desenvolvimento das espécies visadas em dietas artificiais...... 3

2.1.1 Spodoptera frugiperda (J. E. Smith, 1797) ........................................... 3

2.1.2 Heliothis virescens (Fabricius, 1781) ................................................ 5

2.1.3 Diatraea saccharalis (Fabricius, 1794)............................................ 6

2.2 Recipientes para criação de lepidópteros em dietas artificiais................... $\quad 10$

3 MATERIAL E MÉTODOS.................................................................. 18

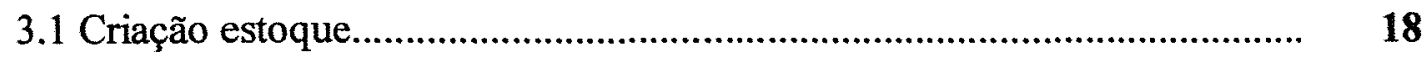

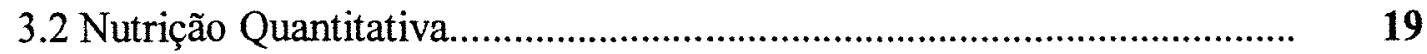

3.2.1 Consumo e utilização de alimento por lagartas de $S$. frugiperda, $H$. virescens, D. saccharalis, em duas temperaturas.......................... 19

3.2.2 Efeito da posição do recipiente de criação no consumo e utilização de alimento.................................................................................. 21

3.2.2.1 Consumo e utilização do alimento por $H$. virescens criada em recipientes de vidro de fundo chato na posição vertical e inclinada.

3.2.2.2 Consumo e utilização do alimento por S. frugiperda criada em recipientes de vidro de fundo chato mantidos na posição inclinada em duas temperaturas.

3.3 Determinação da quantidade mínima de dieta à base de feijão, germede-trigo e levedura para criação de $S$. frugiperda em recipientes de vidro de fundo chato.

3.4 Biologia comparada de $S$. frugiperda em três tipos de recipientes de criação 
3.5 Biologia comparada de $H$. virescens em três tipos de recipientes de criação.

3.6 Biologia comparada de $D$. saccharalis em cinco tipos de recipientes de criação..

3.7 Análise Estatística Geral........................................................................ 32

4 RESULTADOS E DISCUSSÃO..............................................................

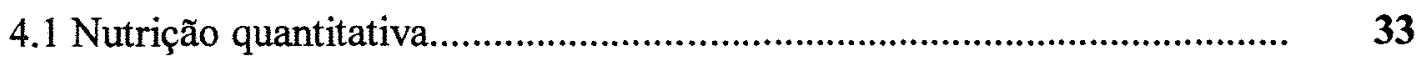

4.1.1 Consumo e utilização de alimento por lagartas de Spodoptera frugiperda (J. E. Smith, 1797), Heliothis virescens (Fabricius, 1781), Diatraea saccharalis (Fabricius, 1794), em duas temperaturas.

4.1.2 Efeito da posição do recipiente de criação no consumo e utilização

4.1.2.1 Consumo e utilização do alimento por $H$. virescens criada em recipientes de vidro de fundo chato na posição vertical e inclinada.

4.1.2.2 Consumo e utilização do alimento por $S$. frugiperda criadas em recipientes de vidro de fundo chato na posição inclinada em duas temperaturas.

4.2 Determinação da quantidade mínima de dieta à base de feijão, germede-trigo e levedura para criação de $S$. frugiperda em recipientes de vidro de fundo chato

4.3 Biologia comparada de $S$. frugiperda em três tipos de recipientes de criação.

4.4 Biologia comparada de $H$. virescens em três tipos de recipientes de criação.

4.5 Biologia comparada de Diatraea saccharalis em cinco tipos de recipientes de criação.

4.6 Considerações Gerais. 


\title{
ADEQUAÇÃO DE RECIPIENTES, PARA CRIAÇÃO EM DIETAS ARTIFICIAIS, DE PRAGAS COM COMPORTAMENTOS VARIÁVEIS.
}

\author{
Autor: ANA MARIA DE LIMA SOUZA \\ Orientador: Prof. JOSÉ ROBERTO POSTALI PARRA
}

\section{RESUMO}

Comparou-se o desenvolvimento de insetos com diferentes características comportamentais, ou seja, canibal, Spodoptera frugiperda (J. E. Smith, 1797), semicanibal, Heliothis virescens (Fabricius, 1781) e não canibal, Diatraea saccharalis (Fabricius, 1794) em diferentes recipientes, descartáveis ou não, selecionando-se os melhores, baseando-se em características biológicas de desenvolvimento e em consumo e utilização de alimento em duas temperaturas, associado ao custo e facilidade de aquisição dos recipientes no mercado brasileiro. $\mathrm{O}$ consumo e utilização de alimento foi variável, dependendo da espécie, da temperatura e da posição em que a dieta foi oferecida. Quando a dieta foi oferecida em recipientes mantidos na posição vertical, a maior eficiência de conversão do alimento ocorreu à $30^{\circ} \mathrm{C}$ para $S$. frugiperda (J. E. Smith, 1797), sendo tal eficiência semelhante à 25 e $30^{\circ} \mathrm{C}$ para $H$. virescens e $D$. saccharalis. A forma como a dieta foi oferecida foi mais importante para $S$. frugiperda, em relação às outras espécies. A quantidade de alimento a ser colocada em um recipiente, determinada pelo consumo do alimento, pode não ser suficiente para o normal desenvolvimento da espécie, pois quando os insetos são criados isoladamente, a perda de água ao longo do tempo, afetou a mortalidade inicial, duração e viabilidade das fases imaturas e pesos de pupas. Assim, para $S$. frugiperda, deve ser colocado $60 \%$ a mais de dieta consumida por indivíduo, para normal desenvolvimento da fase imatura, quando o recipiente é mantido na posição vertical. A maior perda de água, ao longo do 
tempo, não foi suficiente para a escolha de um recipiente. A qualidade do recipiente, que permitiu a perfuração por lagartas, foi decisivo na escolha do recipiente de criação. $O$ tubo de vidro de fundo chato foi o recipiente mais adequado para criação de $S$. frugiperda, H. virescens e $D$. saccharalis, por permitir menor duração e maior viabilidade das fases imaturas e maior peso de pupas e impedir a perfuração pelas lagartas, além de diminuir, sensivelmente, o canibalismo. 


\title{
CONTAINERS ADEQUACY FOR ARTIFICIAL DIETS OF DIFFERENT BEHAVIOR PESTS
}

\author{
Author: ANA MARIA DE LIMA SOUZA \\ Adviser: Prof. JOSÉ ROBERTO POSTALI PARRA
}

\section{SUMMARY}

Insects with different behavioral characteristics were compared, including cannibals - Spodoptera frugiperda (J.B. Smith, 1797), semi-cannibals - Heliothis virescens (Fabricius, 1781), and noncannibals - Diatraea saccharalis (Fabricius, 1784) in different containers, either disposable or not, with the selection of the best ones based on biological development characteristics and on food consumption and use at two temperatures, associated with cost and availability of such containers in the Brazilian market. Both food intake and utilization and use varied in accordance with the species, the temperature, and the position in which the diet was offered. When the diet was set in upright containers, the highest efficiency of the food occurred at $30^{\circ} \mathrm{C}$ for $S$. frugiperda (J.B. Smith, 1797), similarly to that at $25-30^{\circ} \mathrm{C}$ for $H$. virescens and $D$. saccharalis. The manner how the diet was offered was more important for $S$. frugiperda in relation to the other species. The amount of food to be placed in each container, determined by food consumption, may have been not enough for a normal development of a species for when insects are reared under isolation the loss of water along the time affected the initial mortality, the duration and viability of the immature phases, and weight of pupae. Thus, $S$. frugiperda requires extra $60 \%$ of a diet consumed per individual for a normal development of the immature phase when the container is upright. The highest loss of water throughout was not enough for a choice of a container. The container quality allowing perforation by worms was decisive in the choice of a rearing container. The 
flat-bottomed glass container was the most adequate container for S. frugiperda (fall armyworm), $H$. virescens (tobacco budworm), and D. saccharalis (sugarcane borer) rearing since it provide a lesser duration and higher viability of the immature phases and higher pupae weight and for preventing perforation by the worms, in addition to decreasing cannibalism significantly. 


\section{INTRODUÇÃO}

A criação de insetos em dietas artificiais, proporcionou, entre 1950 e 1980, um grande avanço em programas de Manejo de Pragas (Kogan, 1980). Para diversos autores, esta área de criação de insetos, passou a ser, por este motivo, um dos principais componentes da moderna ciência entomológica (Leppla \& Adams, 1987).

Entretanto, o avanço nesta área, ocorreu, primeiramente em locais desenvolvidos, especialmente EUA, países da Europa, Austrália, Nova Zelândia, Canadá, Japão, entre outros. No Brasil, e em outros países menos desenvolvidos, ocorreu uma certa demora para que se começasse a criar os insetos em dietas artificiais, por diversos motivos, dentre os quais, a falta de tradição em criá-los (pois o comum era matá-los com inseticidas) ocupa posição de destaque. Ao lado deste aspecto, vários outros retardaram a expansão nesta área, destacando-se a falta de componentes de dieta no mercado nacional, e, mesmo, recipientes para criá-los (Parra, 1980).

Assim, enquanto nos EUA, rapidamente surgiram empresas privadas, comercializando componentes de dietas, dietas prontas e recipientes descartáveis, no Brasil tradicionalmente, tem-se utilizado recipientes de vidro, reutilizáveis (contando com a mão-de-obra ainda barata em nosso país), ou, muitas vezes, recipientes descartáveis, nem sempre de boa qualidade e adequados aos insetos visados.

São poucos os trabalhos, na literatura mundial, comprovando o desenvolvimento biológico em diferentes recipientes, sendo que os mesmos, são geralmente padronizados, baseando-se na facilidade e economia da criação. Entretanto, o tipo de recipiente é fundamental para que haja um bom desenvolvimento, pois se ocorrer excessiva perda de água da dieta ou mesmo se ele apresentar alguma característica que impeça a tomada de alimento, por exemplo, o inseto não se desenvolverá normalmente. 
Desta forma, devem ser utilizados, para espécies com comportamento semelhantes, recipientes com características adequadas para as mesmas (Parra, 1996).

Assim, o objetivo da pesquisa foi comparar o desenvolvimento de insetos com diferentes características comportamentais, ou seja, canibal, Spodoptera frugiperda (J. E. Smith, 1797), semi-canibal, Heliothis virescens (Fabricius, 1781) e não canibal, Diatraea saccharalis (Fabricius, 1794) em diferentes recipientes, descartáveis ou não, visando selecionar os melhores, baseando-se em características biológicas de desenvolvimento e em consumo e utilização de alimento em duas temperaturas, associadas ao custo e facilidade de aquisição dos recipientes no mercado brasileiro. 


\section{REVISÃO DE LITERATURA}

\subsection{Criação e desenvolvimento das espécies visadas em dietas artificiais}

\subsubsection{Spodoptera frugiperda (J. E. Smith, 1797)}

Marquez et al. (1963-1964) observaram que o ciclo de vida de $S$. frugiperda foi menor quando os insetos foram criados em dieta artificial à base de germe-de-trigo e vitaminas, em relação àqueles criados em folhas de milho.

Lagartas-do-cartucho-do-milho foram mantidas, durante 20 gerações, em dieta artificial, por Revelo \& Raun (1964). Os autores não observaram perda do vigor ou alterações no comportamento das lagartas ao longo das gerações, em relação àquelas criadas em folhas de milho, mostrando a grande capacidade de adaptação deste inseto às dietas artificiais.

Bailey \& Chada (1968) comparando o desenvolvimento de insetos criados sobre folhas de sorgo e em dieta artificial à base de germe-de-trigo e caseína, verificaram que os ciclos de vida de $S$. frugiperda foram semelhantes, ou seja, de 35,6 e 35,0 dias, respectivamente. A média de ovos produzidos por fềmea foi de 849 , para os insetos criados na dieta natural, e, de 869 ovos para aqueles mantidos na dieta artificial.

Kasten Jr. et al. (1978) concluíram que a dieta artificial à base de feijão e levedura, oferecia maior possibilidade de substituir o alimento natural (milho) em criações de laboratório, embora a dieta natural tenha encurtado o ciclo da lagarta-docartucho-do-milho.

Wiseman et al. (1984) observaram que lagartas de S. frugiperda que se alimentaram de dietas que continham farinha de feijão, foram menos pesadas do que 
aquelas que se alimentaram das dietas contendo germe-de-trigo. Assim, com o objetivo de avaliarem o efeito do germe-de-trigo e vitaminas em dietas artificiais sobre alguns parâmetros biológicos da lagarta-do-cartucho-do-milho, Mielitz et al. (1986) definiram a importância do germe-de-trigo para o inseto. Desta forma, lagartas criadas em dietas com este componente foram mais pesadas $(646,7 \mathrm{mg})$, as fases de lagarta, pré-pupa e pupa tiveram menor duração, e o peso de pupas foi maior. Não se evidenciaram efeitos da solução vitamínica sobre a espécie.

Parra \& Carvalho (1984) desenvolveram estudos sobre a espécie à $25^{\circ} \mathrm{C}$, $70 \%$ de UR e fotofase de 14 horas, em dieta artificial, testando 7 variedades de feijão, como variável na pesquisa. A variedade Carioca se mostrou mais adequada, proporcionando um encurtamento do ciclo total e uma maior viabilidade total em relação às demais variedades e pupas fêmeas $30 \%$ mais pesadas que a testemunha.

Pencoe \& Martin (1981) também observaram que as pupas provenientes de dieta artificial, eram mais pesadas (264,3 mg), a duração da fase larval era menor (16 dias), e as lagartas apresentaram 6 ínstares, em relação às 16 plantas hospedeiras da espécie avaliada, cujo número de ínstares variou de 6 a 8 , mostrando uma inadequação nutricional das mesmas.

Em estudos sobre desenvolvimento, longevidade e reprodução da lagarta-do-cartucho-do-milho provenientes de Porto Rico (América Central) e da Lousiana (EUA), alimentadas com dieta artificial à base de feijão e levedura e em dieta natural (folhas de arroz), Pantoja et al. (1987) observaram que as lagartas originárias de Porto Rico se desenvolviam mais lentamente do que as da Lousiana, assim como as pupas eram menos pesadas nos dois substratos alimentares quando provenientes de Porto Rico. Esta diferença não era estendida à longevidade dos adultos ou a outros parâmetros biológicos, mas na geração seguinte as lagartas de Porto Rico eram menores. Os dados relativos ao desenvolvimento não foram influenciados pela dieta e os resultados obtidos, sugerem uma possível diferença genética entre as duas populações, indicando algum grau de isolamento reprodutivo.

Quisenberry \& Whitford (1988) relataram que linhagens de S. frugiperda coletadas em milho, e criadas sobre uma dieta artificial à base de feijão e germe-de- 
trigo, apresentaram pupas significativamente mais pesadas do que quando coletadas em arroz. As progênies das linhagens em milho e arroz, possuiam pesos larvais e sobrevivência similares, mas diferiram significativamente no peso pupal e no tempo de desenvolvimento, quando criadas em dieta artificial.

$\mathrm{Ng}$ et al. (1993) estudando o desenvolvimento biológico da lagarta-docartucho-do-milho em dieta merídica em laboratório à $26,7{ }^{\circ} \mathrm{C}$, nã̃o encontraram diferença significativa no peso larval de machos e fềmeas nas idades estudadas. As lagartas de ambos os sexos pesaram cerca de $370 \mathrm{mg}$ no $10^{\circ}$ dia e não houve diferença de peso de pupas de ambos os sexos. Quanto ao período de desenvolvimento larval de ambos os sexos, este foi semelhante, com valor em torno de 14 dias. No entanto, machos apresentaram período pupal significativamente superior ao das fêmeas.

Bowling (1967), Burton \& Perkins (1972) e Barfield et al. (1978) fizeram observações biológicas desta espécie em dieta artificial, verificando a adequação nutricional destes meios para criação de $S$. frugiperda.

Nalim (1991) avaliou duas dietas artificiais, uma à base de levedura de cerveja e feijão e outra contendo como fontes protéicas levedura de cerveja, germe-detrigo e feijão para a criação de $S$. frugiperda. Através dos estudos biológicos, concluiu que aquela contendo germe-de-trigo foi a mais adequada ao desenvolvimento do inseto.

\subsubsection{Heliothis virescens (Fabricius, 1781)}

Berger (1963) desenvolveu a primeira dieta artificial para a criação de $H$. virescens à base de germe-de-trigo. Houve alterações desta dieta, por Raulston \& Lingren (1969), sendo que Moreti (1980) fez algumas adaptações para as condições brasileiras.

Patana (1969) em criação massal em laboratório, relatou que as lagartas eclodiram em cerca de 72 horas à $27,78^{\circ} \mathrm{C}$ e a duração da fase pupal foi de 12 a 14 dias. Por outro lado, Guerra (1970) em temperatura de $26,67^{\circ} \mathrm{C}$, constatou um período pupal de 13 a 15 dias. Relatou que o peso de uma lagarta de 10 dias se situava entre 277 a 399 mg. 
Vários autores também conseguiram bons resultados criando $H$. virescens em dieta artificial como Hendricks et al. (1971), Montewka et al. (1976), entre outros.

Guerra \& Bhuiya (1977) avaliaram duas dietas, com composições variáveis. Quando as lagartas foram criadas à $27,8^{\circ} \mathrm{C}$ e os adultos mantidos entre 23,3 e $25,6^{\circ} \mathrm{C}$, verificaram que a melhor dieta para a espécie foi aquela à base de germe-de-trigo, obtendo-se peso larval, no $10^{\circ} \mathrm{dia}$, de $398 \mathrm{mg}$ e peso pupal de $300 \mathrm{mg}$. As durações larval e pupal foram de 13 dias e as viabilidades de 79 e $80 \%$ para as fases de lagarta e pupa, respectivamente. Constataram que uma fêmea coloca em média, 300 ovos, com eclosão de $76 \%$, e que o adulto vive em média, 20 dias. Desta forma, em função dos resultados apresentados, fica evidente que $H$. virescens também é um inseto que se adapta a dietas artificiais, inclusive sendo facilmente criado em laboratórios do Brasil (Moreti \& Parra, 1983).

\subsubsection{Diatraea saccharalis (Fabricius, 1794)}

Pan \& Long (1961) compararam a biologia de D. saccharalis em dieta artificial e em meio natural constituído de "ponta" de cana. Não houve diferença significativa entre o consumo alimentar nos dois meios de criação; as fềmeas pareciam ser mais sensíveis às eventuais deficiências nutricionais em ambos os substratos.

Wongsiri \& Randof (1962) compararam a biologia da broca-da-cana-deaçúcar à $25^{\circ} \mathrm{C}$, em meio artificial à base de germe-de-trigo e em meio natural (colmos de sorgo). Observaram a ocorrência de cinco ínstares larvais em ambos os substratos, com a duração da fase larval menor em meio natural. O período pupal foi maior em dieta artificial, sendo que o ciclo total foi de 42,8 e 40 dias respectivamente, nos meios artificial e natural.

Santa Cruz et al. (1964) conduziram uma criação massal de $D$. saccharalis, visando a obtenção de insetos para estudos da resistência de variedades de milho. Com a finalidade de desenvolverem uma dieta mais adequada à criação do inseto, compararam quatro dietas por três gerações sucessivas; as dietas à base de soja e milho opaco foram superiores àquelas preparadas com feijão cru ou cozido, com relação à 
viabilidade pupal, peso médio de pupas, longevidade de adultos e número de ovos por fềmea.

A dieta composta de "pontas" de cana-de-açúcar; água; ágar; metil parahidroxibenzoato; ácido sórbico; formaldeído e ácido ascórbico, foi utilizada para observar os efeitos da temperatura e umidade relativa do ar no desenvolvimento da broca-da-cana-de-açúcar por Miskimen (1965). Ele constatou a adequação da dieta e que a melhor temperatura para a criação do inseto foi a de $26^{\circ} \mathrm{C}$, pois nesta temperatura foram registradas as maiores viabilidades nas diferentes fases de desenvolvimento e menores porcentagens de anormalidades de adultos. Verificou que o primeiro e o segundo ínstares exigem umidades inferiores à $85 \%$, pois umidades mais elevadas podem provocar a condensação nas paredes do tubo de criação, causando a morte das lagartas; a partir do terceiro ínstar, a umidade pode chegar a $90 \%$ sem afetar o desenvolvimento normal do inseto.

Pesquisando técnicas de criação para D. saccharalis, Walker \& Figueroa (1966) utilizaram duas dietas à base de milho: uma com fibra de milho e a outra substituindo a água da dieta por um filtrado de milho. Compararam estas dietas com a proposta por Miskimen (1965) e com a dieta natural, constituída de pedaços de colmo de milho e conseguiram, nas dietas pesquisadas, uma viabilidade total (ovo a adulto) de $90 \%$, em condições de pequenas produções diárias de insetos.

Estudando alguns aspectos da biologia de D. saccharalis, Bowling (1967) relatou que em dieta à base de feijão, em temperatura de $26,6 \pm 1,6^{\circ} \mathrm{C}$ e fotofase de 14 horas, o período médio para o desenvolvimento larval - pupal de $D$. saccharalis era de 38 dias, sendo 30,1 dias para o período larval e 7,9 dias para o período pupal. O peso médio de pupas foi de $95 \mathrm{mg}$, a fecundidade média de 268 ovos por fềmea e o período de incubação de 6,5 dias.

Hensley \& Hammond (1968) desenvolveram a primeira dieta artificial para criação de $D$. saccharalis em laboratório, utilizando um meio nutricionalmente completo. Constataram que esta dieta, com fonte protéica à base de germe-de-trigo e caseína era favorável ao desenvolvimento larval de D. saccharalis, desde que as pupas obtidas eram comparáveis em vigor e tamanho, às obtidas em campo, sobre milho ou 
cana-de-açúcar. A duração do período ovo-pupa durou, em média 32 dias; a viabilidade total foi de $64 \%$ nos meses de verão e $84 \%$ nos meses de inverno.

Van Dinther \& Goossens (1970) estudaram o desenvolvimento biológico de $D$. saccharalis em nove dietas artificiais que continham diferentes quantidades de feijão, milho, cenoura e arroz. Os insetos foram mantidos em laboratório em temperaturas variáveis de 24 a $28{ }^{\circ} \mathrm{C}$, umidade relativa de 65 a $90 \%$ e fotofase de 12 horas. Os autores constataram que os insetos criados na dieta contendo $12 \%$ de feijão, $3,7 \%$ de milho e $1,8 \%$ de cenoura apresentaram alta viabilidade larval (81\%), elevado peso de pupas (machos e fềmeas); maior fertilidade das fềmeas (média de 394 ovos) e alta viabilidade de ovos (94\%), quando comparados com os demais meios.

Os trabalhos com dietas artificiais foram iniciados no Brasil, no Departamento de Entomologia da Escola Superior de Agricultura "Luiz de Queiroz" (ESALQ) da Universidade de São Paulo (USP), em Piracicaba, SP, por Gallo et al. (1969), utilizando a dieta proposta por Hensley \& Hammond (1968), para a multiplicação de $D$. saccharalis em programa de controle biológico desta praga através de taquinídeos.

Com o objetivo de criar D. saccharalis em dieta artificial, Sgrillo (1973) desenvolveu a criação D. saccharalis na dieta de Hensley \& Hammond (1968), automatizando a distribuição da dieta e dos ovos, com aprimoramento das técnicas de manipulação dos insetos e avaliando os custos da criação. Ao lado das inovações para as fases imaturas, encontrou maior produção de ovos, quando colocou, em gaiolas, a proporção de três machos para uma fềmea.

Mendonça Filho (1973) descreveu detalhadamente as operações que se processam em laboratório para a multiplicação dos taquinídeos parasitóides da broca-dacana-de-açúcar, utilizando a dieta de Hensley \& Hammond (1968).

Criando $D$. saccharalis em dieta artificial à base de fibra de cana e pó de cenoura, Risco et al. (1973) obtiveram uma porcentagem de $54,12 \%$ de lagartas no quarto ínstar, aptas a serem "inoculadas" com parasitóides da broca.

King et al. (1975) estudando a biologia de D. saccharalis em temperaturas constantes entre 15,6 e $34{ }^{\circ} \mathrm{C}$, obtiveram um decréscimo no período de 
incubação com a elevação da temperatura até $32{ }^{\circ} \mathrm{C}$. Ocorreu um alongamento do período larval à temperatura de $22^{\circ} \mathrm{C}$, apresentando-se mais curto à temperatura de 30 ${ }^{\circ} \mathrm{C}$. A fase pupal foi menor à $33^{\circ} \mathrm{C}$, embora nesta temperatura a mortalidade tenha sido alta. $\mathrm{O}$ peso de pupas (machos e fềmeas) foi maior à $22^{\circ} \mathrm{C}$. Os adultos apresentaram maior longevidade à $15,6^{\circ} \mathrm{C}$ e as fềmeas produziram maior número de ovos à $24^{\circ} \mathrm{C}$.

Villacorta \& Magro (1975) descreveram uma metodologia de criação de D. saccharalis, em laboratório, com dieta à base de feijão. Testando diferentes variedades de feijão como fonte protéica, Novaretti \& Teran (1976) verificaram que na dieta com feijão branco ocorreu uma maior porcentagem de brocas aptas para a "inoculação" com parasitóides.

Moraes \& Gallo (1976) trabalhando com D. saccharalis, desenvolveram um aparelho para melhor distribuição da dieta nos tubos de criação, e conseguiram uma redução de $85 \%$ do tempo gasto com métodos convencionais.

Sgrillo et al. (1976) pesquisando a criação da broca-da-cana-de-açúcar em uma dieta artificial à base de feijão "Jalo", em laboratório com temperatura de $25^{\circ} \mathrm{C}$ e umidade relativa de $75 \%$, obtiveram uma postura média de 350 ovos por fềmea, com viabilidade de $91 \%$. O período larval foi de 30 dias e o pupal de 10 dias. As pupas que deram origem a fềmeas pesaram $100 \mathrm{mg}$ e as que originaram machos $63 \mathrm{mg}$.

Brewer (1981) comparou duas dietas artificiais para criação de $D$. saccharalis, uma à base de soja e óleo de milho e a outra à base de soja e germe-detrigo. As lagartas foram criadas em laboratório, com temperatura de $29^{\circ} \mathrm{C}$, umidade relativa de $75 \%$ e fotofase de 14 horas. Verificou que os períodos larval e pupal foram menores nos insetos criados na dieta de soja e óleo de milho, sendo as pupas mais pesadas nessa dieta.

Roe et al. (1982) criando $D$. saccharalis em nove dietas artificiais à base de germe-de-trigo, caseína e farinha de milho verificaram que à $30^{\circ} \mathrm{C}$ o período larval constou de até sete ínstares, com $28,3 \%$ das lagartas apresentando cinco, $68,9 \%$, seis e $2,8 \%$, sete instares. 
Macedo et al. (1983) descreveram a técnica de criação de parasitóides larvais de $D$. saccharalis, com detalhes da criação da broca-da-cana em dieta artificial.

Parra \& Mihsfeldt (1992) avaliaram quatro tipos de dietas com fontes protéicas variáveis para a criação de $D$. saccharalis e constataram que a dieta à base de milho "Nutrimaiz", levedura de cerveja e germe-de-trigo pode ser usada para a criação dessa espécie, especialmente nas condições do Brasil, devido à disponibilidade e ao baixo custo dos ingredientes.

\subsection{Recipientes para criação de lepidópteros em dietas artificiais}

A escolha do recipiente é de grande importância para criações de insetos em meios naturais, mas assume importância maior quando se passa a criá-los em dietas artificiais, pois tal escolha pode afetar a sanidade e nutrição dos insetos. O grande problema é que, considerando-se a grande diversidade de hábitos alimentares e de comportamentos de insetos, não podem ser feitas generalizações, pois o, recipiente pode ser variável dependendo das características mencionadas. Peterson (1964) fez uma tentativa, dando exemplos de recipientes de criação quando se utilizam meios naturais. Burton \& Perkins (1984) fizeram uma revisão sobre recipientes para manutenção de insetos em dietas artificiais, podendo-se observar que muitos tipos de recipientes têm sido utilizados para criar insetos em meios artificiais. Neste caso, na escolha devem ser levados em consideração: o hábito e comportamento do inseto (se é canibal, por exemplo), o tipo de criação (se se trata de uma criação para pesquisa ou criação massal), se tal criação é ou não automatizada e o pais em que se está pretendendo fazer tal criação. Assim, países como os EUA, em que há tradição de criação de insetos em dietas artificiais, com uma mão-de-obra mais cara, porém com disponibilidade de recursos, os recipientes podem ser descartáveis, enquanto que no Brasil, por exemplo, tais recipientes, em muitos casos, podem ser reutilizados.

Smith (1966) listou mais de 40 recipientes de criação, incluindo recipientes plásticos, de papelão, de vidro, metálicos, de diferentes tamanhos e formas de acordo com sua adequação e disponibilidade. Com o advento das dietas artificiais, 
houve uma tendência à padronização. Assim, Singh (1977) amostrou 75 espécies pertencentes a 50 famílias e 10 ordens de insetos criadas em dietas, e, constatou que $34 \%$ eram criadas em copos plásticos, $22 \%$ em recipientes de vidro, $17 \%$ em placas de Petri, e o restante em recipientes de diversos materiais, incluindo até copos de sorvetes. O mais utilizado atualmente nos EUA é o recipiente plástico de poliestireno de $30 \mathrm{ml}$ de capacidade, que tem inúmeras vantagens, pois é barato para os padrões americanos, serve para pequenas e grandes criações, fornece um micro-ambiente favorável ao inseto, é facilmente encontrado no mercado, serve para criações automatizadas ou não, e, permite o isolamento de espécies canibais. Para espécies não canibais, copos de refrigerantes (de papelão ou plástico) são utilizados para criações de insetos.

No Brasil, ainda é muito comum a utilização de recipientes de vidro de fundo chato $(8,5 \mathrm{~cm}$ de altura $\times 2,5 \mathrm{~cm}$ de diâmetro) para criações em pequena escala $\mathrm{e}$ em criações massais de insetos, sendo, tais recipientes, reutilizáveis (Parra, 1996). Entretanto, muitos laboratórios, começam a utilizar recipientes descartáveis.

Assim, para que um recipiente seja considerado adequado, deve ter as seguintes características: ser barato; transparente; facilmente encontrado no mercado; ser de material não tóxico e que mantenha umidade (Parra, 1996). Para criação de brocas, a dureza do material do recipiente pode ser de grande importância.

$\mathrm{Se}$ os insetos forem criados individualmente, as possibilidades de alastramento de doenças e contaminação são reduzidas. A criação do inseto individualizado elimina canibalismo, embora existam casos em que mesmo se as espécies forem gregárias, elas podem se tornar canibais, quando os insetos são agrupados ou se as dietas forem nutricionalmente inadequadas. Um dos grandes problemas de um recipiente é a evaporação da dieta, levando a uma alteração das suas caracteristicas fisicas como textura, dificultando a sua palatabilidade. Em linhas gerais, a escolha de recipiente vai depender da criatividade do pesquisador e do tipo de trabalho a ser realizado (Parra, 1996).

A padronização é quase impossivel devido à diversidade citada entre os insetos. Alguns exemplos serão citados a seguir e que foram utilizados por diferentes pesquisadores e para várias espécies de insetos. 
Shorey \& Hale (1965) desenvolveram uma dieta artificial, que possibilitou a criação de nove espécies de noctuídeos em copos de papel. Os copos têm uma capacidade de aproximadamente $180 \mathrm{ml}$ e possuem tampa de papelão. Segundo os autores, a troca de ar através da tampa e das paredes do copo foram suficientes para permitir uma adequada respiração larval e pupal durante 3 a 4 semanas e evitar o excessivo ressecamento da dieta. Neste sistema de criação, as lagartas de Helicoverpa zea (Boddie) e H. virescens são transferidas para outros recipientes antes de atingirem o $3^{0}$ instar. Tais recipientes contêm aproximadamente $60 \mathrm{ml}$ de dieta e possuem uma divisão com 6 compartimentos de papelão, sendo colocada uma lagarta por compartimento.

Desenvolvendo a criação massal de Pectinophora gossypiella (Saunders), Richmond \& Martin (1966) utilizaram copos plásticos de aproximadamente $270 \mathrm{ml}$. Compararam dois métodos de "inoculação": um com ovos em solução de ágar e o método padrão (colocando-se lagartas do $1^{0}$ ínstar). Ambos os métodos foram igualmente eficientes.

Burton et al. (1966) desenvolveram duas máquinas para facilitar a criação de lagartas de lepidópteros. Uma colocava quantidades determinadas da dieta nos recipientes de criação e a outra coletava e distribuía as lagartas recém eclodidas na dieta.

Bailey \& Chada (1968) estudando alguns aspectos biológicos de H. zea, S. frugiperda, e Diatraea grandiosella (Dyar), criaram essas espécies em formas de gelo plásticas com 14 divisões $(4,45 \mathrm{~cm}$ de comprimento $\times 3,18 \mathrm{~cm}$ de largura $\times 2,54 \mathrm{~cm}$ de altura) em dieta artificial e compararam com o desenvolvimento em sorgo. Observaram que $D$. grandiosella perfurou os copos plásticos, havendo necessidade de substituírem as formas de gelo por frascos de vidro $(2,54 \mathrm{~cm}$ de diâmetro $x 9,53 \mathrm{~cm}$ de altura).

Ignoffo \& Boening (1970) criaram continuamente Trichoplusia ni (Hübner), H. zea, H. virescens e Spodoptera exigua (Hübner) por mais de cinco anos, em bandejas plásticas em células individualizadas. Cerca de 20 espécies de lepidópteros foram criadas neste mesmo tipo de bandeja, com a recomendação de que haja o mínimo manuseio dos insetos, visando a redução de contaminação externa e a propagação de 
doenças entre os indivíduos. Técnicas similares foram utilizadas por Raulston \& Lingren (1969), Morrison et al. (1975) e Hartley et al. (1982).

Singh \& Jerram (1976) criaram Epiphyas postvittana (Walker) (Lepidoptera: Tortricidae) em sacos plásticos, que se mostraram inadequados, pois, o inseto perfurava os mesmos. Leppla et al. (1975) adaptaram recipientes utilizados para roedores para criar insetos.

Davis (1982) criou D. grandiosella, S. frugiperda e H. zea em copos plásticos transparentes de $30 \mathrm{ml}$ de capacidade, com resultados satisfatórios.

Davis et al. (1990) modificaram uma bandeja de criação com divisões para criar $D$. saccharalis, $S$. frugiperda, $H$. zea e $H$. virescens. Compararam a criação dessas quatro espécies em bandejas plásticas $(27,94 \mathrm{~cm}$ de comprimento x 15,24 cm de largura), contendo 32 divisões, em relação àquelas criadas em copos plásticos de $30 \mathrm{ml}$. Utilizaram máquinas automatizadas para o preparo da dieta e para selar as divisões. As pupas foram retiradas por um coletor descrito por Davis (1982).

Parra et al. (1993) criaram Anticarsia gemmatalis (Hübner) em recipientes de material plástico transparente de $24 \times 12 \times 9 \mathrm{~cm}$. Os recipientes foram mantidos em prateleiras metálicas com o respectivo sistema de oxigenação e filtragem do ar. O sistema foi mantido por meio de um compressor, equipado com um motor de 2 HP, que permitiu a oxigenação do sistema, o qual recebeu o ar puro através de filtros contendo carvão ativado. A manutenção da umidade das dietas foi feita através de água existente no interior de recipientes de vidro. Este sistema permitiu, a criação, em uma única prateleira metálica, lagartas suficientes para multiplicarem Baculovirus anticarsia a serem aplicados em 600 ha de soja.

Wood \& Hughes (1996) desenvolveram uma caixa de criação com o objetivo de adequar as necessidades fisicas e nutricionais para criar uma determinada espécie, para produção de vírus. A meta desse recipiente foi criar um modelo que maximizasse o número de lagartas $/ \mathrm{cm}^{2}$ de dieta e a área de criação. $\mathrm{O}$ recipiente consistia de uma caixa com tampa removível, sendo que a parte interna é dividida em 3 espaços: (1) uma área superior para dieta, (2) área central que é ocupada pelas lagartas que vai aumentando de acordo com o consumo de dieta e (3) área inferior, onde as fezes 
são coletadas. Nestes espaços existem orifícios de ventilação que permitem a circulação do ar para evitar o excesso de umidade. Com esse sistema, os autores criaram com sucesso $T$. ni, Lymantria dispar L. e $S$. exigua, observando que houve um acréscimo no peso das pupas em comparação com os sistemas tradicionais de criação, especialmente para espécies não canibais.

Alguns exemplos de estudos com as espécies utilizadas na presente pesquisa serão referidos a seguir.

Burton \& Cox (1966) modificaram uma máquina de empacotar alimentos para criar grandes quantidades $S$. frugiperda, para um sistema automatizado regulado para distribuir $30 \mathrm{ml}$ de dieta por copo, sendo as lagartas colocadas sobre a dieta misturada a um diluente. As lagartas não foram afetadas pelo tratamento (diluente) e colocavam-se de 6-8 lagartas/ 0,5 g de diluente. Obtinham-se, em média 1,5 pupas/copo. Neste sistema, a sobrevivência pupal foi de $90 \%$. O tempo dispendido era de 1 homem/hora, sendo processados 3000 copos/h em comparação a 12 horas/ homem pelo método manual. Este tipo de equipamento poderia, segundo os autores, ser utilizado para outros insetos como $H$. zea.

Hare et al. (1973) relataram que a umidade dentro das células de criação afetava o desenvolvimento embrionário e a produção de $H$. zea. S. frugiperda e $H$. zea foram criadas em células de criação de material plástico de aproximadamente $30 \mathrm{ml}$ de capacidade. Os autores concluíram que o excesso de umidade da dieta prejudicava a coleta mecânica das pupas.

Petterson \& Debolt (1975) usaram um saco de papel parafinado como método de criação de $S$. exigua.

Um grande número de $S$. exigua e $T$. $n i$ foi criado em bandejas plásticas reutilizáveis. Um estudo comparativo de desenvolvimento de $S$. exigua em 4 tipos de recipientes: bandejas com divisões, saco de papel parafinado, copos plásticos de $100 \mathrm{ml}$ e bandejas sem divisões, permitiu concluir que a bandeja é o recipiente mais adequado para a espécie (Petterson \& Debolt, 1976).

O principal problema de criações de $H$. virescens e $H$. zea é que depois de um determinado ínstar, as lagartas devem ser separadas devido ao canibalismo. A maior 
parte dos laboratórios que cria Heliothis sp, usa copos plásticos de aproximadamente 30 $\mathrm{ml}$ ou $60 \mathrm{ml}$ como recipientes de criação. Contudo, Lingren \& Bryan (1965) criaram grupos de 20 a 30 indivíduos de Heliothis spp. em cartões, até o $3^{0}$ ínstar, registrando baixos níveis de canibalismo. Burton \& Cox (1966) e Burton \& Harrell (1966) descreveram métodos para criação de lagartas de lepidópteros em tais copos. Entretanto, esses métodos săo complicados quanto ao manuseio e distribuição da dieta, além das lagartas de Heliothis sp. tenderem a perfurar a tampa do copo. Roberson \& Noble (1968) relataram um método para criação de $H$. virescens, colocando os ovos individualmente dentro de recipientes do tipo Honeycomb Hexcel®, que demonstrou ser mais eficiente quando comparado ao uso de copos plásticos.

Nos casos em que se tentam criar várias lagartas em um único recipiente, sem separá-los, não se tem conseguido sucesso. Em geral, duas ou três lagartas recémeclodidas são criadas com bons resultados em copos plásticos de aproximadamente 60 $\mathrm{ml}$, sem a individualização, pois esta prática é trabalhosa e cara. Roberson \& Noble (1968) compararam a criação de lagartas de $H$. virescens em bandejas com células, em relação às lagartas criadas em copos plásticos de $30 \mathrm{ml}$. Obtiveram, em média, 0,68 pupas/células, comparadas com uma estimativa de produção ligeiramente maior do que 1 pupa/recipiente, utilizando-se o copo plástico de $30 \mathrm{ml}$. A bandeja, apesar desta desvantagem, pode ser reutilizada após lavagem e desinfecção. Por outro lado, o copo nem sempre pode ser reutilizado, devido ao alto custo da limpeza (para as condições americanas).

Guerra \& Buhuiya (1977) criaram H. virescens em copos plásticos e em bandeja Hexcel® com compartimentos, descrita por Raulston \& Lingren (1972) para criação em grande escala. Afirmaram que a dieta pode ser usada com sucesso nos dois tipos de recipientes. Desenvolveram uma dieta artificial mais econômica, para esta espécie, com pouca quantidade de ágar e sem germe-de-trigo e que é capaz de manter o crescimento e o desenvolvimento do inseto sem afetar sua reprodução. Afirmaram que a dieta pode ser usada com sucesso nos dois tipos de recipientes.

Hartley et al. (1982) modificaram uma unidade de criação de bandeja com células para criação massal de pupas de Heliothis spp. para o programa de liberação de 
machos estéreis. Eles produziram mais de 10 milhões de pupas de Heliothis sp. e desenvolveram um método para retirada e limpeza das pupas através de jato de ar, que reduziu a mortalidade pupal e a deformação dos adultos.

Estudando o mesmo inseto, Brewer (1983) avaliou vários parâmetros biológicos de uma linhagem híbrida na produção massal de $H$. virescens. Os parâmetros foram avaliados para verificar os efeitos de vários processos de produção quanto à qualidade e quantidade de insetos híbridos produzidos. H. virescens foi criada em bandejas e as pupas foram coletadas manualmente e mecanicamente segundo Hartley et al.(1982). O processo mecânico afetou a qualidade dos insetos.

Pan \& Long (1961) utilizaram frascos Erlenmeyer de 125 ou $250 \mathrm{ml}$, tamponados com algodão para a criação em grande escala de $D$. saccharalis em dieta artificial e em dieta natural à base de "ponta" de cana.

Hensley \& Hammond (1968) criaram a broca-da-cana-de-açúcar em pequena escala em laboratório, utilizando tubos de ensaio de $(2,3 \mathrm{~cm}$ de diâmetro $\times 8,5$ $\mathrm{cm}$ de altura), contendo dieta até $1 / 3$ do seu volume total, muito similar àquela utilizada até hoje nas condições brasileiras (Parra, 1996). Os autores relataram que o sucesso da criação massal depende do número de lagartas por recipiente, pois o número exagerado pode levar ao canibalismo desde que lagartas grandes podem destruir pupas.

King et al. (1975) criaram lagartas de D. saccharalis em copos plásticos de $30 \mathrm{ml}$ em dieta à base de germe-de-trigo e soja. Colocaram de 10-15 ml de dieta/copo. Concluíram que há uma tendência no aumento do período larval, da mortalidade e da diminuição do peso pupal dos machos quando se aumenta o número de lagartas de $D$. saccharalis por copo plástico.Também relataram que as lagartas maiores danificam as primeiras pupas formadas e que a incidência de tais danos está correlacionada à densidade de lagartas por copo.

Pesquisando um método de criação massal de D. saccharalis, Villacorta \& Magro (1975) utilizaram a dieta de Bowling (1967) modificada, em potes de vidro (11,0 cm de diâmetro $x 17,0 \mathrm{~cm}$ de altura) preenchidos com aproximadamente $3,0 \mathrm{~cm}$ de (altura) de dieta. A postura foi colocada na dieta, obtendo um bom desenvolvimento larval de D. saccharalis. 
Macedo \& Campos (1998) utilizaram frascos de vidro transparente de boca larga, de $500 \mathrm{ml}$, em formato de garrafa, com tampa constituída de um anel plástico com rosca e fundo de tela metálica de malha 200 mesh, criação massal de lagartas de $D$. saccharalis, em substituição aos recipientes convencionais (tubos de vidro de fundo chato). A produção de lagartas de $4^{0}$ ínstar, aptas para receberem o parasitóide Cotesia flovipes (Cameron), foi comparada à produção de 20 tubos de fundo chato convencionais. Obtiveram uma produção média de lagartas, $29 \%$ superior nos frascos. Segundo os autores, os custos neste sistema correspondem a um terço dos custos do sistema convencional. 


\section{MATERIAL E MÉTODOS}

O trabalho foi desenvolvido no Laboratório de Biologia de Insetos do Departamento de Entomologia, Fitopatologia e Zoologia Agrícola da Escola Superior de Agricultura "Luiz de Queiroz" - (ESALQ), da Universidade de São Paulo - (USP), Piracicaba-SP.

\subsection{Criação estoque}

As lagartas de Spodoptera frugiperda (J. E. Smith, 1797), (lagarta-docartucho-do-milho), Heliothis virescens (Fabricius, 1781), (lagarta-da-maçã-doalgodoeiro) e Diatraea saccharalis (Fabricius, 1794), (broca-da-cana-de-açúcar) foram criadas em dietas artificiais, respectivamente de Nalim (1991), Parra \& Mihsfeldt (1992) e King \& Hartley (1985). A metodologia de criação adotada, para as três espécies, foi aquela proposta por Parra (1996), utilizando-se tubos de vidro de fundo chato de $2,5 \mathrm{~cm}$ de diâmetro x $8,5 \mathrm{~cm}$ de altura, mantendo-os à $25 \pm 2{ }^{\circ} \mathrm{C}$, UR de $60 \pm 10 \%$ e fotofase de 14 horas. Foi considerado, para o presente trabalho, que a espécie $S$. frugiperda é canibal, caracteristica determinada geneticamente a partir do $3^{0}$ ínstar, independente de outros fatores (sexo, qualidade e disponibilidade de alimento, espaço para criação, densidade populacional) (Fox, 1975a; Joyner \& Gould, 1987). Por outro lado, $H$. virescens foi considerada semi-canibal, ou seja, parte da população apresenta canibalismo e parte não apresenta, podendo tornar-se canibal em função de caracteristicas de ambiente (polifenismo canibalístico) (Polis, 1981). E D. saccharalis 
foi considerada não canibal na fase larval, pois apenas em condições excepcionais ocorre tal comportamento, ou apenas as lagartas maiores atacam as pupas recém formadas (Hensley \& Hammond, 1968).

\subsection{Nutriçầo Quantitativa}

\subsubsection{Consumo e utilização de alimento por lagartas de $S$. frugiperda, $H$. virescens, D. saccharalis, em duas temperaturas}

Os estudos de consumo e utilização foram conduzidos em duas temperaturas $\left(25\right.$ e $\left.30^{\circ} \mathrm{C}\right)$, em grades metálicas, sendo os tubos com dietas mantidos em posição vertical. Para cada temperatura, foram estudadas 50 lagartas (por espécie), provenientes da criação estoque (3.1), individualizadas nos mesmos tubos de vidro da referida criação. Ao atingirem o máximo desenvolvimento (último ínstar), as lagartas foram retiradas dos tubos de criação, pesadas, mortas por congelamento e levadas à estufa, juntamente com a sobra da dieta e as fezes existentes nos tubos, visando a obtenção do peso de matéria seca destas três variáveis, ou seja, alimento consumido e ganho de peso das lagartas, além de peso das fezes, essenciais para a determinação dos índices de consumo e utilização de alimento.

Paralelamente, foi separada, uma alíquota de 10 tubos, por espécie, sem as lagartas, para cada tratamento $\left(25\right.$ e $\left.30^{\circ} \mathrm{C}\right)$, para determinação de peso seco inicial da dieta, segundo Parra (1991).

Para a determinação dos índices de nutrição quantitativa da fase larval, adotou-se a metodologia proposta por Waldbauer (1968) e modificada por Scriber \& Slansky Jr. (1981). Para o cálculo destes índices, foram utilizados os seguintes parâmetros:

$\mathrm{T}=$ duração do periodo de alimentação (dias);

$\mathrm{Af}=$ peso do alimento fornecido ao inseto $(\mathrm{g})$; 
$\mathrm{Ar}=$ peso da sobra do alimento fornecido ao inseto $(\mathrm{g})$, após $\mathrm{T}$;

$\mathrm{F}=$ peso das fezes produzidas $(\mathrm{g})$ durante $\mathrm{T}$;

$\mathrm{B}=$ ganho de peso pelas lagartas $(\mathrm{g})$ durante $\mathrm{T}: \mathrm{B}=(\mathrm{I}-\mathrm{F})-\mathrm{M}$;

$\overline{\mathrm{B}}=$ peso médio das lagartas $(\mathrm{g})$ durante $\mathrm{T}$;

$\mathrm{I}$ = peso do alimento ingerido $(\mathrm{g})$ durante $\mathrm{T}$;

$\mathrm{I}-\mathrm{F}=$ alimento assimilado $(\mathrm{g})$ durante $\mathrm{T}$;

$\mathrm{M}=(\mathrm{I}-\mathrm{F})-\mathrm{B}=$ alimento metabolizado durante período de alimentação $(\mathrm{g})$.

Foram determinados os índices de consumo e utilização para cada tratamento, através das seguintes fórmulas:

-Taxa de consumo relativo $(\mathrm{g} / \mathrm{g} / \mathrm{dia})-\mathrm{RCR}=\frac{\mathrm{I}}{\overline{\mathrm{B}} \times \mathrm{T}}$

-Taxa de crescimento relativo (g/g/dia) $-\mathrm{RGR}=\frac{\mathrm{B}}{\overline{\mathrm{B}} \times \mathrm{T}}$

-Taxa metabólica relativa $(\mathrm{g} / \mathrm{g} / \mathrm{dia})-\mathrm{RMR}=\frac{\mathrm{M}}{\overline{\mathrm{B}} \times \mathrm{T}}$

-Digestibilidade aproximada $(\%)-A D=\underline{I-F} \times 100$

-Eficiência de conversão do alimento ingerido $(\%)-E C I=\frac{B}{I} \times 100$

-Eficiência de conversão do alimento digerido (\%) $-\mathrm{ECD}=\frac{B}{I-F} \times 100$

-Custo metabólico $(\%)=100-$ ECD 
3.2.2 Efeito da posição do recipiente de criação no consumo e utilização de alimento

\subsubsection{Consumo e utilização do alimento por $H$. virescens criada em recipientes de vidro de fundo chato na posição vertical e inclinada}

O consumo e a utilização do alimento foram determinados adotando-se a mesma metodologia citada em 3.2.1. Foram avaliadas 50 lagartas por tratamento, oriundas da criação estoque, individualizando-as e considerando-se cada lagarta uma repetição. O desenvolvimento foi estudado, mantendo-se os recipientes de criação em duas posições, em grades (vertical) e prateleira (inclinada) (Figura 1). As lagartas de $H$. virescens foram mantidas em câmara climatizada regulada à $25^{\circ} \mathrm{C}$, com UR de $60 \pm$ $10 \%$ e fotofase de 14 horas.

Cada tubo recebeu um volume de $5 \mathrm{ml}$ de dieta, suficientes para a complementação da fase larval (conforme 3.2.1). Após 24 horas, tempo suficiente para o resfriamento do meio, os tubos foram colocados em grades de arame $(27,0 \mathrm{~cm}$ de comprimento $x 17,5 \mathrm{~cm}$ de largura $\times 6,6 \mathrm{~cm}$ de altura) e levados à uma câmara asséptica por 30 minutos, para esterilização externa. Nesta câmara, foi feita a transferência das lagartas recém-eclodidas para os tubos de dieta, com auxílio de um pincel fino e levemente umedecido com água. Comparou-se o consumo e utilização de alimento do inseto na grade (posição vertical) e prateleira (posição inclinada) adotando-se a mesma metodologia utilizada em 3.2.1. Cada tubo foi fechado com algodão hidrófugo esterilizado, numerado e mantido ou em grades de arame, em posição vertical, com a abertura voltada para baixo para que as lagartas pudessem subir até a dieta, ou, em posição inclinada, nas prateleiras de $37,0 \mathrm{~cm}$ de comprimento $\mathrm{x} 10,5 \mathrm{~cm}$ de largura $\mathrm{x}$ $28,0 \mathrm{~cm}$ de altura (Figura 1). 

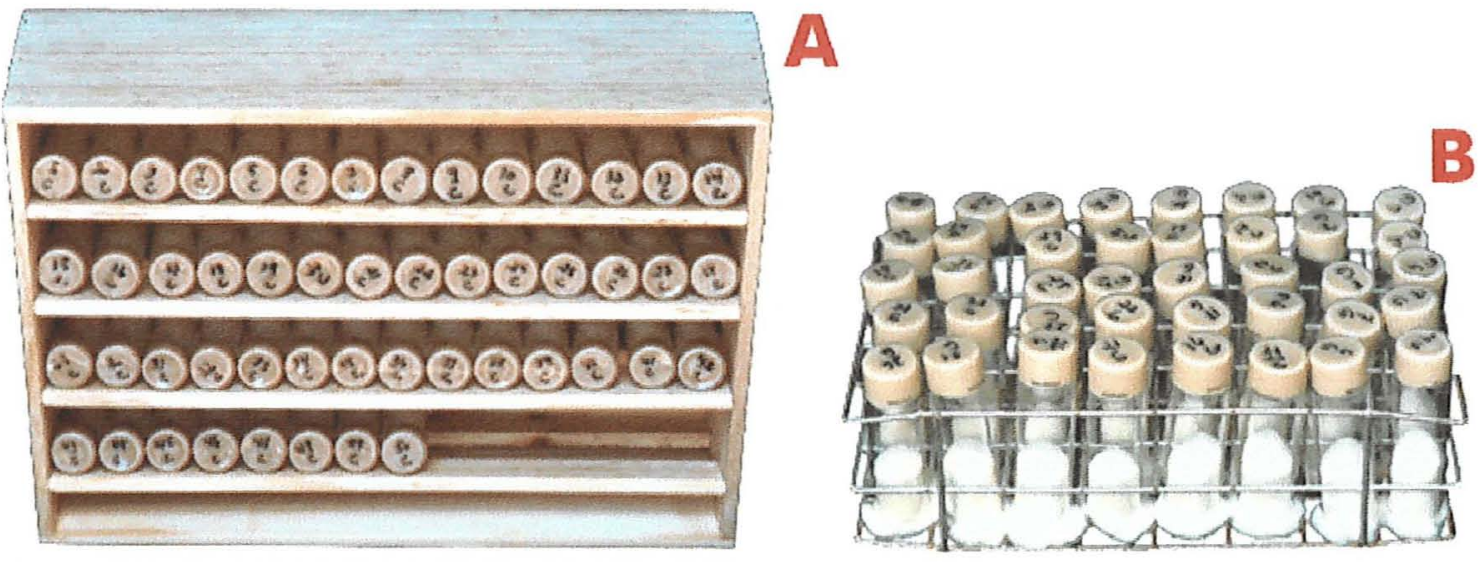

Figura 1. Recipientes (tubos de vidro) dispostos em posição inclinada, na prateleira (A) e em posição vertical, na grade (B) contendo dieta artificial.

\subsubsection{Consumo e utilização do alimento por $S$. frugiperda criada em recipientes de vidro de fundo chato mantidos na posição inclinada em duas temperaturas}

O consumo e utilização do alimento foram determinados adotando-se a mesma metodologia utilizada nos experimentos 3.2.1 e 3.2.2.1. Avaliaram-se 50 lagartas por tratamento, oriundas da criação estoque, individualizando-as e considerando-se cada lagarta uma repetição. $\mathrm{O}$ desenvolvimento foi estudado mantendo-se os recipientes de criação com lagartas em prateleiras (posição inclinada), colocadas em câmaras climatizadas reguladas à 25 e $30^{\circ} \mathrm{C}$, com UR de $60 \pm 10 \%$ e fotofase de 14 horas. Este trabalho serviu de complementação àquele realizado em 3.2.1 cuja avaliação de consumo e utilização foi realizada na posição vertical (grades) e conduzido em duas temperaturas, por terem sido observadas diferenças no consumo e utilização à 25 e $30^{\circ} \mathrm{C}$ (3.2.1.). 


\subsection{Determinação da quantidade mínima de dieta à base de feijão, germe-de- trigo e levedura para criação de $S$. frugiperda em recipientes de vidro de fundo chato}

Embora tenha sido determinada em 3.2.1 a quantidade de alimento consumida por $S$. frugiperda, pode ocorrer que se for colocada a quantidade mínima exigida pelo inseto, haja um ressecamento da dieta (pois a dieta normalmente perde água ao longo do tempo) e, como conseqüência, um desenvolvimento inadequado da espécie (Machado \& Parra, 1987). Assim, o objetivo da pesquisa foi avaliar a mínima quantidade de dieta a ser colocada por recipiente para que haja um bom desenvolvimento de $S$. frugiperda, evitando-se, porém, perda de dietas. Foram estudados quatro tratamentos $(5,6,7$ e $8 \mathrm{ml}$ de dieta/tubo criação), colocando-se duas lagartas/tubo, com 70 repetições, sendo os tubos mantidos à $30^{\circ} \mathrm{C}$, UR de $60 \pm 10 \%$ e fotofase 14 horas.

Paralelamente, para cada tratamento, foi pesada diariamente, uma alíquota de 10 tubos de fundo chato contendo dieta, porém sem lagartas, para avaliar a perda de água do meio, em cada condição.

Foram determinados os parâmetros biológicos:

- Fase larval: Viabilidade no $7^{\mathbf{o}}$ dia ("pegamento")

duração (incluindo a fase de pré-pupa)

viabilidade

- Fase pupal: duração

peso com 24 horas de idade

viabilidade

razão sexual

porcentagem de deformação

- Fase adulta: porcentagem de deformação (asas)

As lagartas de $S$. frugiperda foram observadas diariamente, a fim de se verificar se ocorria contaminação por patógenos. 


\subsection{Biologia comparada de $S$. frugiperda em três tipos de recipientes de criação}

A biologia da $S$. frugiperda foi comparada em três tipos de recipientes: vidro de fundo chato (testemunha), copo plástico Uniãoß e bandeja de criação Bio-RT-32® (Figura 2), utilizando-se um volume de dieta baseado no consumo larval de S. frugiperda (3.2.1).

$\mathrm{O}$ experimento foi conduzido em câmaras climatizadas reguladas à $30 \pm 1{ }^{\circ} \mathrm{C}$, condição em que se obtiveram maior consumo e ganho de peso (3.2.1), UR $60 \pm 10 \%$ e fotofase de 14 horas, sendo as lagartas provenientes da criação "estoque" (3.1).

Para os recipientes de vidro, foram "inoculadas" três lagartas por tubo, mantidos em posição inclinada, onde obtiveram-se os melhores resultados (3.2.2.2), colocando-se $15 \mathrm{ml}$ de dieta por recipiente, baseado no consumo de 3.2.1, num total de 100 repetições.

No caso dos copos plásticos transparentes União@ de $40 \mathrm{ml}$, as dietas foram distribuídas em 100 copos plásticos, com $20 \mathrm{ml}$ de dieta/copo. Os copos foram tampados com tampa acrílica transparente MEBUKI $(4,6 \mathrm{~cm}$ de diâmetro $\times 0,3 \mathrm{~cm}$ de altura), "inoculando"-se cinco lagartas/copo, e mantidos sobre bandejas metálicas (Figura $2 \mathrm{C}^{\prime}$ ).

As bandejas de criação Bio-RT-32®, que possuem 32 compartimentos (94,0 cm de comprimento $\times 19,0 \mathrm{~cm}$ de largura $\times 2,5 \mathrm{~cm}$ de altura), receberam a dieta, correspondendo a $20 \mathrm{ml}$ de dieta/compartimento. Foram colocadas cinco lagartas por compartimento, selado por fina camada plástica transparente PULL N'PEEL TAB Biocv-4® (Figura 2B'). 


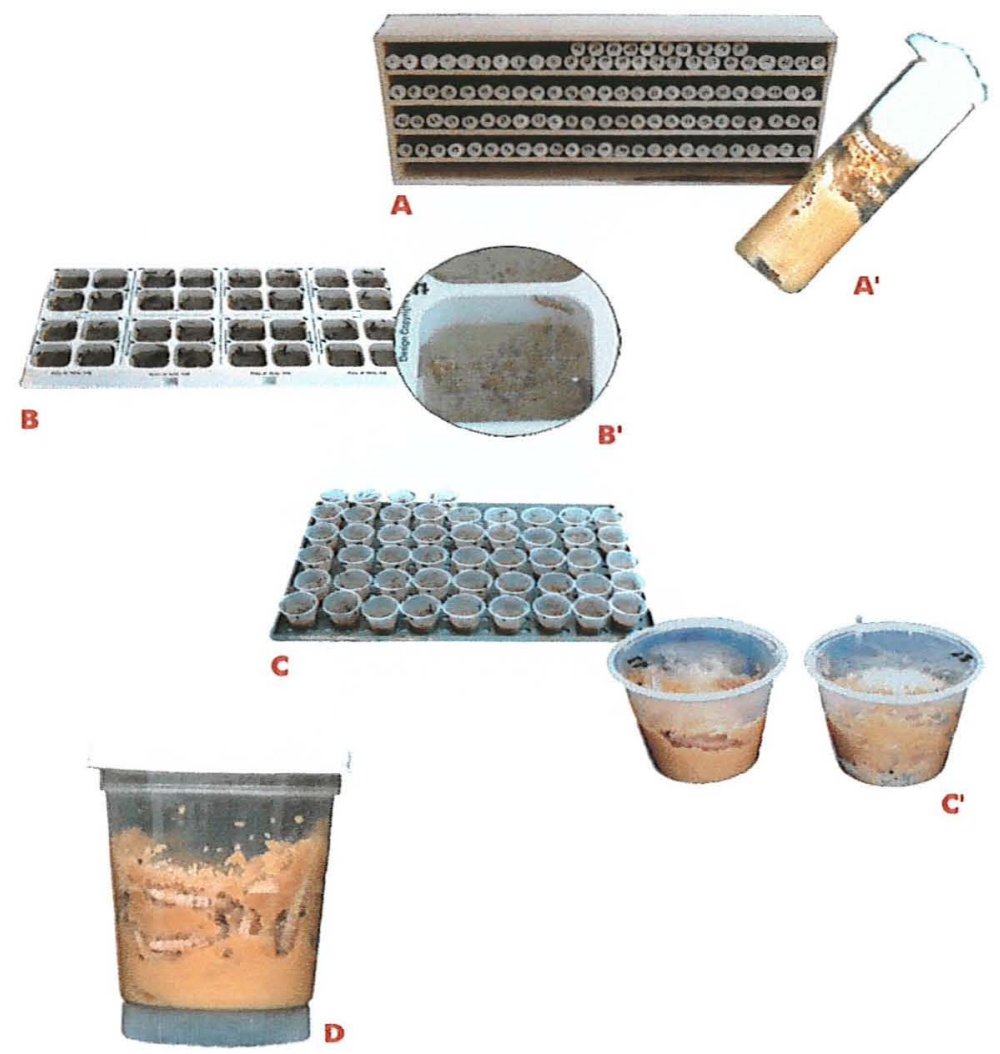

Figura 2. Recipientes utilizados para as espécies $S$. frugiperda, $H$. virescens e $D$. saccharalis. Tubos de vidro na prateleira (A) e em detalhe $\left(\mathrm{A}^{\prime}\right)$; bandeja de criação Bio-RT-32® $(\mathrm{B})$ e detalhe da tampa $\left(\mathrm{B}^{\prime}\right)$; copo plástico União ${ }^{\circledR}$ com tampa acrílica na bandeja metálica $(C)$ e em detalhe $\left(\mathrm{C}^{\prime}\right)$; copo plástico Arteplast ${ }^{\circledR}$ com tampa (D). 
Foram avaliados, para cada tratamento (recipiente), os seguintes parâmetros biológicos:

- Fase larval: viabilidade no $7^{0}$ dia ("pegamento")

duração (incluindo a fase de pré-pupa)

viabilidade

- Fase pupal: duração

peso com 24 horas de idade

viabilidade

razão sexual: $\frac{q}{q+\sigma^{x}}$

porcentagem de deformação

- Fase adulta: longevidade de machos e fềmeas

período de pré-oviposição

período de oviposição

número de posturas por fềmea

número de ovos por fềmea/postura

total de ovos por fềmea

porcentagem de deformação (asas)

- Fase de ovo: período de incubação

viabilidade

- Ciclo total (ovo a adulto): duração

viabilidade

Diariamente, foi avaliada a mortalidade (por canibalismo ou outras causas); foram também avaliados: número de recipientes perfurados e número de recipientes com contaminação por patógenos.

Para se avaliar a perda de água foram pesados, diariamente, 10 recipientes de vidro, 10 copos plásticos União® e 10 compartimentos da bandeja de criação Bio RT - $32 \circledast$ contendo dieta, porém sem lagartas. 
As pupas foram separadas por sexo (Butt \& Cantu, 1962) e individualizadas em copos plásticos de café de $40 \mathrm{ml}$, mantidos sobre bandejas metálicas, até a emergência.

Após a emergência, foram separados 25 casais de mesma idade de cada tipo de recipiente, visando a obtenção dos dados relativos à fase adulta.

Os casais, individualizados, foram mantidos em gaiolas de PVC $(10,0 \mathrm{~cm}$ de diâmetro x 20,0 cm de altura), fechadas nas extremidades por uma placa de Petri de 14,0 cm de diâmetro. Cada gaiola foi revestida internamente por papel jornal, o qual serviu de substrato para postura, sendo os ovos retirados e contados diariamente. Como alimento, foi oferecido uma solução aquosa de mel a 10\%, colocada em um recipiente de vidro, com tampa de alumínio ou plástico com um orifício na parte central. Através deste orificio, foi colocado um rolo dental Johnson's®, que permitiu a alimentação do inseto por capilaridade. Este alimento foi renovado a cada dois dias para evitar problemas de contaminação por patógenos.

O método de contagem dos ovos, foi o mesmo utilizado por Leuck \& Perkins (1972), realizando-se a contagem do número de ovos na camada superior e multiplicando-se este valor pelo número de camadas existentes por postura, adicionando-se os ovos contados nas bordas das camadas subseqüentes.

Para a determinação da viabilidade de ovos e do período de incubação, foram consideradas todas as posturas por casal, de cada tipo de recipiente. As posturas obtidas foram colocadas em placas de Petri de $9,0 \mathrm{~cm}$ de diâmetro, contendo papel de filtro, na parte inferior, umedecido com água destilada. As placas contendo os ovos foram fechadas por tampas de igual diâmetro e vedadas com filme plástico PVC (Magipack $®$ ), fixado com fita adesiva.

Diariamente, foi observada a eclosão das lagartas para a determinação do período de incubação e respectiva viabilidade por recipiente (tratamento). 


\subsection{Biologia comparada de $H$. virescens em três tipos de recipientes de criação}

A biologia da $H$. virescens foi desenvolvida nos mesmos recipientes utilizados para S. frugiperda, com lagartas provenientes da criação estoque (3.1).

$\mathrm{O}$ experimento foi conduzido em sala mantida à $25 \pm 1{ }^{\circ} \mathrm{C}$, UR $60 \pm 10 \%$ e fotofase de 14 horas, com cada tipo de recipiente, em função dos resultados obtidos em 3.2.1.

A dieta para $H$. virescens à base de farinha de milho, levedura e germede-trigo (Parra \& Mihsfeldt, 1992) foi preparada conforme procedimento descrito por Parra (1996) acrescendo-se 0,24 g de tetraciclina (Tetrex®) e 2,4 g de metil parahidroxibenzoato (Nipagin) para evitar contaminação.

No recipiente de vidro, foram colocados $10 \mathrm{ml}$ de dieta, devido aos resultados obtidos em 3.2.1, "inoculando"-se três lagartas por tubo, mantendo-se tais tubos em prateleiras (Figura 2A).

Os copos plásticos União ${ }^{\circledR}$ receberam $15 \mathrm{ml}$ de dieta/copo plástico. Após 24 horas, tempo suficiente para o resfriamento da dieta, tais copos plásticos foram levados à câmara asséptica, para esterilização externa com lâmpada germicida, onde foram colocadas as tampas acrílicas transparentes MEBUKI (4,6 cm de diâmetro x 0,3 $\mathrm{cm}$ de altura). Nesta câmara, foi feita a transferência de cinco lagartas recém-eclodidas para cada copo plástico, com auxilio de um pincel fino umedecido em água. Cada copo plástico foi tampado com tampa acrílica MEBUKI®, numerado e colocado em bandeja metálica para ser transportado até a sala, onde permaneceu na posição vertical com a tampa acrilica para cima (Figura $2 \mathrm{C}$ ).

As bandejas de criação Bio-RT-32® receberam $15 \mathrm{ml}$ de dieta/compartimento. Logo após o recebimento das dietas, as bandejas foram cobertas com papel de filtro até o resfriamento.

Após 24 horas, tempo suficiente para o resfriamento da dieta, as bandejas de criação foram colocadas em câmara asséptica. Em cada compartimento, foram transferidas cinco lagartas e o conjunto, a seguir, foi selado com uma fina camada de plástico transparente PULL N' PEEL TAB Bio-cv-4®. 
Nos três tratamentos (recipientes) foi avaliada a perda de água, com procedimento semelhante ao utilizado para $S$. frugiperda. Os parâmetros biológicos estudados foram também os mesmos referidos em 3.4.

Devido à dificuldade de visualização das pupas nas células da bandeja (tratamento 3) optou-se pela pesagem de $50 \%$ das pupas/tratamento com 24 horas de idade, abrindo-se diariamente tais células (no período estimado para pupação) para verificar se já havia ocorrido tal pupação. As demais 50 células não foram manipuladas até próximo à emergência.

As observações de adultos e ovos foram análogas a 3.4. Para a determinação da viabilidade de ovos e do período de incubação, foi considerada a segunda postura de cada casal para cada tipo de recipiente, observando-se todos os ovos obtidos, de forma semelhante à 3.5 .

\subsection{Biologia comparada de $D$. saccharalis em cinco tipos de recipientes de criação}

A biologia da $D$. saccharalis foi comparada em recipientes de vidro de fundo chato (testemunha), copo plástico transparente União® de $40 \mathrm{ml}$, bandeja de criação Bio-RT-32®, copo plástico translúcido da Arteplast $\circledast$ de $200 \mathrm{ml}$ e caixa acrílica.

$\mathrm{O}$ experimento foi conduzido em sala mantida à $25 \pm 1{ }^{\circ} \mathrm{C}$, UR $60 \pm 10 \%$ e fotofase 14 horas, conforme os resultados obtidos em 3.2.1. Os parâmetros biológicos observados foram os mesmos citados em 3.4, determinando-se também o número de recipientes perfurados, número de lagartas mortas (canibalismo ou outras causas) e a contaminação por patógenos.

Cada tubo de ensaio recebeu $15 \mathrm{ml}$ de dieta/tubo, de acordo com os dados obtidos em 3.2.1. Para cada tubo foram transferidas cinco lagartas recém-eclodidas, num total de 100 repetições.

No caso dos copos plásticos transparentes União® de $40 \mathrm{ml}$, a dieta foi distribuída em 100 copos plásticos com $20 \mathrm{ml}$ de dieta/copo plástico (sendo que cada copo foi considerado uma repetição). Os copos foram tampados com uma tampa acrílica 
transparente MEBUKI®. Foram inoculadas sete lagartas/copo plástico, num total de 100 repetições, com procedimento análogo ao descrito em 3.2.2.1.

Nas bandejas de criação, cada compartimento recebeu $15 \mathrm{ml}$ de dieta, inoculando-se cinco lagartas/divisão. Cada divisão foi selada com uma fina camada de plástico transparente PULL N' PELL TAB Bio-cv-4®.

Nos copos plásticos translúcidos Arteplast ${ }^{\circledR}(6,75 \mathrm{~cm}$ de diâmetro x 8,9 $\mathrm{cm}$ de altura), a dieta foi distribuída na base de $100 \mathrm{ml} /$ copo e foram "inoculados" 15 copos plásticos com 35 lagartas/copo (sendo que cada copo plástico foi considerado como uma repetição) de acordo com o procedimento do experimento 3.2.2.1. Logo após a "inoculação", os copos foram tampados com tampa branca de pressão $(7,5 \mathrm{~cm}$ de diâmetro x 0,8 cm de altura) (Figura 2D).

Para as caixas acrílicas translúcidas, a dieta foi distribuída na base de 500 $\mathrm{ml} /$ caixa (25,0 cm de comprimento $\times 12,4 \mathrm{~cm}$ de largura $\mathrm{x} 7,0 \mathrm{~cm}$ de altura) (Figura 3).

Em cada caixa acrílica foram transferidas 176 lagartas devido aos resultados obtidos no consumo (3.2.1) e, logo em seguida, foram tampadas com uma tampa marrom (25,4 cm de comprimento $\mathrm{x} 13,3 \mathrm{~cm}$ de largura $\times 3,0 \mathrm{~cm}$ de altura) de material plástico. Elas ficaram viradas com a tampa para baixo durante 24 horas para que as lagartas permanecessem sobre a dieta.

Logo após a "inoculação", as caixas acrílicas foram transferidas para a prateleira, na qual foi instalado o sistema de criação massal proposto por Parra et al. (1993), onde as lagartas desenvolveram-se até a pupação.

Devido ao grande número de pupas obtidos na caixa acrílica, foi extraída uma amostra de cinco pupas/caixa, para pesagem diária.

Nos cinco tratamentos (recipientes) foi avaliada perda de água, pesandose diariamente, 10 recipientes de vidro, 10 copos plásticos União $\circledast, 5$ copos plásticos Arteplast $\Theta, 10$ compartimentos da bandeja de criação Bio-RT-32® e 5 caixas acrílicas , com dietas, porém sem lagartas.

Depois da emergência, foram separados 25 casais de mesma idade, de cada tipo de recipiente para a obtenção dos dados relativos à fase adulta. Para instalar as 


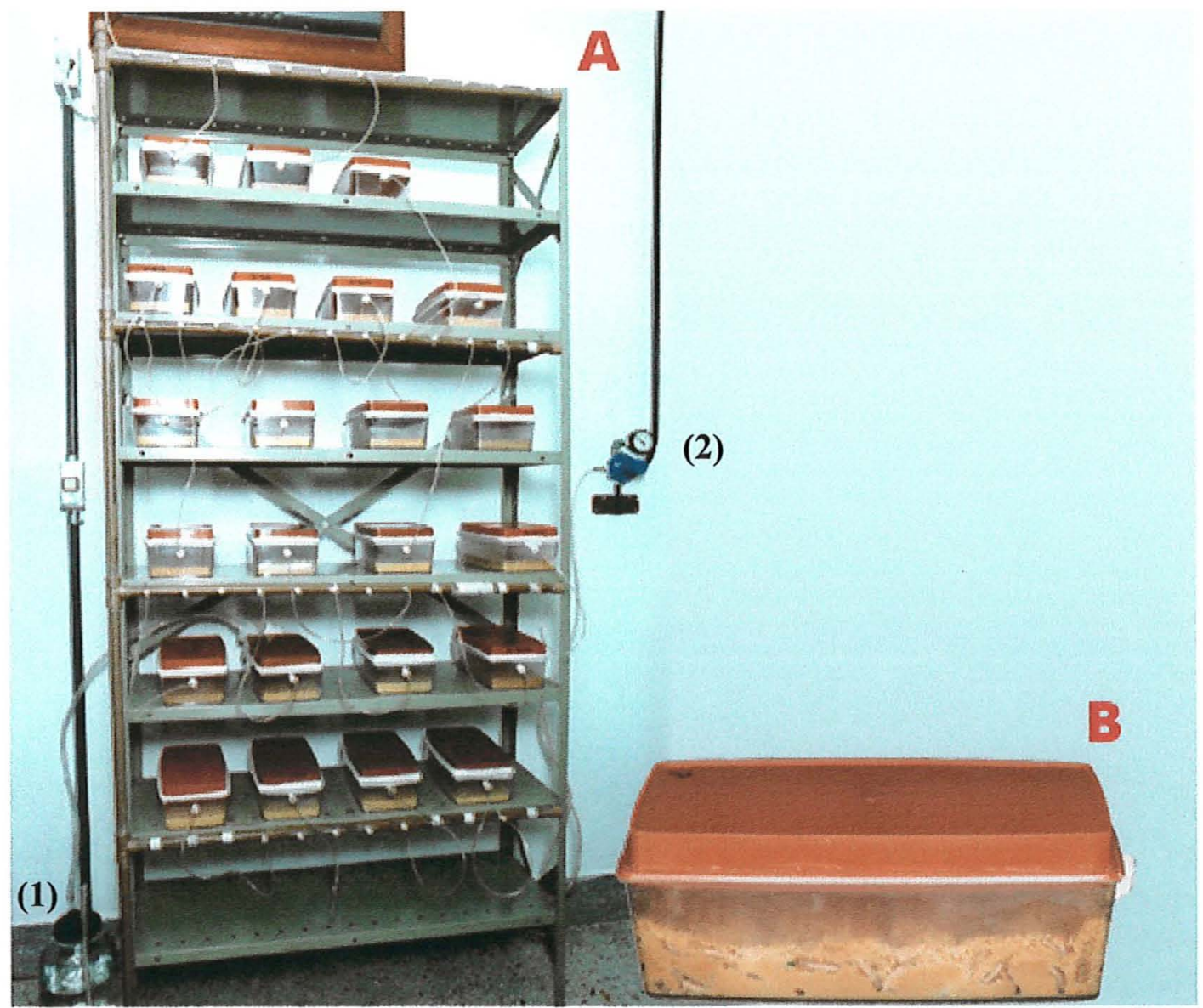

Figura 3. A) Sistema de produção de Diatraea saccharalis, em recipientes ligados a frasco com água (1) e compressor externo, com relógio de tempo (2) para controle da sala de criação; B) detalhe do recipiente individualizado.

gaiolas de acasalamento, foi utilizada a metodologia de Macedo et al. (1983). Os parâmetros biológicos foram os mesmos determinados no experimento 3.4. Para a determinação da viabilidade de ovos e do período de incubação, foram considerados 100 ovos da segunda postura, por casal, de cada tipo de recipiente. 


\subsection{Análise Estatística Geral}

Os dados obtidos nos diversos recipientes foram submetidos à análise da variância e as médias comparadas pelo teste de Tukey, ao nível de $5 \%$ de probabilidade.

Os dados que não apresentaram homogeneidade de variâncias foram comparados pelo teste $t$, ou através da análise não paramétrica - Escore de Van der Warden.

Os dados da razão sexual foram comparados pelo teste não paramétrico de qui-quadrado.

A perda de água entre os recipientes utilizados para $S$. frugiperda, $H$. virescens e $D$. saccharalis foi comparada por espécie, baseando-se nos valores médios correspondentes a $50 \%$ e $100 \%$ do período médio de desenvolvimento larval. Para tal comparação, utilizou-se o teste de Tukey, ao nível de $5 \%$ de probabilidade.

Procedeu-se a uma análise (regressão linear), relacionando-se a perda diária de água com o tempo de pesagem, para os diversos recipientes estudados. 


\section{RESULTADOS E DISCUSSÃO}

\subsection{Nutrição quantitativa}

4.1.1 Consumo e utilização de alimento por lagartas de Spodoptera frugiperda (J. E. Smith, 1797), Heliothis virescens (Fabricius, 1781), Diatraea saccharalis (Fabricius, 1794), em duas temperaturas

Para S. frugiperda o maior peso fresco, no máximo desenvolvimento, foi obtido à $30^{\circ} \mathrm{C}$ (Figura 4). O maior ganho de peso para esta espécie foi também registrado na temperatura de $30^{\circ} \mathrm{C}$, apesar da quantidade de alimento consumido e das fezes excretadas não diferirem estatisticamente entre si à 25 e $30^{\circ} \mathrm{C}$ (Figura 5).

$\mathrm{O}$ índice de consumo (CI), a taxa metabólica relativa (RMR) e a digestibilidade aparente ( $A D)$, que representa a percentagem do alimento que foi efetivamente assimilada, não diferiram nas duas temperaturas (Tabela 1). Por outro lado, a razão de crescimento (GR) e o aproveitamento de alimento (ECI e ECD), foram maiores à $30^{\circ} \mathrm{C}$, o que levou a um menor custo metabólico nesta condição térmica (Tabela 1).

Os índices nutricionais obtidos, encontram-se na faixa dos valores relatados por Nalim (1991) à $25^{\circ} \mathrm{C}$ em dieta à base de feijão, levedura de cerveja e germe-de-trigo. Os resultados obtidos, encontram-se também na faixa dos valores referidos por $\mathrm{Ng}$ et al. (1993) que estudaram a biologia e o consumo e utilização do alimento de $S$. frugiperda, à $26,7^{\circ} \mathrm{C}$ em dieta à base de germe-de-trigo e caseína. 


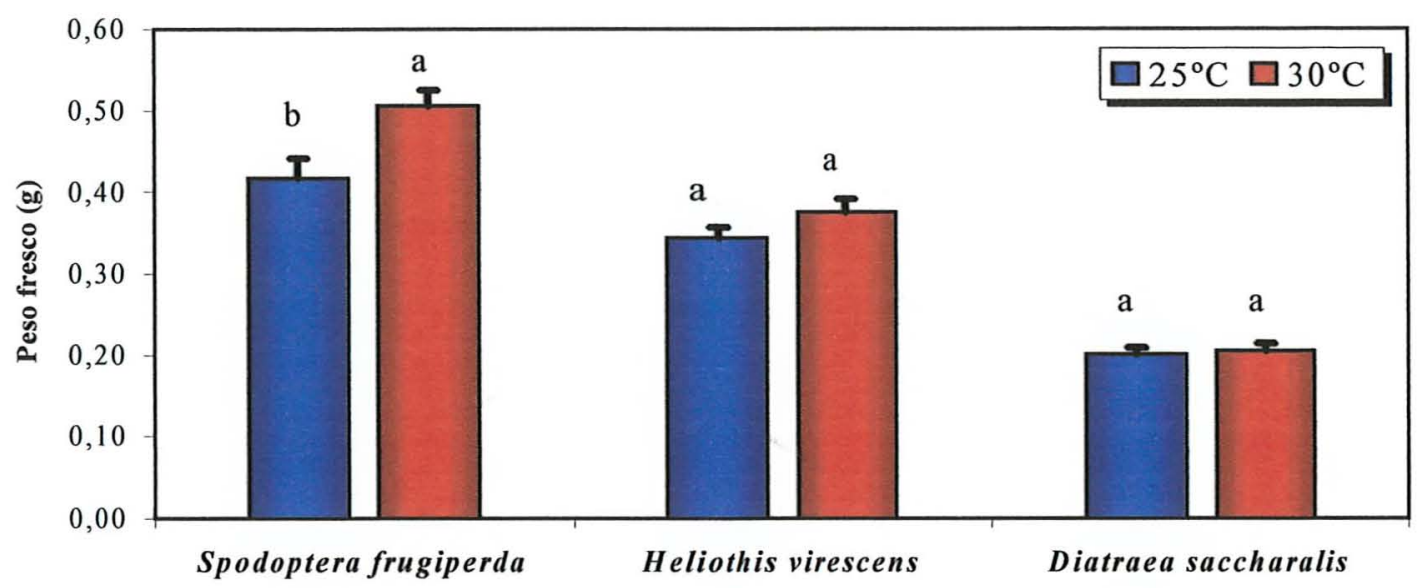

Figura 4. Peso fresco de lagartas de Spodoptera frugiperda, Heliothis virescens e Diatraea saccharalis, no máximo desenvolvimento, em dieta artificial, em recipientes mantidos em posição vertical. Temperatura: 25 e $30{ }^{\circ} \mathrm{C}$; UR: $60 \pm 10 \%$; fotofase: 14 horas.

Agrupamentos de colunas, seguidos de mesma letra, não diferem, estatisticamente entre si, pelo teste de Tukey, ao nível de $5 \%$ de probabilidade.

No máximo desenvolvimento, $H$. virescens apresentou peso semelhante à 25 e $30{ }^{\circ} \mathrm{C}$ (Figura 4), sendo também o ganho de peso, a quantidade de alimento consumido e as fezes excretadas semelhantes nos dois regimes térmicos (Figura 6). Apesar disto, os índices CI, GR e RMR diferiram estatisticamente nas duas temperaturas, sendo superiores à $30^{\circ} \mathrm{C}$ (Tabela 2), observando-se o mesmo com relação à $\mathrm{AD}$, uma vez que nesta condição térmica, o alimento foi mais facilmente assimilado. Os demais índices, ou seja, ECI e ECD não diferiram nas duas condições, o que resultou na não diferença no custo metabólico pelo inseto nas duas temperaturas de estudo (Tabela 2). 


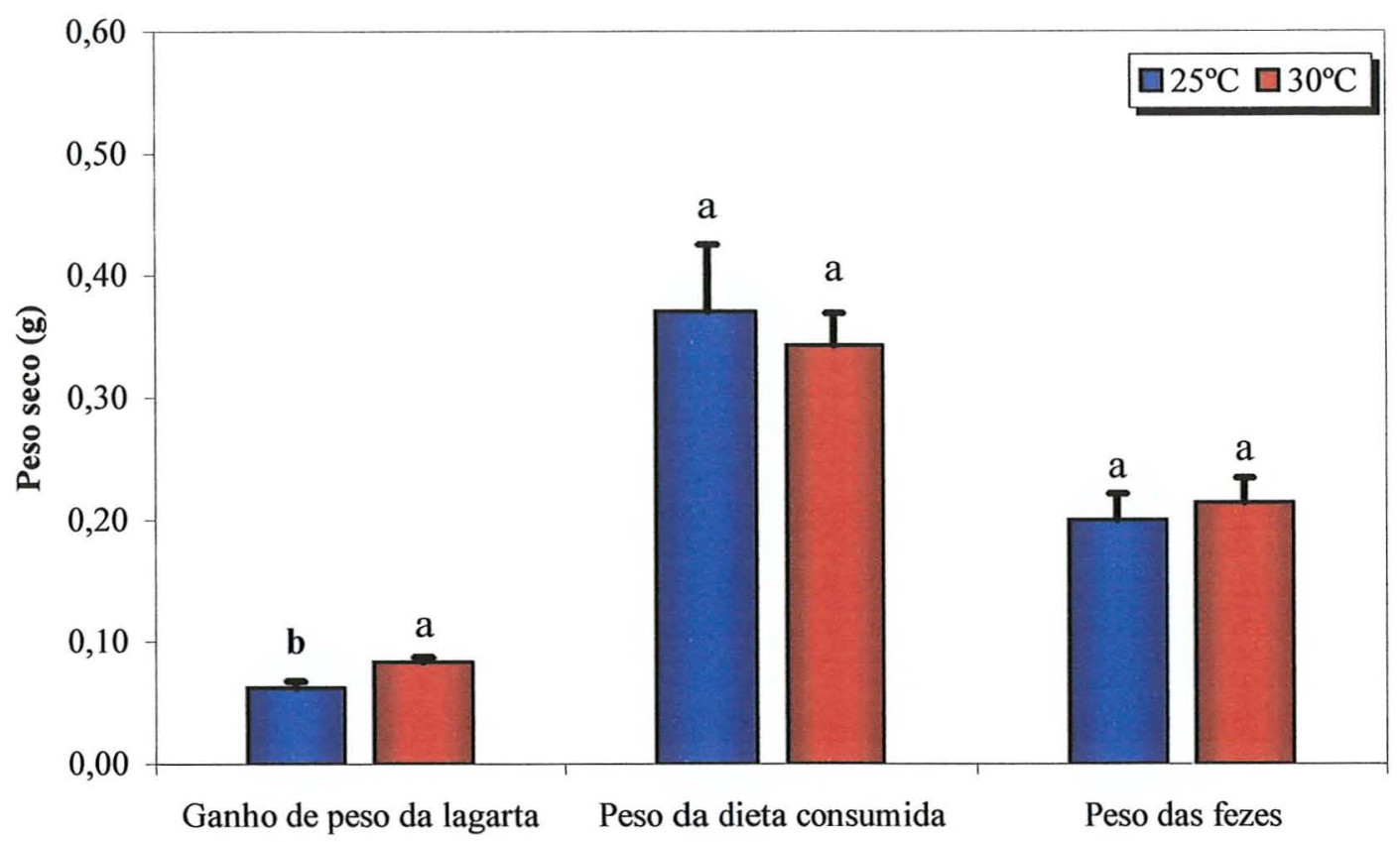

Figura 5. Ganho de peso de lagartas, peso da dieta consumida e de fezes de Spodoptera frugiperda no máximo desenvolvimento, em dieta artificial, em recipientes mantidos em posição vertical. Temperatura: 25 e $30{ }^{\circ} \mathrm{C}$; UR: $\pm 6010 \%$; fotofase: 14 horas.

Agrupamentos de colunas, seguidos de mesma letra, não diferem, estatisticamente entre si, pelo teste de Tukey, a o nível de $5 \%$ de probabilidade.

Também para $D$. saccharalis, o peso fresco da lagarta, no máximo desenvolvimento, foi semelhante à 25 e $30^{\circ} \mathrm{C}$ (Figura 4), o mesmo ocorrendo com relação ao ganho de peso, embora a quantidade de dieta consumida e o peso das fezes excretadas tenham diferido estatisticamente, registrando-se maiores valores à $25^{\circ} \mathrm{C}$ (Figura 7).

Houve para esta espécie uma alternância nos valores de índices nutricionais obtidos à 25 e $30^{\circ} \mathrm{C}$, sendo, por exemplo, registrado maior valor de ECI à $30{ }^{\circ} \mathrm{C}$, e, por outro lado, maior valor de ECD a $25^{\circ} \mathrm{C}$ (Tabela 3). Embora tenha havido maior custo metabólico à $30^{\circ} \mathrm{C}$, o que poderia indicar uma inadequação desta condição, pode-se, em função dos resultados obtidos, optar-se tanto por $25^{\circ} \mathrm{C}$ como à $30^{\circ} \mathrm{C}$ para 
TABELA 1. Índice de consumo (CI), razão de crescimento (GR), taxa metabólica relativa (RMR), digestibilidade aparente $(A D)$, eficiência de conversão do alimento ingerido (ECI), eficiência de conversão do alimento digerido (ECD) e custo metabólico (CM) para lagartas de Spodoptera frugiperda, criada em dieta artificial à 25 e $30^{\circ} \mathrm{C}$, UR de $60 \pm 10 \%$ e fotofase de 14 horas.

\begin{tabular}{lcc}
\hline Índices nutricionais & $25^{\circ} \mathrm{C}$ & $30^{\circ} \mathrm{C}$ \\
\hline CI (g/g.dia) & $0,5653 \pm 0,1364 \mathrm{a}$ & $0,5620 \pm 0,0231 \mathrm{a}$ \\
GR (g/g.dia) & $0,0835 \pm 0,0060 \mathrm{~b}$ & $0,1407 \pm 0,0040 \mathrm{a}$ \\
RMR (g/g.dia) & $0,2057 \pm 0,1260 \mathrm{a}$ & $0,0748 \pm 0,0084 \mathrm{a}$ \\
$\mathrm{AD}(\%)$ & $42,04 \pm 3,39 \mathrm{a}$ & $38,90 \pm 1,00 \mathrm{a}$ \\
$\mathrm{ECI}(\%)$ & $19,67 \pm 1,44 \mathrm{~b}$ & $26,26 \pm 1,40 \mathrm{a}$ \\
$\mathrm{ECD}(\%)$ & $53,30 \pm 5,06 \mathrm{~b}$ & $67,06 \pm 3,04 \mathrm{a}$ \\
$\mathrm{CM}(\%)$ & $46,70 \pm 5,06 \mathrm{a}$ & $32,94 \pm 3,04 \mathrm{~b}$ \\
\hline
\end{tabular}

Médias seguidas da mesma letra, não diferem entre si, pelo teste de Tukey, ao nível de $5 \%$ de probabilidade.

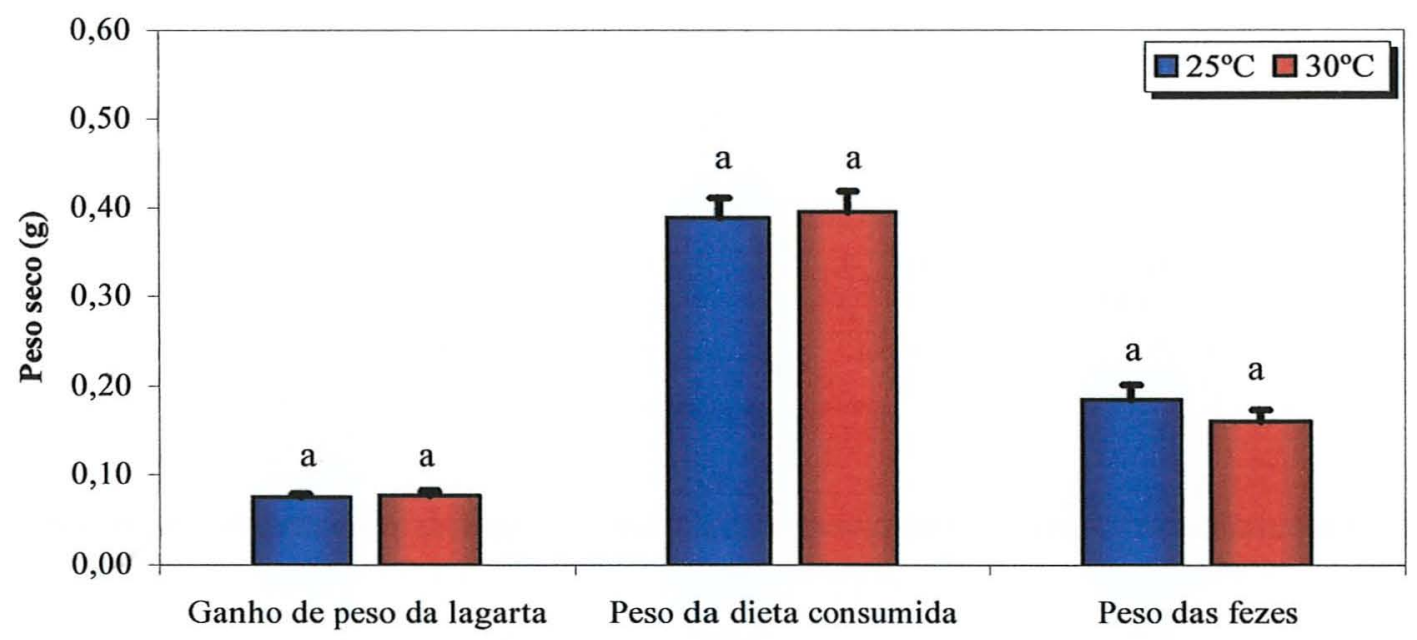

Figura 6. Ganho de peso de lagartas, peso da dieta consumida e de fezes de Heliothis virescens, no máximo desenvolvimento, em dieta artificial, em recipientes mantidos em posição vertical. Temperatura: 25 e $30{ }^{\circ} \mathrm{C}$; UR: $60 \pm 10 \%$; fotofase: 14 horas.

Agrupamentos de colunas, seguidos de mesma letra, não diferem estatisticamente entre si, pelo teste Tukey, ao nível de 5\% de probabilidade. 
TABELA 2. Índice de consumo (CI), razão de crescimento (GR), taxa metabólica relativa (RMR), digestibilidade aparente $(A D)$, eficiência de conversão do alimento ingerido (ECI), eficiência de conversão do alimento digerido (ECD) e custo metabólico (CM) para lagartas de Heliothis virescens, criada em dieta artificial à 25 e $30^{\circ} \mathrm{C}$, UR de $60 \pm 10 \%$ e fotofase de 14 horas.

\begin{tabular}{lcc}
\hline Indices nutricionais & $25^{\circ} \mathrm{C}$ & $30^{\circ} \mathrm{C}$ \\
\hline $\mathrm{CI}(\mathrm{g} / \mathrm{g}$.dia) & $0,8139 \pm 0,0333 \mathrm{~b}$ & $1,2289 \pm 0,0472 \mathrm{a}$ \\
$\mathrm{GR}(\mathrm{g} / \mathrm{g}$.dia) & $0,1500 \pm 0,0036 \mathrm{~b}$ & $0,2315 \pm 0.0041 \mathrm{a}$ \\
$\mathrm{RMR}(\mathrm{g} / \mathrm{g}$.dia) & $0,3026 \pm 0,0315 \mathrm{~b}$ & $0,5264 \pm 0,0474 \mathrm{a}$ \\
$\mathrm{AD}(\%)$ & $54,55 \pm 2,22 \mathrm{~b}$ & $60,64 \pm 1,68 \mathrm{a}$ \\
$\mathrm{ECI}(\%)$ & $19,77 \pm 0,95 \mathrm{a}$ & $19,53 \pm 0,56 \mathrm{a}$ \\
$\mathrm{ECD}(\%)$ & $40,07 \pm 2,99 \mathrm{a}$ & $33,73 \pm 1,66 \mathrm{a}$ \\
$\mathrm{CM}(\%)$ & $59,93 \pm 2,99 \mathrm{a}$ & $66,27 \pm 1,66 \mathrm{a}$ \\
\hline
\end{tabular}

Médias seguidas da mesma letra, não diferem entre si, pelo teste de Tukey, ao nível de $5 \%$ de probabilidade.

sua criação. Entretanto, sugerem-se associações de estudos biológicos com nutricionais para que possa ser definida a melhor condição para criação desta espécie na faixa de 25 à $30^{\circ} \mathrm{C}$.

Os resultados de consumo e utilização de alimento obtidos para $D$. saccharalis, encontram-se próximos aos valores constatados por Brewer (1981), Mihsfeldt (1985) e Parra \& Mihsfeldt (1992) que realizaram estudos de comparação de dietas baseando-se nos parâmetros nutricionais. Também os valores obtidos por Almeida (1986), estudando consumo e utilização de alimento e a influência da densidade populacional de $D$. saccharalis, encontram-se na faixa dos resultados obtidos na presente pesquisa.

Estes resultados demonstraram claramente variações de consumo e utilização de alimento dependendo da espécie de inseto e de temperatura. Isto era de se esperar, desde que Crócomo \& Parra (1985) observaram grandes variações destes índices nutricionais para a mesma espécie ( $S$. frugiperda) criada em diferentes 
hospedeiros. Assim, na presente pesquisa, fica evidente que para $S$. frugiperda, a melhor temperatura para aproveitamento alimentar é à de $30^{\circ} \mathrm{C}$, pois nesta condição as lagartas crescem mais (Figura 4) e a eficiência de conversão de alimento é maior (Tabela 1). No entanto, Ferraz (1982) estudando as exigências térmicas de $S$. frugiperda, concluiu que a temperatura mais favorável para o desenvolvimento do inseto é a de $25^{\circ} \mathrm{C}$.

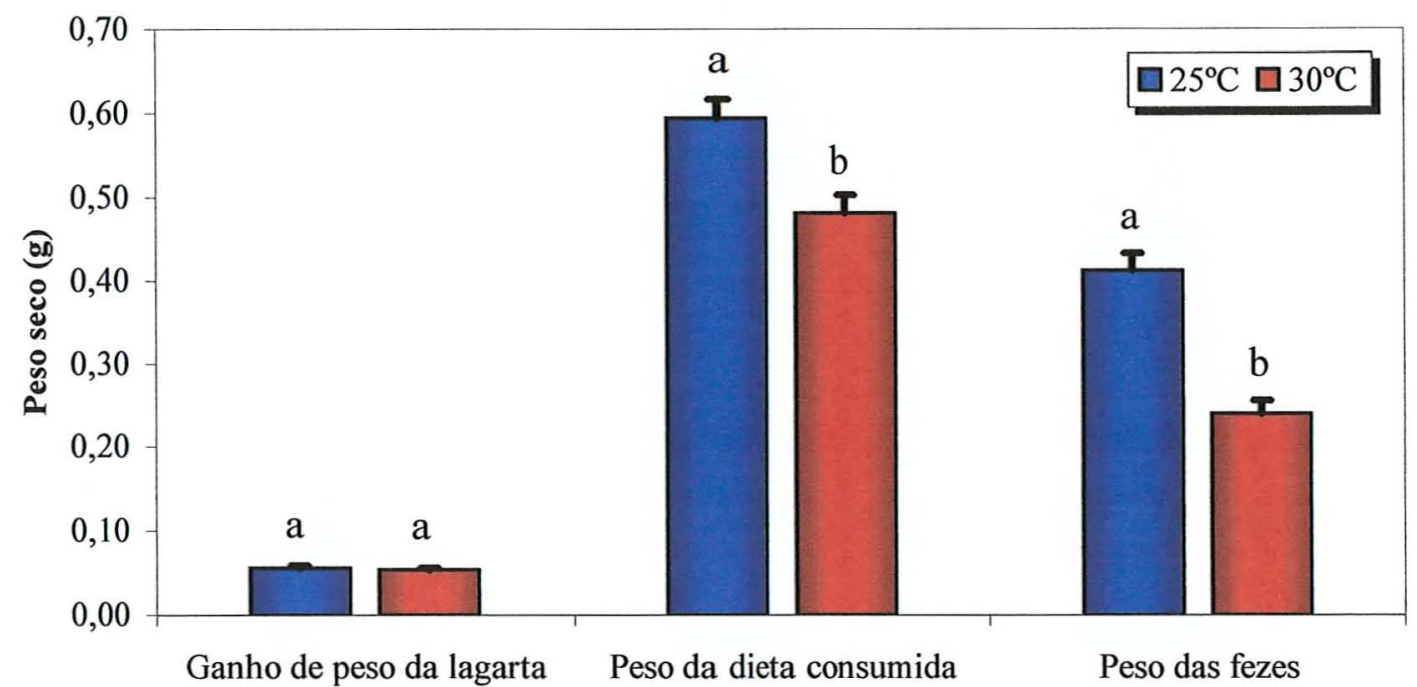

Figura 7. Ganho de peso de lagartas, peso da dieta consumida e de fezes de Diatraea saccharalis, no máximo desenvolvimento, em dieta artificial, em recipientes mantidos em posição vertical. Temperatura: 25 e $30{ }^{\circ} \mathrm{C}$; UR: $60 \pm 10 \%$; fotofase: 14 horas.

Agrupamentos de colunas, seguidos de mesma letra, não diferem estatisticamente entre si, pelo teste Tukey, ao nível de $5 \%$ de probabilidade.

Embora nas duas outras espécies, os insetos tenham crescido igualmente à 25 e $30^{\circ} \mathrm{C}$, há uma tendência, para $D$. saccharalis, de $30^{\circ} \mathrm{C}$ ser a temperatura mais adequada, pois nesta condição o inseto consumiu menos e ganhou o mesmo peso que o inseto mantido à $25^{\circ} \mathrm{C}$ (Figura 7). Desta forma, em criações massais de D. saccharalis para produção de parasitóides (Macedo et al., 1983), opta-se por $30^{\circ} \mathrm{C}$, exatamente por 
TABELA 3. Índice de consumo (CI), razão de crescimento (GR), taxa metabólica relativa (RMR), digestibilidade aparente ( $\mathrm{AD})$, eficiência de conversão do alimento ingerido (ECI), eficiência de conversão do alimento digerido (ECD) e custo metabólico (CM) para lagartas de Diatraea saccharalis, criada em dieta artificial à 25 e $30^{\circ} \mathrm{C}$, UR de $60 \pm 10 \%$ e fotofase de 14 horas.

\begin{tabular}{lcc}
\hline Indices nutricionais & $25^{\circ} \mathrm{C}$ & $30^{\circ} \mathrm{C}$ \\
\hline $\mathrm{CI}(\mathrm{g} / \mathrm{g}$.dia) & $0,8848 \pm 0,0497 \mathrm{~b}$ & $1,0899 \pm 0,0667 \mathrm{a}$ \\
$\mathrm{GR}(\mathrm{g} / \mathrm{g}$.dia) & $0,0771 \pm 0,0016 \mathrm{~b}$ & $0,1142 \pm 0,0026 \mathrm{a}$ \\
$\mathrm{RMR}(\mathrm{g} / \mathrm{g}$. dia $)$ & $0,1879 \pm 0,0132 \mathrm{~b}$ & $0,4619 \pm 0,0619 \mathrm{a}$ \\
$\mathrm{AD}(\%)$ & $31,43 \pm 1,37 \mathrm{~b}$ & $50,91 \pm 2,16 \mathrm{a}$ \\
$\mathrm{ECI}(\%)$ & $9,52 \pm 0,39 \mathrm{~b}$ & $11,64 \pm 0,60 \mathrm{a}$ \\
$\mathrm{ECD}(\%)$ & $31,87 \pm 1,51 \mathrm{a}$ & $24,23 \pm 1,45 \mathrm{~b}$ \\
$\mathrm{CM}(\%)$ & $68,13 \pm 1,51 \mathrm{~b}$ & $75,77 \pm 1,45 \mathrm{a}$ \\
\hline
\end{tabular}

Médias seguidas da mesma letra, não diferem entre si, pelo teste de Tukey, ao nível de $5 \%$ de probabilidade.

reduzir o ciclo da broca-da-cana e, conseqüentemente, aumentar o número de insetos produzidos durante $o$ ano.

Os valores dos índices nutricionais são também, extremamente variáveis dependendo da espécie em estudo, fato já relatado por Scriber \& Slansky (1985). Se forem tomados como exemplo, os índices de eficiência de conversão (ECI e ECD) para as três espécies do presente estudo, eles são muito maiores para $S$. frugiperda, enquanto que a digestibilidade aparente é maior para $H$. virescens. Em termos gerais, o aproveitamento de $S$. frugiperda nas duas condições térmicas, é maior que as demais espécies, pois o índice de consumo foi menor (Tabelas 1,2 e 3). É conveniente salientar que a pesquisa foi conduzida por apenas uma geração, e o inseto quando criado por gerações sucessivas em temperaturas mais elevadas $\left(30^{\circ} \mathrm{C}\right)$, devido à maior atividade metabólica, pode ficar estressado e ter o seu desenvolvimento prejudicado. Sugerem-se pesquisas neste sentido. 


\subsubsection{Efeito da posição do recipiente de criação no consumo e utilização}

4.1.2.1 Consumo e utilização do alimento por $H$. virescens, criada em recipientes de vidro de fundo chato, na posição vertical e inclinada

A posição do tubo de vidro influenciou o consumo e utilização do alimento de $H$. virescens na temperatura escolhida $\left(25^{\circ} \mathrm{C}\right)$. Assim, o maior peso fresco, no máximo desenvolvimento, o maior ganho de peso e quantidade de alimento consumido foram obtidos nos recipientes mantidos em posição inclinada (Figura 8).

$\mathrm{O}$ índice de consumo (CI), a taxa metabólica relativa (RMR) e a digestibilidade aparente (AD), não diferiram nos insetos criados nas duas posições (Tabela 4). Por outro lado, a razão de crescimento (GR) e o aproveitamento de alimento (ECI e ECD), foram superiores na posição inclinada, resultando em menor custo metabólico do inseto, quando criado nesta posição (Tabela 4). Torna-se dificil a explicação para a preferência pela posição inclinada (Figura 8 ) pois a tomada de alimento e o índice de consumo foram semelhantes nas duas posições (Tabela 4). Outros fatores ligados à evaporação da dieta, alterando sua textura e consistência, ou mesmo a luminosidade, em função da posição dos recipientes, poderiam, talvez, explicar o melhor aproveitamento alimentar na posição inclinada. A facilidade na tomada de alimento pelas lagartas quando os tubos se encontravam na posição inclinada, poderia ter levado aos melhores resultados. 


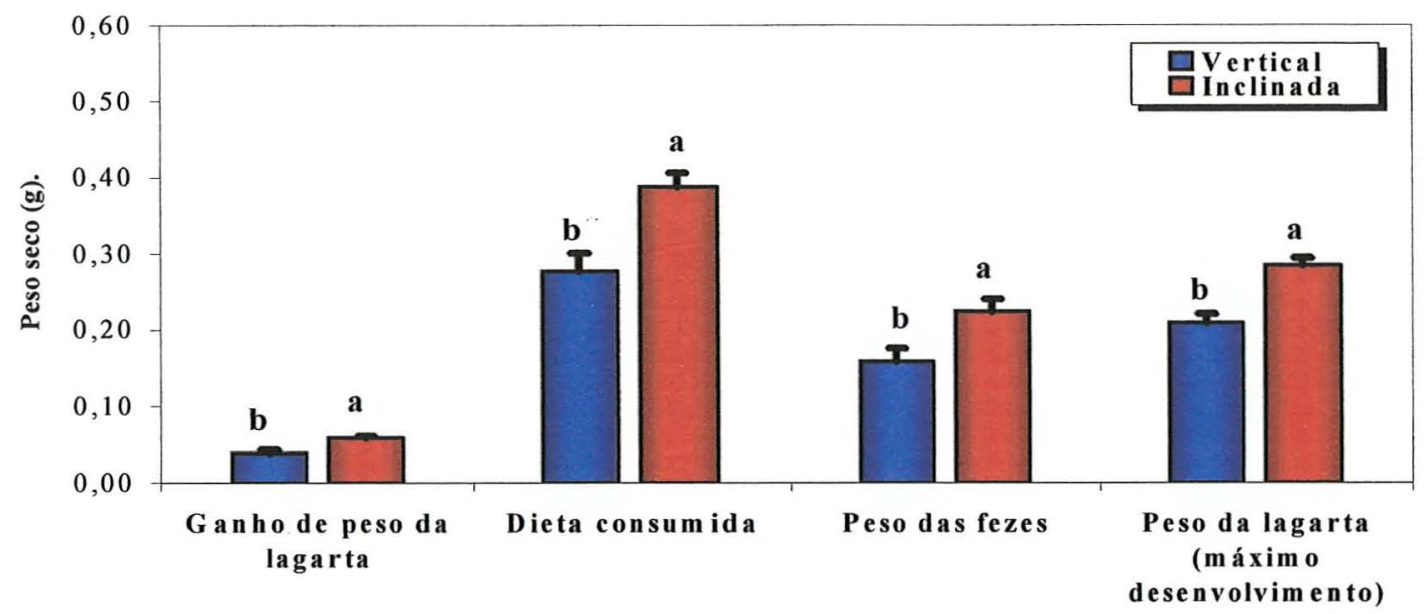

Figura 8. Ganho de peso de lagartas, peso da dieta consumida, peso de fezes e peso fresco de Heliothis virescens, no máximo desenvolvimento, em dieta artificial, em tubos de vidro mantidos na posição vertical e inclinada. Temperatura: 25 ${ }^{\circ} \mathrm{C}$; UR: $60 \pm 10 \%$; fotofase: 14 horas.

Médias seguidas da mesma letra, não diferem estatisticamente entre si, pelo teste de Tukey, ao nível de $5 \%$ de probabilidade.

TABELA 4. Índice de consumo (CI), razão de crescimento (GR), taxa metabólica relativa (RMR), digestibilidade aparente (AD), eficiência de conversão do alimento ingerido (ECI), eficiência de conversão do alimento digerido (ECD) e custo metabólico (CM) para lagartas de Heliothis virescens, criada em dieta artificial e cujos recipientes foram mantidos em posições vertical e inclinada. Temperatura: $25^{\circ} \mathrm{C}$, UR de $60 \pm 10 \%$ e fotofase de 14 horas.

\begin{tabular}{lcc}
\hline Índices nutricionais & Posição vertical & Posição inclinada \\
\hline CI (g/g.dia) & $0,6765 \pm 0,0356 \mathrm{a}$ & $0,70830 \pm 0,0384 \mathrm{a}$ \\
GR (g/g.dia) & $0,0905 \pm 0,0039 \mathrm{~b}$ & $0,1043 \pm 0,0034 \mathrm{a}$ \\
RMR (g/g.dia) & $0,2308 \pm 0,0235 \mathrm{a}$ & $0,2019 \pm 0,0124 \mathrm{a}$ \\
AD (\%) & $45,92 \pm 1,53 \mathrm{a}$ & $45,07 \pm 1,65 \mathrm{a}$ \\
ECI (\%) & $13,86 \pm 0,45 \mathrm{~b}$ & $15,82 \pm 0,52 \mathrm{a}$ \\
ECD (\%) & $31,76 \pm 1,58 \mathrm{~b}$ & $35,86 \pm 1,29 \mathrm{a}$ \\
CM (\%) & $68,24 \pm 1,58 \mathrm{a}$ & $64,14 \pm 1,29 \mathrm{~b}$ \\
\hline
\end{tabular}

Médias seguidas da mesma letra, não diferem entre si, pelo teste de Tukey, ao nível de $5 \%$ de probabilidade. 
4.1.2.2 Consumo e utilização do alimento por $S$. frugiperda criadas em recipientes de vidro de fundo chato na posição inclinada em duas temperaturas

O maior peso fresco das lagartas, no máximo desenvolvimento, bem como, o maior ganho de peso e a maior quantidade de dieta consumida foram obtidos à $25^{\circ} \mathrm{C}$ (Figura 9).

$\mathrm{O}$ índice de consumo (CI), a razão de crescimento (GR), a taxa metabólica relativa (RMR), diferiram estatisticamente entre as temperaturas estudadas, sendo superiores à $30^{\circ} \mathrm{C}$. Entretanto, a digestibilidade aparente $(\mathrm{AD})$ não diferiu entre 25 e $30^{\circ} \mathrm{C}$ (Tabela 5). Por outro lado, o aproveitamento do alimento (ECI e ECD) foi superior à $25^{\circ} \mathrm{C}$, levando a um menor custo metabólico, nesta condição térmica (Tabela 5).

Desta forma, a posição do recipiente pode interferir na utilização de alimento, pois quando criado na posição vertical, a melhor condição para $S$. frugiperda foi a de $30^{\circ} \mathrm{C}$ (4.1.2) enquanto na posição inclinada, a melhor condição foi a de $25^{\circ} \mathrm{C}$. Vázquez (1988) observou este efeito da posição do recipiente e da própria dieta dentro do mesmo, como fatores importantes no desenvolvimento de Pseudoplusia includens (Walker).

4.2 Determinação da quantidade mínima de dieta à base de feijão, germe-detrigo e levedura para criação de $S$. frugiperda em recipientes de vidro de fundo chato

Houve diferença estatística na mortalidade inicial de lagartas de $S$. frugiperda, dependendo da quantidade de dieta utilizada. A sobrevivência (ação fagoestimulante) foi maior nos tubos de vidro com mais de $6 \mathrm{ml}$ de dieta por tubo (Tabela 6). 


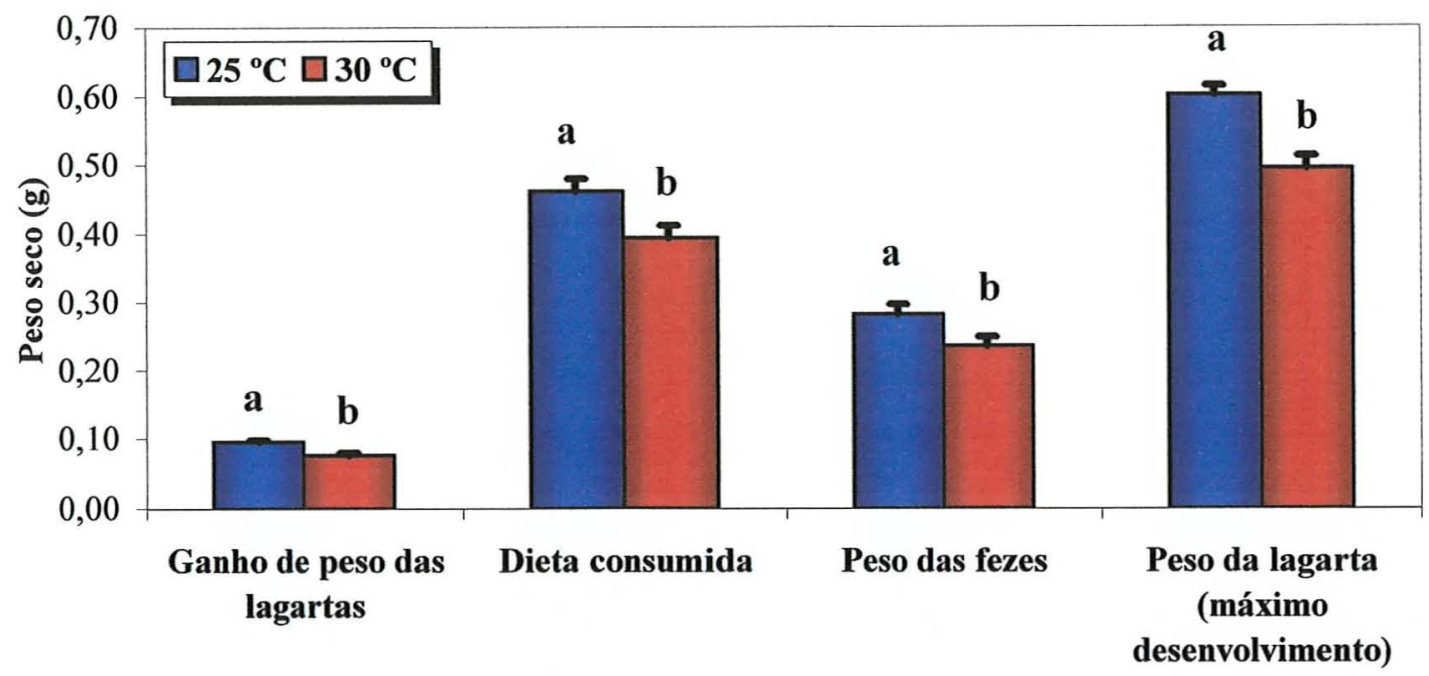

Figura 9. Ganho de peso de lagartas, da dieta consumida, peso de fezes e peso fresco de Spodoptera frugiperda, no máximo desenvolvimento, em dieta artificial, em recipientes mantidos na posição vertical e inclinada. Temperatura: 25 e $30^{\circ} \mathrm{C}$; UR: $60 \pm 10 \%$; fotofase: 14 horas.

Médias seguidas da mesma letra, não diferem estatisticamente entre si, pelo teste de Tukey, ao nível de $5 \%$ de probabilidade.

Entretanto, ao longo do desenvolvimento, foi ficando evidente a quantidade insuficiente de dieta em alguns tratamentos, pois com 5 e $6 \mathrm{ml}$, houve um alongamento da fase larval e as maiores viabilidades somente foram obtidas com 7 e 8 $\mathrm{ml}$ de dieta/recipiente (Tabela 6).

Os resultados obtidos para a fase pupal, indicam, em geral, que as lagartas que se transformaram em pupas tiveram duração, viabilidade e razão sexual semelhantes, independente do tratamento (Tabela 7). Entretanto, especialmente para machos, ficou clara a influência da quantidade de dieta por tubo de vidro, com relação ao peso, pois nas pupas originárias de tubos com $5 \mathrm{ml}$ de dieta, os pesos foram menores. $\mathrm{O}$ mesmo ocorreu para fêmeas, pois com 7 e $8 \mathrm{ml}$ de dieta por tubo, obtiveram-se os maiores pesos. Esta constatação é muito importante, desde que existe uma estreita correlação entre peso de pupas (fềmeas) e número de ovos colocados (Parra, 1996). Os 
TABELA 5. Índice de consumo (CI), razão de crescimento (GR), taxa metabólica relativa (RMR), digestibilidade aparente (AD), eficiência de conversão do alimento ingerido (ECI), eficiência de conversão do alimento digerido (ECD) e custo metabólico (CM) para lagartas de Spodoptera frugiperda, criada em dieta artificial à 25 e $30^{\circ} \mathrm{C}$, UR de $60 \pm 10 \%$ e fotofase de 14 horas, com recipientes mantidos em posição inclinada.

\begin{tabular}{lll}
\hline Indices nutricionais & $25^{\circ} \mathrm{C}$ & $30^{\circ} \mathrm{C}$ \\
\hline CI (g/g.dia) & $0,5537 \pm 0,0201 \mathrm{~b}$ & $0,7800 \pm 0,0375 \mathrm{a}$ \\
GR (g/g.dia) & $0,1151 \pm 0,0025 \mathrm{~b}$ & $0,1477 \pm 0,0044 \mathrm{a}$ \\
RMR (g/g.dia) & $0,0966 \pm 0,0058 \mathrm{~b}$ & $0,1660 \pm 0,0092 \mathrm{a}$ \\
AD (\%) & $38,88 \pm 0,88 \mathrm{a}$ & $41,10 \pm 0,86 \mathrm{a}$ \\
ECI (\%) & $21,54 \pm 0,61 \mathrm{a}$ & $19,77 \pm 0,60 \mathrm{~b}$ \\
ECD (\%) & $55,66 \pm 1,22 \mathrm{a}$ & $48,33 \pm 1,31 \mathrm{~b}$ \\
CM (\%) & $44,34 \pm 1,22 \mathrm{~b}$ & $51,67 \pm 1,31 \mathrm{a}$ \\
\hline
\end{tabular}

Médias seguidas da mesma letra, não diferem entre si, pelo teste de Tukey, ao nível de $5 \%$ de probabilidade.

Tabela 6. Viabilidade ( $7^{\circ}$ dia), duração e viabilidade larval de Spodoptera frugiperda em dieta artificial, em recipientes de vidro com $5,6,7$ e $8 \mathrm{ml}$ de dieta. Temperatura: $30 \pm 1{ }^{\circ} \mathrm{C}$; UR: $60 \pm 10 \%$; fotofase: 14 horas.

\begin{tabular}{cccc}
\hline $\begin{array}{c}\text { Quantidade de dieta } \\
(\mathrm{ml})\end{array}$ & $\begin{array}{c}\text { Viabilidade } \\
\left(\% / 7^{0} \text { dia }\right)\end{array}$ & $\begin{array}{c}\text { Duração larval } \\
\text { (dias) }\end{array}$ & $\begin{array}{c}\text { Viabilidade larval } \\
(\%)\end{array}$ \\
\hline 5 & $53,57 \pm 3,22 \mathrm{~b}$ & $18,07 \pm 1,13 \mathrm{a}$ & $10,00 \pm 1,09 \mathrm{~b}$ \\
6 & $70,00 \pm 4,50 \mathrm{a}$ & $16,79 \pm 0,37 \mathrm{a}$ & $24,29 \pm 5,92 \mathrm{~b}$ \\
7 & $80,00 \pm 3,93 \mathrm{a}$ & $15,44 \pm 0,20 \mathrm{~b}$ & $35,71 \pm 2,30 \mathrm{ab}$ \\
8 & $85,00 \pm 3,93 \mathrm{a}$ & $15,30 \pm 0,16 \mathrm{~b}$ & $47,86 \pm 1,49 \mathrm{a}$ \\
\hline
\end{tabular}

Médias seguidas da mesma letra, na vertical, não diferem estatisticamente entre si, pelo teste de $t$, ao nível de $5 \%$ de probabilidade. 


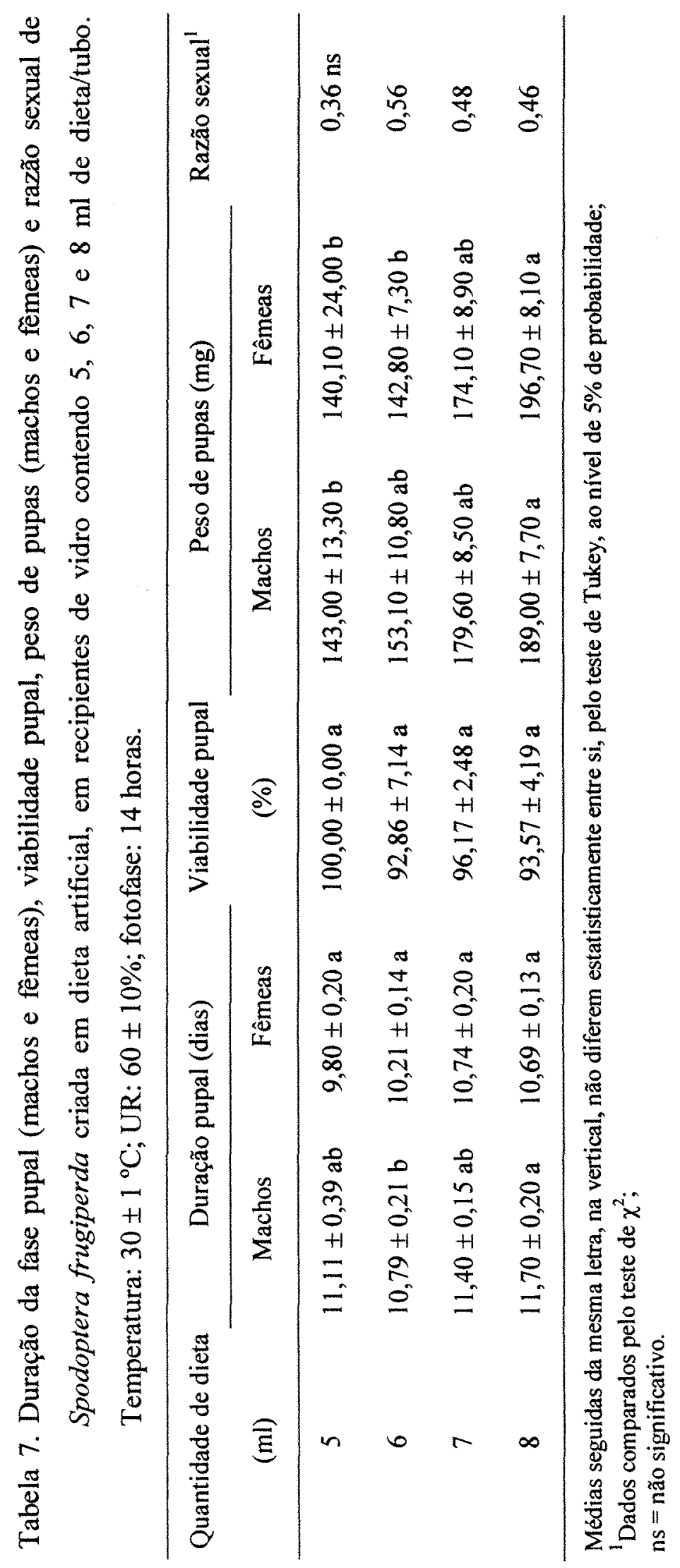


valores de duração da fase pupal de machos e fềmeas registrados por Ferraz (1982), estudando as exigências térmicas de $S$. frugiperda na mesma condição térmica, foram menores do que os valores obtidos na presente pesquisa. Entretanto, os dados da duração da fase larval do presente estudo, são semelhantes àqueles referidos por Nalim (1991), também em estudo de biologia e nutrição quantitativa de $S$. frugiperda à $25^{\circ} \mathrm{C}$.

Os valores verificados para peso de pupas, encontram-se na faixa dos valores observados por Ferraz (1982), e inferiores aos constatados por Parra \& Carvalho (1984), à $25^{\circ} \mathrm{C}$ enquanto que os valores obtidos para fêmeas (140,0 a $196,7 \mathrm{mg}$ ) são inferiores aos referidos por Nalim (1991). A viabilidade pupal e a razão sexual obtidas são também semelhantes àqueles registrados por estes autores, embora as temperaturas de estudo tenham sido variáveis.

A deformação de pupas não foi afetada pela quantidade dieta, sendo variável de $0,71 \%$ a $2,14 \%$ nos diferentes tratamentos. Não foi constatada a presença de patógenos nos recipientes contendo diferentes volumes de dietas.

A inadequação dos menores volumes de dieta $(5$ e $6 \mathrm{ml})$ no desenvolvimento de S. frugiperda, se deveu à perda de água diária muito maior que nos maiores volumes (7 e $8 \mathrm{ml}$ ) (Tabela 8 e Figura 10). Já no $8^{0}$ dia (50\% do desenvolvimento) estas diferenças eram significativas, acentuando-se no $16^{0}$ dia (próximo à pupação). Em todos os volumes avaliados, ocorreu uma perda linear de água, em função do tempo, embora esta perda tenha sido muito mais drástica e rápida nos menores volumes $(5$ e $6 \mathrm{ml})$ (Figura 10). Esta perda de água, tornou a dieta impalatável, provavelmente alterando as suas caracteristicas físicas. 
Tabela 8. Perda acumulada de água (g) de dietas mantidas em tubos de vidro de fundo chato em quantidades variáveis, em períodos correspondentes a $50 \%$ ( $8^{\circ}$ dia) e final de desenvolvimento larval (16 $6^{\circ}$ dia) de Spodoptera frugiperda. Temperatura: $30 \pm 1{ }^{\circ} \mathrm{C}$; UR: $60 \pm 10 \%$; fotofase: 14 horas.

\begin{tabular}{ccc}
\hline \multirow{2}{*}{\begin{tabular}{c} 
Quantidade de dieta \\
\cline { 2 - 3 }
\end{tabular}} & \multicolumn{2}{c}{ Perda d'água (g) acumulada } \\
\cline { 2 - 3 }$(50 \%$ do desenvolvimento larval $)$ & (Final do desenvolvimento larval) \\
\hline 5 & $0,1659 \pm 0,0034 \mathrm{a}$ & $0,3279 \pm 0,0049 \mathrm{a}$ \\
7 & $0,1370 \pm 0,0034 \mathrm{~b}$ & $0,2680 \pm 0,0049 \mathrm{~b}$ \\
8 & $0,1164 \pm 0,0028 \mathrm{c}$ & $0,2276 \pm 0,0041 \mathrm{c}$ \\
\hline
\end{tabular}

Médias seguidas da mesma letra, na vertical, não diferem estatisticamente entre si, pelo teste de Tukey, ao nivel de $5 \%$ de probabilidade; 


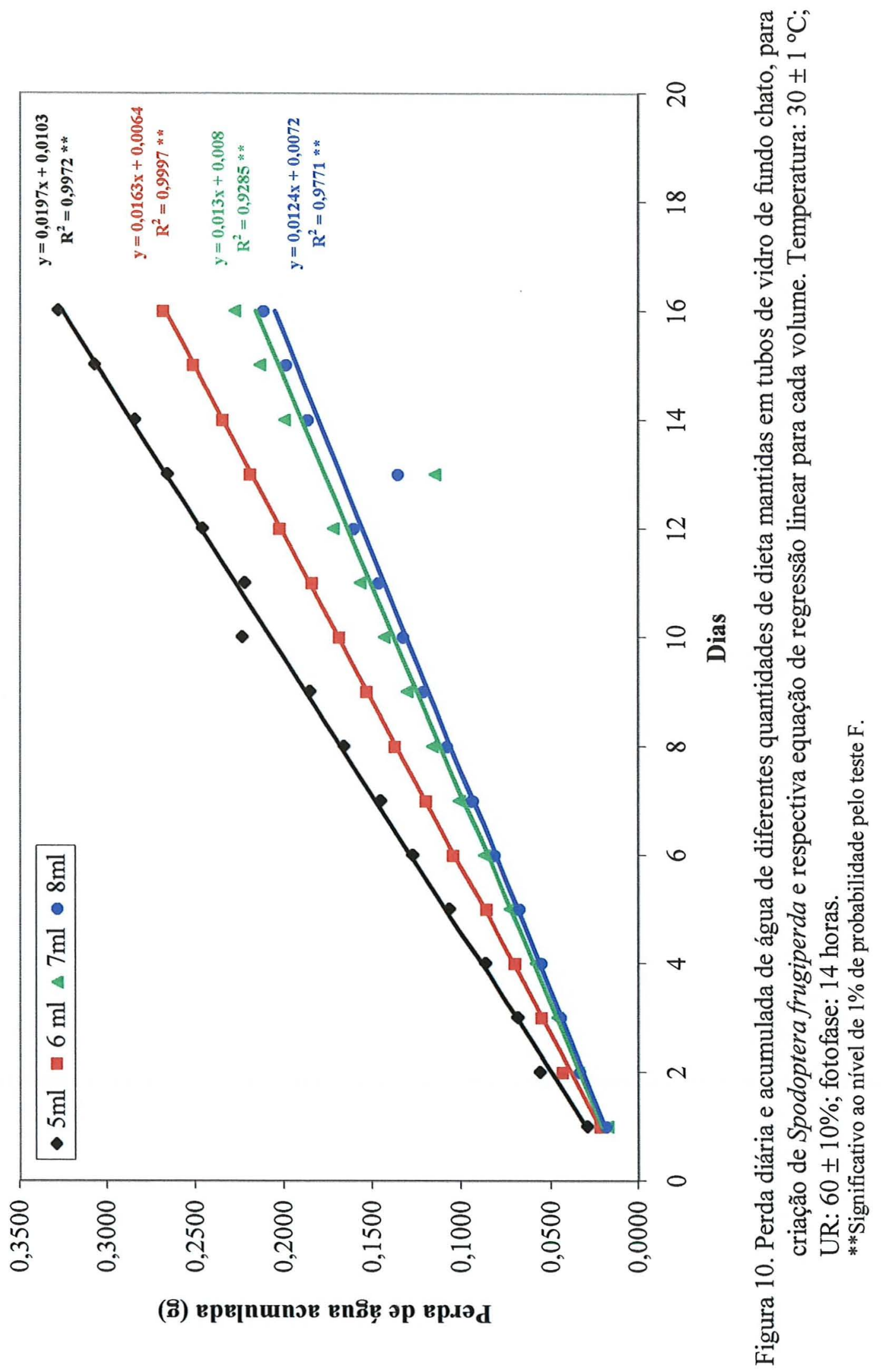




\subsection{Biologia comparada de $S$. frugiperda em três tipos de recipientes de criação}

O "pegamento", isto é, a viabilidade de lagartas após sete dias da "inoculação", foi semelhante nos três tipos de recipientes utilizados para a criação de $S$. frugiperda (Tabela 9).

O tipo de recipiente afetou a duração da fase larval, que foi menor quando o inseto foi criado em tubos de vidro (Tabela 10). Os resultados encontrados estão dentro da faixa dos valores registrados por outros autores como Nalim (1991) e Parra \& Carvalho (1984), sendo que estes autores obtiveram resultados semelhantes, pois também utilizaram tubos de vidro, embora as pesquisas tenham sido conduzidas à $25^{\circ} \mathrm{C}$. Entretanto, os valores observados no presente trabalho são superiores aos obtidos por diversos autores (Bailey \& Chada, 1968; Ferraz, 1982; Kasten Jr. et al., 1978 e Oliveira, 1987), embora o primeiro autor tenha desenvolvido a criação de $S$. frugiperda em copo plástico de sorvete e apenas Ferraz (1982) estudou a biologia na mesma condição térmica e no mesmo tipo de recipiente. Entretanto, a despeito de pequenas variações numéricas, o inverso ocorreu com relação à fase pupal, em que houve um alongamento do período em tubos de vidro de fundo chato (Tabela 10). Os valores constatados em copo plástico União $\circledast$ e bandeja de criação Bio-RT-32® foram menores aos registrados por Davis et al. (1990), que desenvolveram um sistema de criação para lepidópteros, utilizando uma bandeja semelhante e copos plásticos de $30 \mathrm{ml}$, para a criação de $S$. frugiperda. Estes autores concluíram que não houve diferença significativa entre estes dois recipientes, à semelhança do que ocorreu na presente pesquisa. Os ovos provenientes de insetos criados nos diferentes tipos de recipientes não tiveram sua duração afetada (Tabela 10) e os resultados obtidos foram semelhantes aos de diversos autores, que trabalharam com temperaturas entre 25 e $30^{\circ} \mathrm{C}$ (Bailey \& Chada, 1968; Ferraz, 1982; Kasten Jr. et al., 1978 e Nalim, 1991). A duração do ciclo total foi afetada pelo recipiente, sendo que houve um alongamento do ciclo em copo plástico União $\circledast$ e um encurtamento em tubo de vidro e bandeja de criação. O resultado obtido em tubo de vidro foi menor do que aquele referido por Ferraz (1982) na mesma condição térmica. 
Tabela 9. Viabilidade no $7^{\circ}$ dia de Spodoptera frugiperda em dieta artificial, criadas em tubo de vidro, copo plástico União ${ }^{\circledR}$, bandeja de criação Bio-RT-32®. Temperatura: $30 \pm 1{ }^{\circ} \mathrm{C}$; UR: $60 \pm 10 \%$; fotofase: 14 horas.

\begin{tabular}{lc}
\hline \multicolumn{1}{c}{ Recipientes } & Viabilidade (\%) ao $7^{\mathbf{0}}$ dia \\
\hline Tubo de vidro & $31,67 \pm 2,06$ a \\
Copo plástico União ${ }^{\circledR}$ & $34,00 \pm 2,17$ a \\
Bandeja Bio-RT-32® & $38,60 \pm 1,69$ a \\
\hline
\end{tabular}

Médias seguidas da mesma letra, não diferem estatisticamente entre si, pelo teste de Tukey, ao nível de $5 \%$ de probabilidade.

Por se tratar de um inseto canibal, as baixas viabilidades observadas no estágio larval (Tabela 11), foram decorrentes do alto canibalismo registrado. Mostrando a sua adequação para criação do inseto, foi no tubo de vidro que constatou-se o menor canibalismo, e, portanto, maior viabilidade larval (Figura 11). Nalim (1991) estudando o

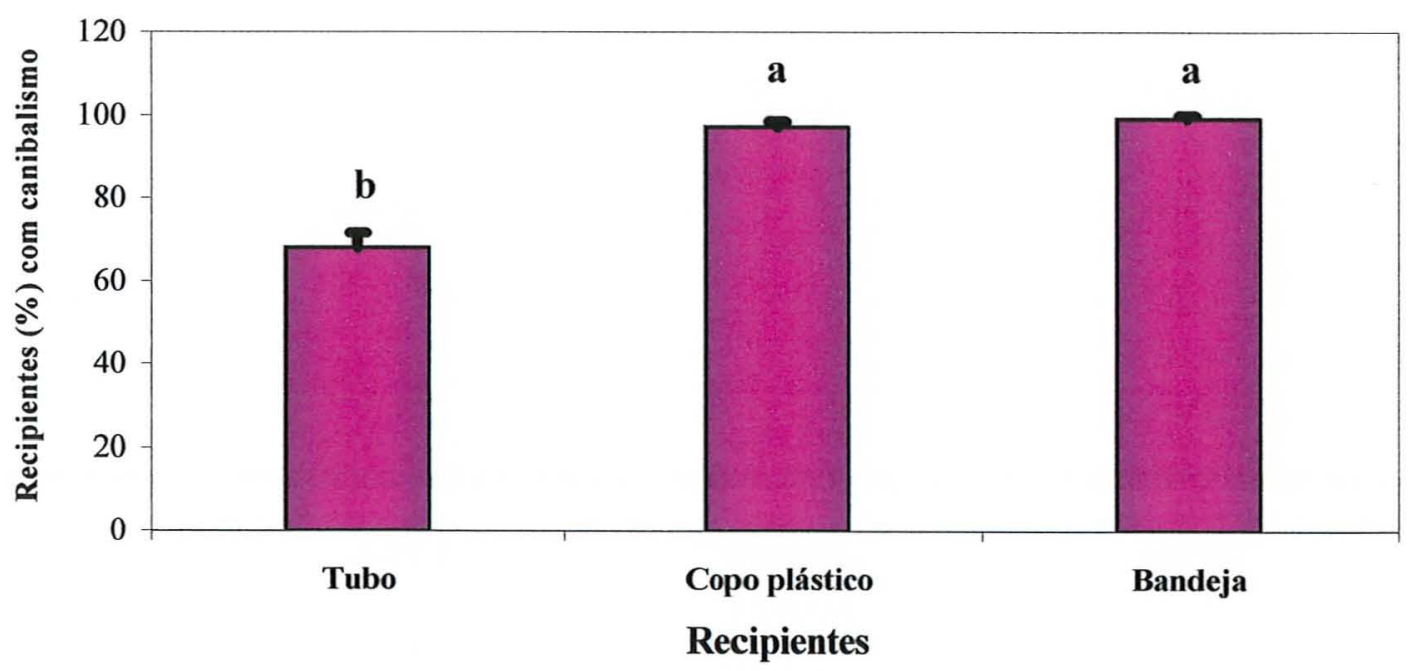

Figura 11. Porcentagem de recipientes em que ocorreu canibalismo, na criação de Spodoptera frugiperda, em três tipos de recipientes. Temperatura: $30 \pm 1{ }^{\circ} \mathrm{C}$; UR: $60 \pm 10 \%$; fotofase: 14 horas.

Médias seguidas da mesma letra, não diferem estatisticamente entre si, pelo teste de Tukey, ao nível de $5 \%$ de probabilidade. 

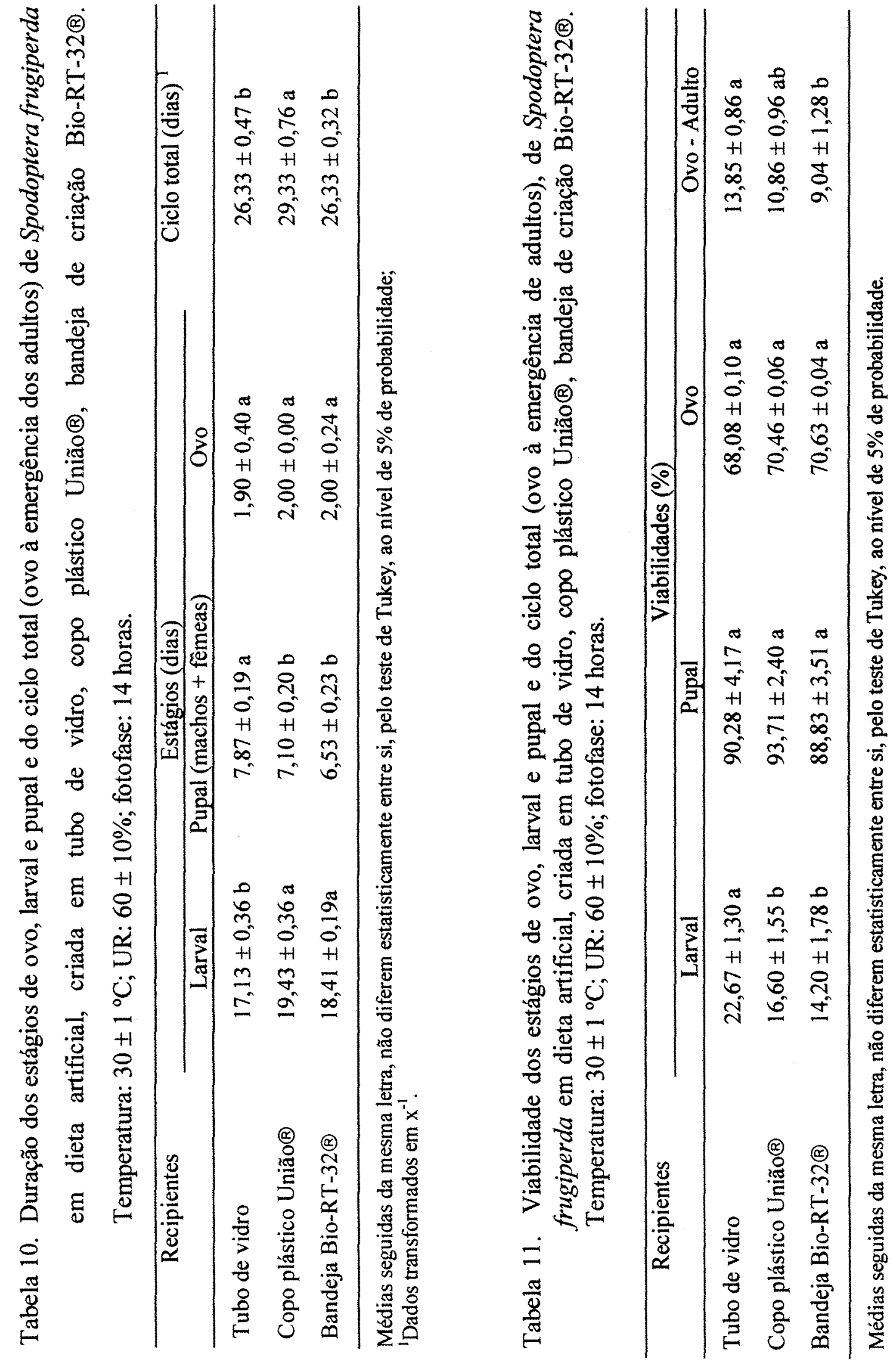
canibalismo de $S$. frugiperda, constatou $54,9 \%$ de viabilidade larval quando "inoculou" três lagartas/tubo e 47,9\% com quatro lagartas/tubo, em dieta artificial à base de feijão, levedura de cerveja e germe-de-trigo. Este mesmo autor, também observou o canibalismo em placas de vidro $(9,5 \mathrm{~cm}$ de diâmetro $\mathrm{x} 4,0 \mathrm{~cm}$ de altura) contendo alimento natural (milho), e obteve $46,7 \%$ de viabilidade larval com três lagartas/placa e $30 \%$ com quatro lagartas/placa. Relatou que à medida que se aumenta o número de lagartas por recipiente de criação a viabilidade, em relação ao padrão (uma lagarta/tubo), apresentou uma tendência de diminuição para todos os substratos analisados. Segundo observações de vários autores, com outras espécies, à medida que o número de indivíduos é aumentado no recipiente de criação, independente do substrato alimentar, o comportamento canibal torna-se mais acentuado (Fox, 1975a; Joyner \& Gould, 1985 e 1987; Polis, 1981 e Raffa, 1987).

As viabilidades pupais e de ovos (da geração seguinte) não foram afetadas pelo tipo de recipiente (Tabela 11). Tais viabilidades foram relativamente altas, se comparadas à viabilidade larval. Embora a viabilidade total tenha sido bastante baixa, muito aquém dos $75 \%$, preconizados por Singh (1983), para que uma dieta seja considerada adequada, foi possível verificar a superioridade do tubo de vidro para criação de $S$. frugiperda, embora sem diferir estatisticamente do copo plástico União® (Tabela 11). A viabilidade total foi bem aquém dos valores referidos outros autores (Ferraz, 1982 e Nalim, 1991).

A maior perda de água nos tubos de vidro durante todo o desenvolvimento larval (Tabela 12 e Figura 12) embora não tenha afetado a fase larval, afetou a duração da fase pupal de ambos os sexos e peso de pupas machos(Tabela 13). Aparentemente, as fềmeas de $S$. frugiperda são mais resistentes à perda de água, desde que o seu peso foi semelhante nos três recipientes. No tubo de vidro a duração da fase pupal de ambos os sexos é similar aos valores referidos por Ferraz (1982) na mesma temperatura e recipiente embora os pesos de ambos os sexos, na presente pesquisa, 
Tabela 12. Perda acumulada de água $(\mathrm{g})$ de dietas mantidas em tubo de vidro, copo plástico União $\circledast$, bandeja de criação Bio-RT-32®. Análise realizada no período correspondente à $50 \%\left(9^{\circ}\right.$ dia $)$ do desenvolvimento larval e no final (18 ${ }^{\circ}$ dia) deste periodo de Spodoptera frugiperda. Temperatura: $30 \pm 1{ }^{\circ} \mathrm{C}$; UR: $60 \pm 10 \%$; fotofase: 14 horas.

\begin{tabular}{|c|c|c|}
\hline \multirow[t]{2}{*}{ Recipientes } & \multicolumn{2}{|c|}{ Perda d'água (g) acumulada } \\
\hline & $\begin{array}{c}9 \text { dias } \\
\text { (50\% do desenvolvimento larval) }\end{array}$ & $\begin{array}{c}18 \text { dias } \\
\text { (Final do desenvolvimento larval) }\end{array}$ \\
\hline Tubo de vidro & $0,1063 \pm 0,0023 \mathrm{a}$ & $0,1958 \pm 0,0037 \mathrm{a}$ \\
\hline Copo plástico União® & $0,0414 \pm 0,0015 b$ & $0,0776 \pm 0,0033 b$ \\
\hline Bandeja Bio - RT $-32 \AA$ & $0,0322 \pm 0,0022 \mathrm{c}$ & $0,0776 \pm 0,0033 b$ \\
\hline
\end{tabular}

Médias seguidas da mesma letra, não diferem estatisticamente entre si, pelo teste de Tukey, ao nível de $5 \%$ de probabilidade.

tenham sido superiores. Davis et al. (1990) sem fazer distinção de sexos, observou variações de pesos de pupas, dependendo do recipiente de criação. A razão sexual e longevidade não foram afetadas pelo tipo de recipiente (Tabela 13 e 14). $O$ valor observado para a razão sexual em tubo de vidro foi similar ao registrado por Ferraz (1982) na mesma temperatura e também por Kasten Jr. et al. (1978) à $27^{\circ} \mathrm{C}$, em dieta à base de germe-de-trigo, ambos utilizando o mesmo tipo de recipiente de vidro

As caracteristicas dos adultos de $S$. frugiperda originários das diferentes condições não foram afetadas (Tabela 14), quer seja, período de pré-oviposição, oviposição, número total de ovos por fêmea bem como o número de ovos por postura e o número de posturas, e longevidade (Tabela 14, Figuras 13 e 14). O número de ovos por massa (postura) foi de 187,43; 154,62 e 174,18 ovos em tubo de vidro, copo plástico União $\circledast$ e bandeja de criação Bio-RT-32®, respectivamente. 


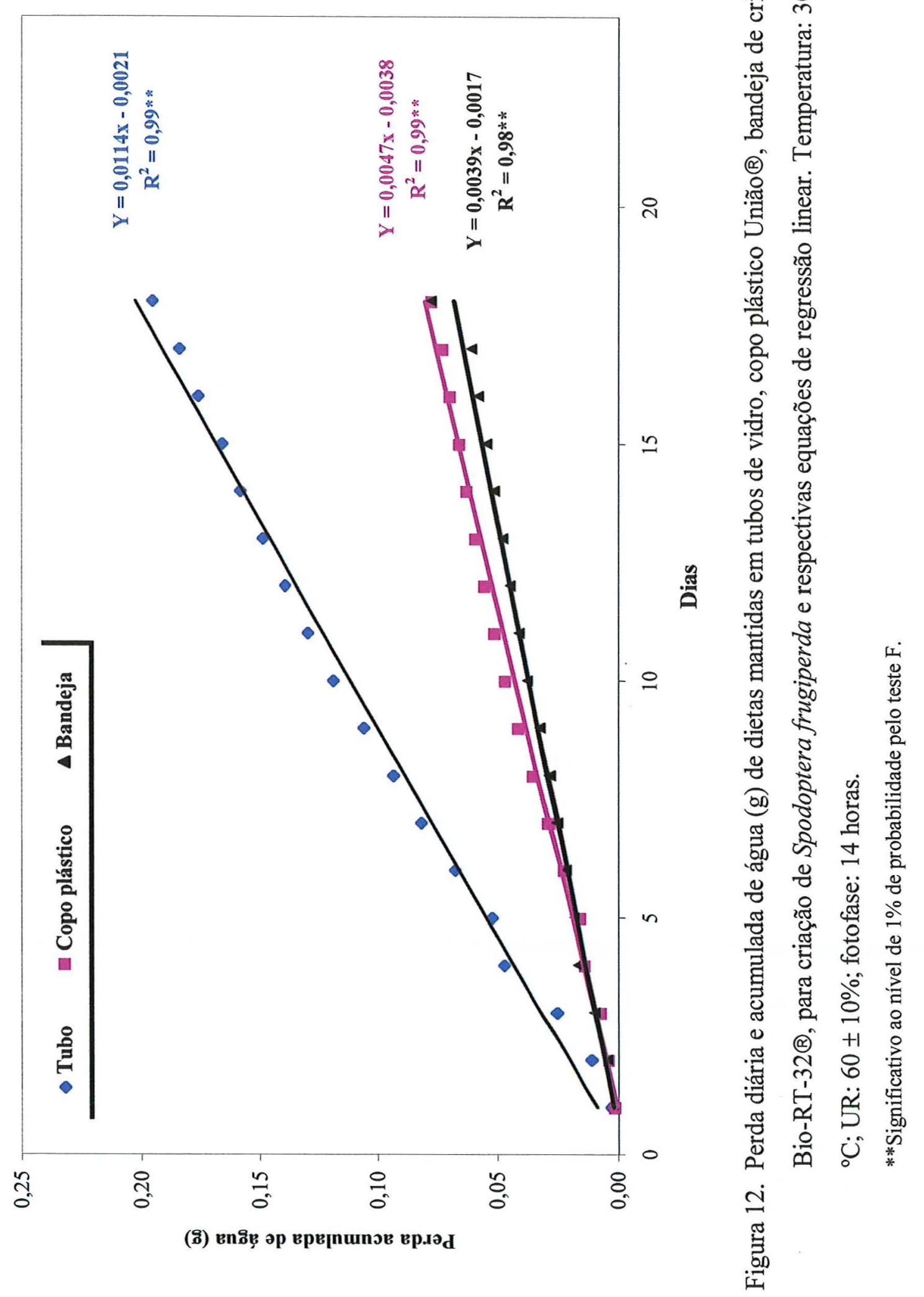




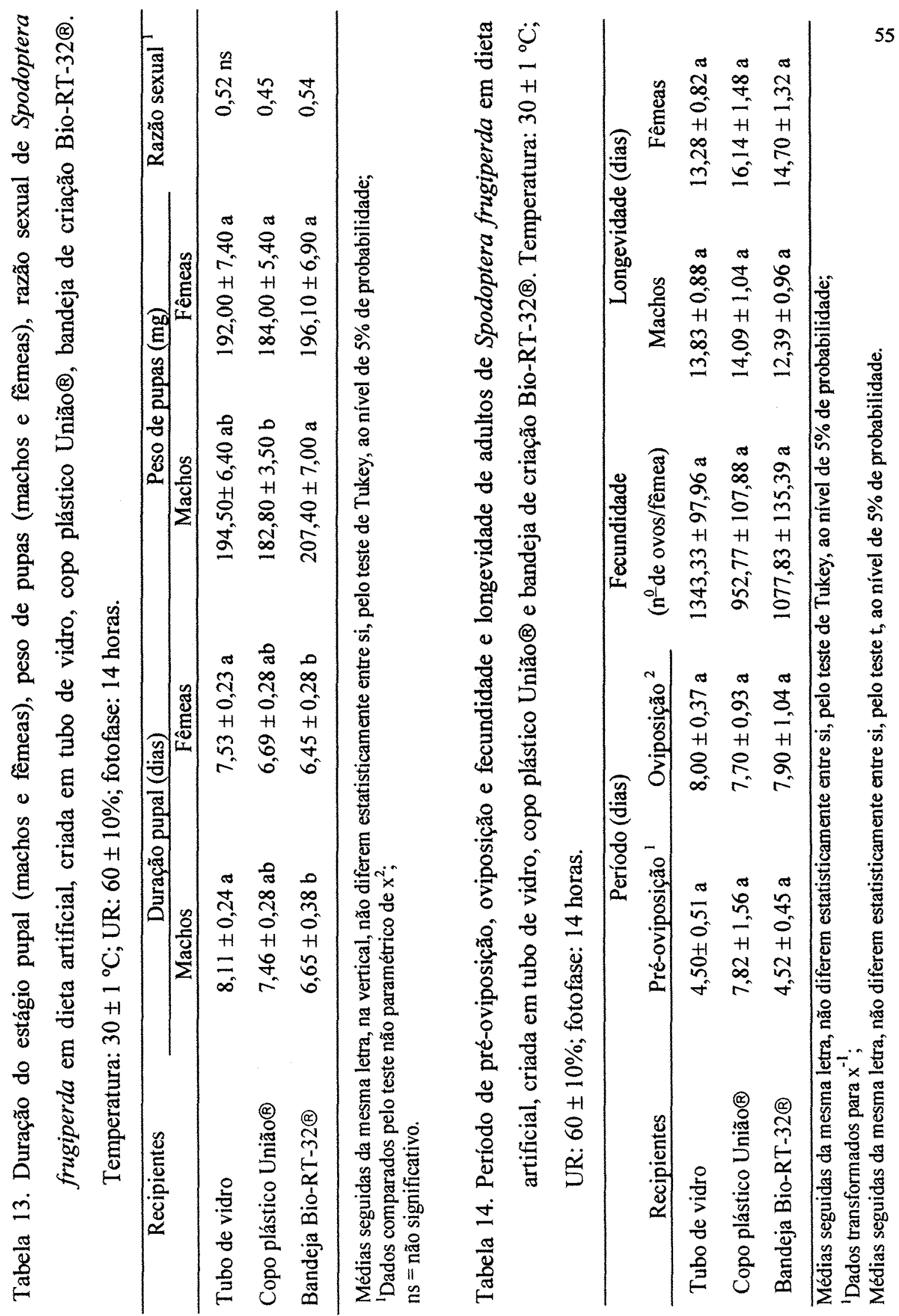




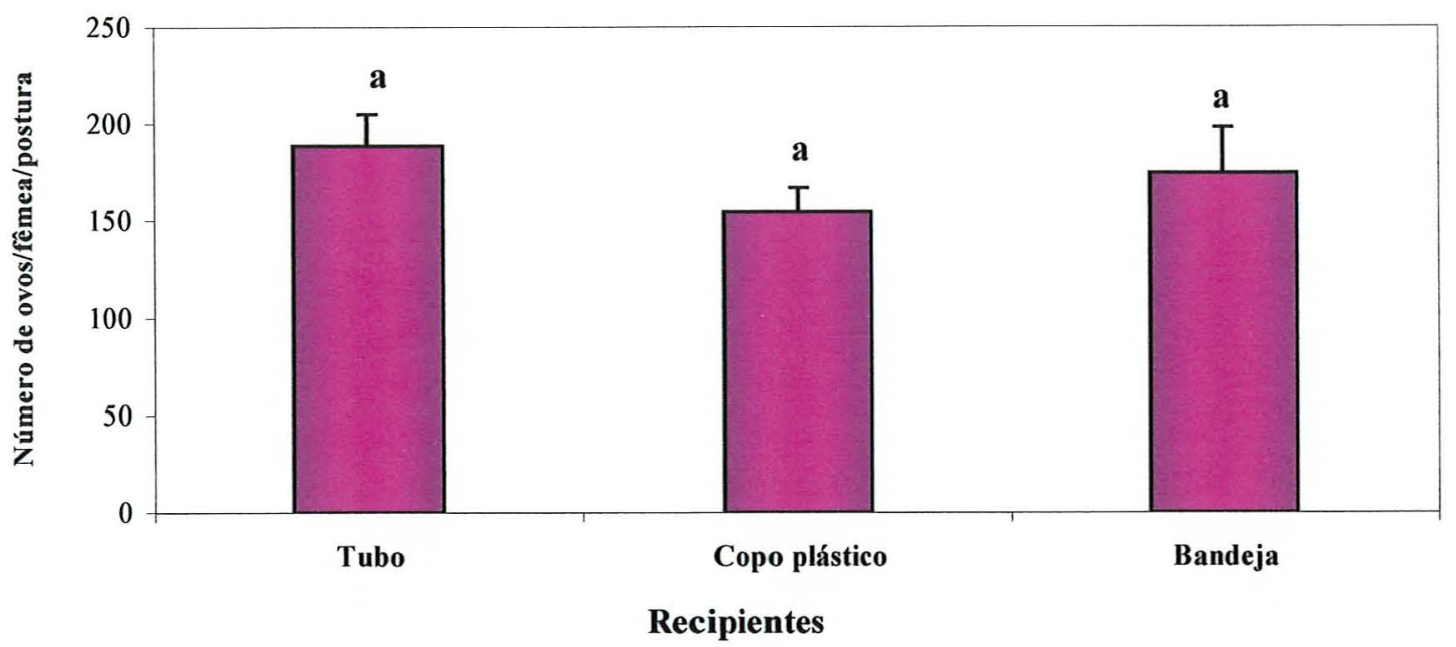

Figura 13. Número de ovos por postura de Spodoptera frugiperda, cujas lagartas foram criadas em tubos de vidro, copo plástico União ${ }^{\circledR}$ e bandeja de criação Bio-RT-32®. Temperatura: $30 \pm 1{ }^{\circ} \mathrm{C}$; UR: $60 \pm 10 \%$; fotofase: 14 horas.

Médias seguidas da mesma letra, não diferem estatisticamente entre si, pelo teste t. ao nível de $5 \%$ de probabilidade.

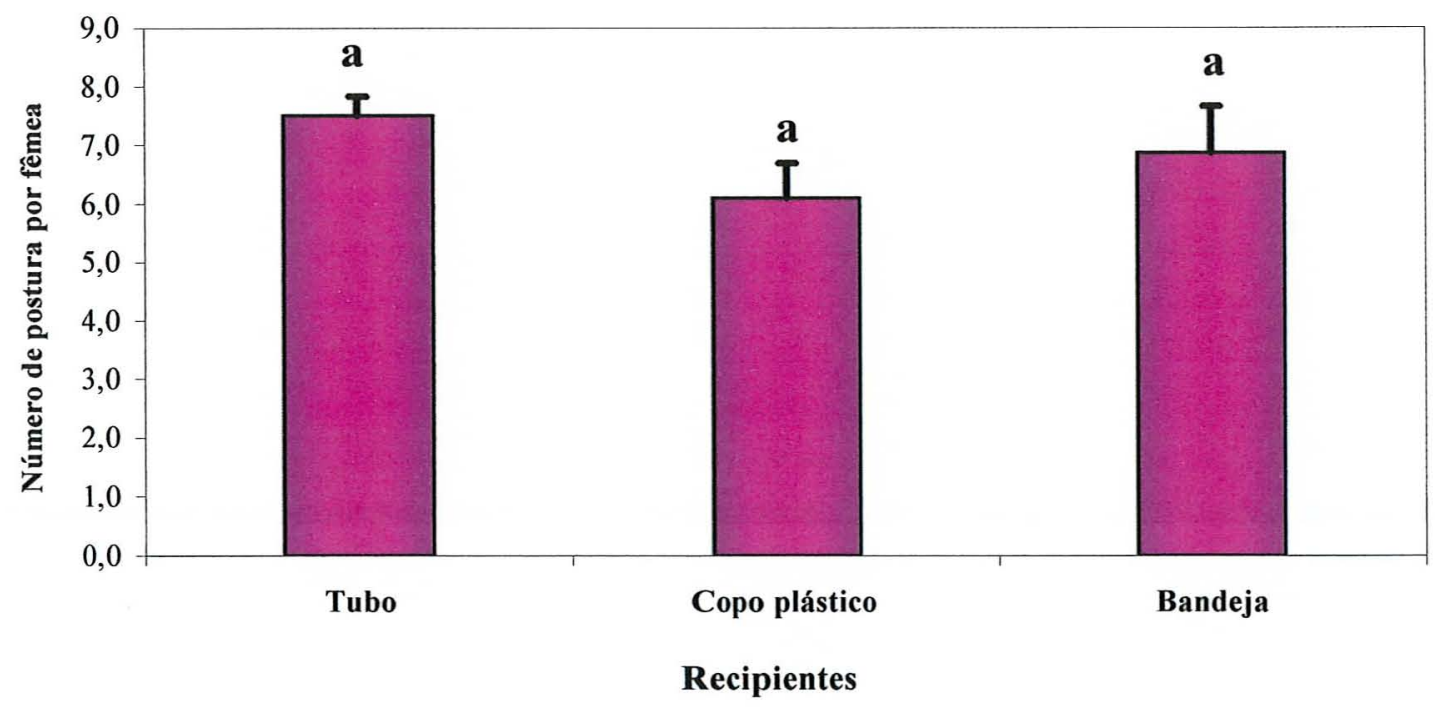

Figura 14. Número de postura por fềmea de Spodoptera frugiperda, cujas lagartas foram criada em tubo de vidro, copo plástico União ${ }^{\circledR}$ e bandeja de criação Bio-RT-32®. Temperatura: $30 \pm 1{ }^{\circ} \mathrm{C}$; UR: $60 \pm 10 \%$; fotofase: 14 horas.

Médias seguidas da mesma letra, não diferem estatisticamente entre si, pelo teste de Tukey, ao nível de $5 \%$ de probabilidade. 
Houve uma tendência numérica, embora sem diferir estatisticamente, dos insetos provenientes dos tubos de vidro, colocarem mais ovos $(1343,33)$, terem maior número de ovos por postura $(187,43)$, bem como realizarem maior número de posturas $(7,44)$ (Figuras 13 e 14). Além destas vantagens, não ocorreram, pelas suas características de dureza, possibilidade de perfuração do recipiente de vidro pelas lagartas de $S$. frugiperda, fato observado com $10 \%$ dos outros dois tipos de recipientes.

Torna-se difícil qualquer tipo de comparação com outros autores, desde que os objetivos dos trabalhos são diferentes. A despeito da variação de temperaturas, "strains", metodologias, recipientes de criação, alimentação de adultos, etc., os valores relacionados a adultos, obtidos na presente pesquisa, se enquadram naqueles relatados por Bowling (1967); Burton \& Perkins (1972); Combs \& Valerio (1980); Escalante (1974); Ferraz (1982); Nalim (1991); Ng et al.(1993) e Pencoe \& Martin (1982).

\subsection{Biologia comparada de $H$. virescens em três tipos de recipientes de criação}

A ação fagoestimulante, medida através da viabilidade de lagartas após sete dias da "inoculação", diferiu nos três recipientes utilizados para a criação de $H$. virescens. A maior viabilidade ocorreu em tubos de vidro de fundo chato, registrando-se maior mortalidade na bandeja Bio RT-32® (Tabela 15).

Tabela 15. Viabilidade, no $7^{0}$ dia de Heliothis virescens em dieta artificial, criadas em tubo de vidro, copo plástico União ${ }^{\circledR}$, bandeja de criação Bio-RT-32®. Temperatura: $25 \pm 1{ }^{\circ} \mathrm{C}$; UR: $60 \pm 10 \%$; fotofase: 14 horas.

\begin{tabular}{ll}
\hline \multicolumn{1}{c}{ Recipientes } & Viabilidade (\%) no $7^{\mathbf{0}}$ dia \\
\hline Tubo de vidro & $77,67 \pm 2,44 \mathrm{a}$ \\
Copo plástico União® & $74,60 \pm 1,55 \mathrm{ab}$ \\
Bandeja Bio-RT-32@ & $68,60 \pm 2,95 \mathrm{~b}$ \\
\hline
\end{tabular}

Médias seguidas da mesma letra, não diferem estatisticamente entre si, pelo teste de Tukey, ao nível de $5 \%$ de probabilidade. 
A duração da fase larval de $H$. virescens foi menor nos tubos de vidro, aumentando bastante tal período quando criada na bandeja Bio RT-32® (Tabela 16). Os resultados observados em bandeja são semelhantes aos obtidos por Souza (1981) à $25^{\circ} \mathrm{C}$ em tubo de vidro, e próximos aos dos registrados por Moreti \& Parra (1983) à $24^{\circ} \mathrm{C}$ em e em dieta à base de germe-de-trigo, em tubo de vidro na $1^{\underline{a}}$ geração de laboratório. Por outro lado, comparando os resultados obtidos por outros autores: (Guerra \& Bhuiya, 1977 que utilizaram copo plástico; Montewka et al., 1976 e Shorey \& Hale, 1965 que utilizaram copo de papel), que estudaram a biologia em dieta artificial, em diferentes condições térmicas, os resultados do presente trabalho foram superiores, fato explicável, devido à não separação da fase de pré-pupa. Por outro lado, houve um encurtamento acentuado da fase pupal neste último tipo de recipiente (Tabela 16). Davis et al. (1990), utilizando uma bandeja de criação semelhante à da presente pesquisa e copos plásticos transparentes de $30 \mathrm{ml}$, em dieta à base de nutriente de soja e germe-de-trigo, verificaram que a duração pupal foi 13 dias tanto para copo plástico como para a bandeja à $26,7{ }^{\circ} \mathrm{C}$. Estes valores foram menores do que os obtidos em copo plástico União ${ }^{\circledR}$ (volume de $40 \mathrm{ml}$ ) e da bandeja de criação na presente pesquisa. Por outro lado, a duração da fase pupal (machos e fềmeas) observada na bandeja de criação, encontra-se na faixa da duração relatada por Souza (1981) à $25^{\circ} \mathrm{C}$. A despeito deste encurtamento da fase pupal, o ciclo total foi menor quando o inseto foi criado nos tubos de vidro, embora sem diferir do valor obtido quando foi criado no copo plástico União® (Tabela 16). O valor obtido na presente pesquisa foi inferior ao relatado por Souza (1981), ou seja, 42,24 dias, diferença que pode estar ligada à composição da dieta artificial utilizada.

Ocorreu elevada contaminação (37\%) por patógenos (fungos não identificados) nos tubos de vidro, especialmente entre $013^{\underline{0}}$ e $17^{\underline{0}}$ dias de desenvolvimento larval, sendo que os patógenos se concentravam no algodão e nas 


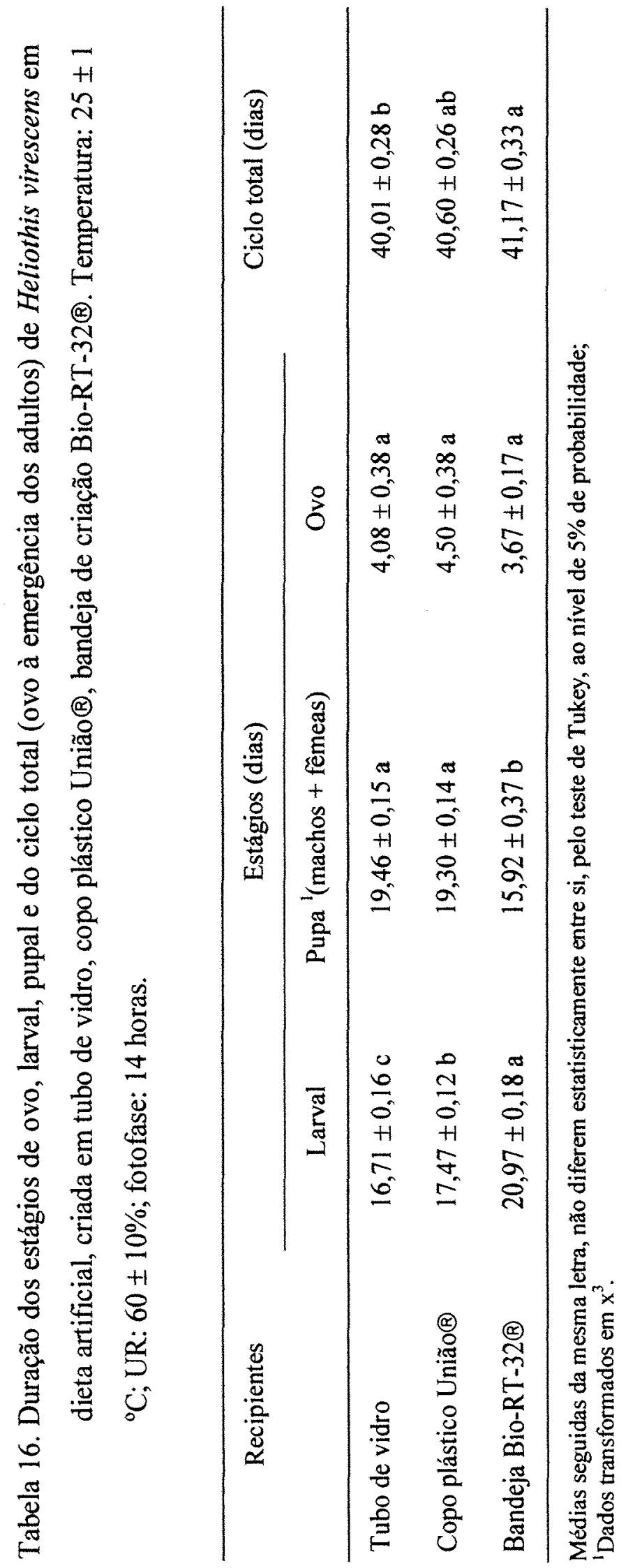


fezes (Tabela 17). Também nas bandejas, houve 19\% de recipientes contaminados, sendo que, nos copos plásticos, este percentual foi de somente 1\%. Esta contaminação reduziu a viabilidade larval nos tubos e na bandeja, embora tal viabilidade tenha sido semelhante nos três tipos de recipientes (Tabela 18). A viabilidade, baixa em todos os tratamentos, devido ao canibalismo no final do desenvolvimento larval, foi maior no copo plástico União® (Tabela 18 e Figura 15). Os resultados de viabilidade larval foram inferiores aos referidos por Souza (1981) na mesma condição térmica e também por Moreti \& Parra (1983) na $1^{\text {a }}$ geração da praga, embora, estes autores tenham individualizado as lagartas, diferente da presente pesquisa na qual trabalhou-se com um número diferente de lagartas para cada tipo de recipiente.

Tabela 17. Porcentagem de recipientes em que ocorreu contaminação e perfuração por Heliothis virescens criada, em dieta artificial, em tubo de vidro, copo plástico União $\circledast$ e bandeja de criação Bio-RT-32®. Temperatura: $25 \pm 1{ }^{\circ} \mathrm{C}$; UR: 60 $\pm 10 \%$; fotofase: 14 horas.

\begin{tabular}{lrr}
\hline \multicolumn{1}{c}{ Recipientes } & \multicolumn{2}{c}{ Porcentagem (\%) } \\
\cline { 2 - 3 } & \multicolumn{1}{c}{ Contaminação } & \multicolumn{1}{c}{ Perfuração } \\
\hline Tubo de vidro & $37,00 \pm 8,95 \mathrm{a}$ & $0,00 \pm 0,00 \mathrm{~b}$ \\
Copo plástico União® & $1,00 \pm 1,00 \mathrm{~b}$ & $3,00 \pm 1,53 \mathrm{~b}$ \\
Bandeja Bio-RT-32® & $19,00 \pm 3,48 \mathrm{a}$ & $41,00 \pm 6,40 \mathrm{a}$ \\
\hline
\end{tabular}

Médias seguidas da mesma letra, não diferem estatisticamente entre si, pelo teste $t$, ao nível de $5 \%$ de probabilidade. 


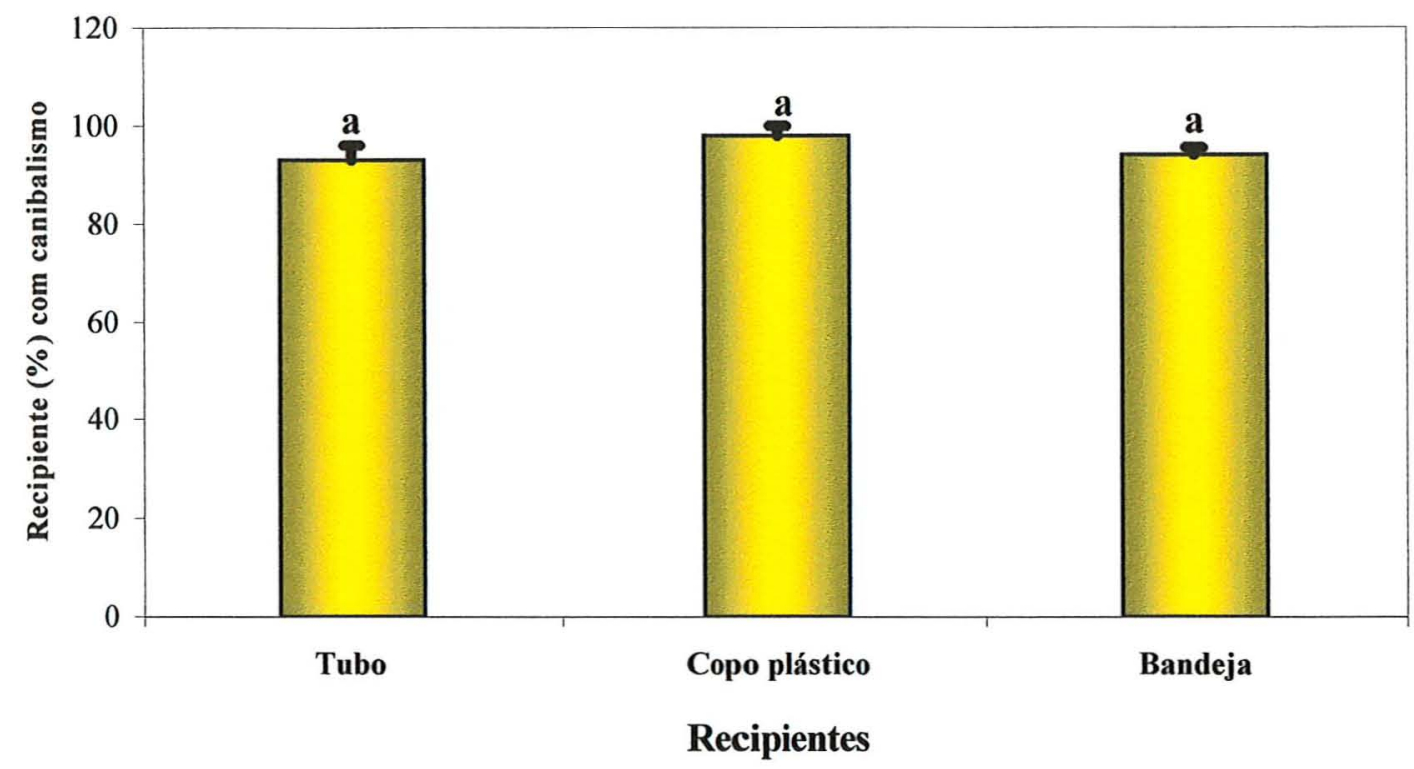

Figura 15. Porcentagem de recipientes em que ocorreu canibalismo, na criação de Heliothis virescens, em dieta artificial em três tipos de recipientes. Temperatura: $25 \pm 1{ }^{\circ} \mathrm{C}$; UR: $60 \pm 10 \%$; fotofase: 14 horas.

Médias seguidas da mesma letra, não diferem estatisticamente entre si, pelo teste de Tukey, ao nível de $5 \%$ de probabilidade.

A duração e viabilidade do período embrionário da geração seguinte não foram afetados pelo recipiente de criação utilizado (Tabelas 16 e 18). O resultado constatado em tubo de vidro, quanto à duração do período de incubação, foi semelhante ao de Souza (1981) com o mesmo recipiente e condição térmica, enquanto que a viabilidade dos ovos foi superior ao registrado por este autor e inferior ao obtido por Moreti \& Parra (1983).

Uma das vantagens do tubo de vidro em relação aos demais recipientes, é que o inseto não consegue perfurá-lo durante o desenvolvimento, fato este que inviabilizou a utilização da bandeja, pois $41 \%$ das repetições deste tipo de recipiente foram perfuradas pela lagarta-da-maçã (Tabela 17). Embora em menor número, também o copo plástico apresentou esta desvantagem, com 3\% dos recipientes sendo perfurados (Tabela 17). Este resultado confirma as observações de Raulston \& Lingren (1969), que relataram que a lagarta de $H$. virescens perfura ou corta tampa de copos plásticos. 


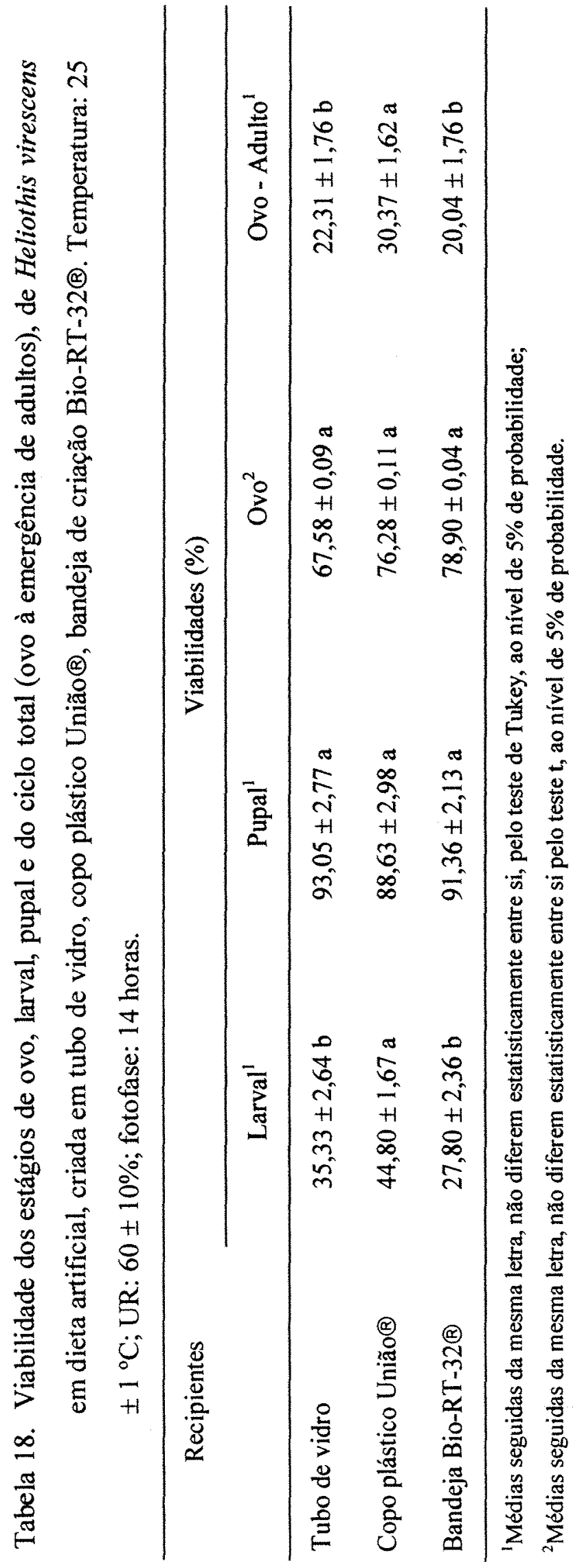


Embora a duração da fase pupal (para machos e fềmeas), tenha sido menor nas bandejas (Tabela 19), o peso de pupas para ambos os sexos foi menor neste recipiente, o mesmo acontecendo quando os insetos foram criados no copo plástico. Os maiores valores de peso de pupas foram obtidos no tubo de vidro (Tabela 19). Os valores encontrados de peso de pupas de machos e fềmeas em tubo de vidro foram maiores do que os referidos por Souza (1981) e Moreti \& Parra (1983). Davis et al. (1990), avaliaram o peso de pupas (não separadas por sexo) em bandeja semelhante em comparação às pupas obtidas em copos plásticos de $30 \mathrm{ml}$. Concluíram que o peso foi maior em bandeja do que em copo plástico. O tipo de recipiente não afetou a razão sexual, longevidade de machos e fêmeas e nem características dos adultos, incluindo fecundidade (Tabelas 19 e 20 e Figura 16), embora o número de ovos por postura $(52,26 ; 40,39$ e 64,42$)$ tenha sido menor no copo plástico (Figura 17). A razão sexual observada em insetos criados no tubo de vidro está próxima ao valor referido por Souza (1981), que foi de 0,54 à $25^{\circ} \mathrm{C}$. Já, os dados de longevidade referidos por Moreti \& Parra (1983) e Souza (1981) à $25^{\circ} \mathrm{C}$ foram inferiores aos constatados na presente pesquisa, apesar destes autores terem utilizado o mesmo alimento (mel 10\%) para adultos. O resultado obtido em tubo de vidro de fundo chato do período de préoviposição foi semelhante ao obtido por Souza (1981) enquanto que o número de ovos por fềmea $(672,80)$ foi maior.

A porcentagem de deformação de pupas e adultos foi baixa, não podendo ser considerada um aspecto limitante para exclusão (ou seleção) de um dos recipientes (Tabela 21). O valor verificado de deformação de pupas e adultos em tubo de vidro foi bem menor ao relatado por Moreti \& Parra (1983) com este mesmo recipiente.

Embora uma das características importantes para seleção de um recipiente, seja a perda de água, tal perda, maior no tubo de vidro, não foi suficiente para prejudicar o desenvolvimento de $H$. virescens (Tabela 22 e Figura 18). 


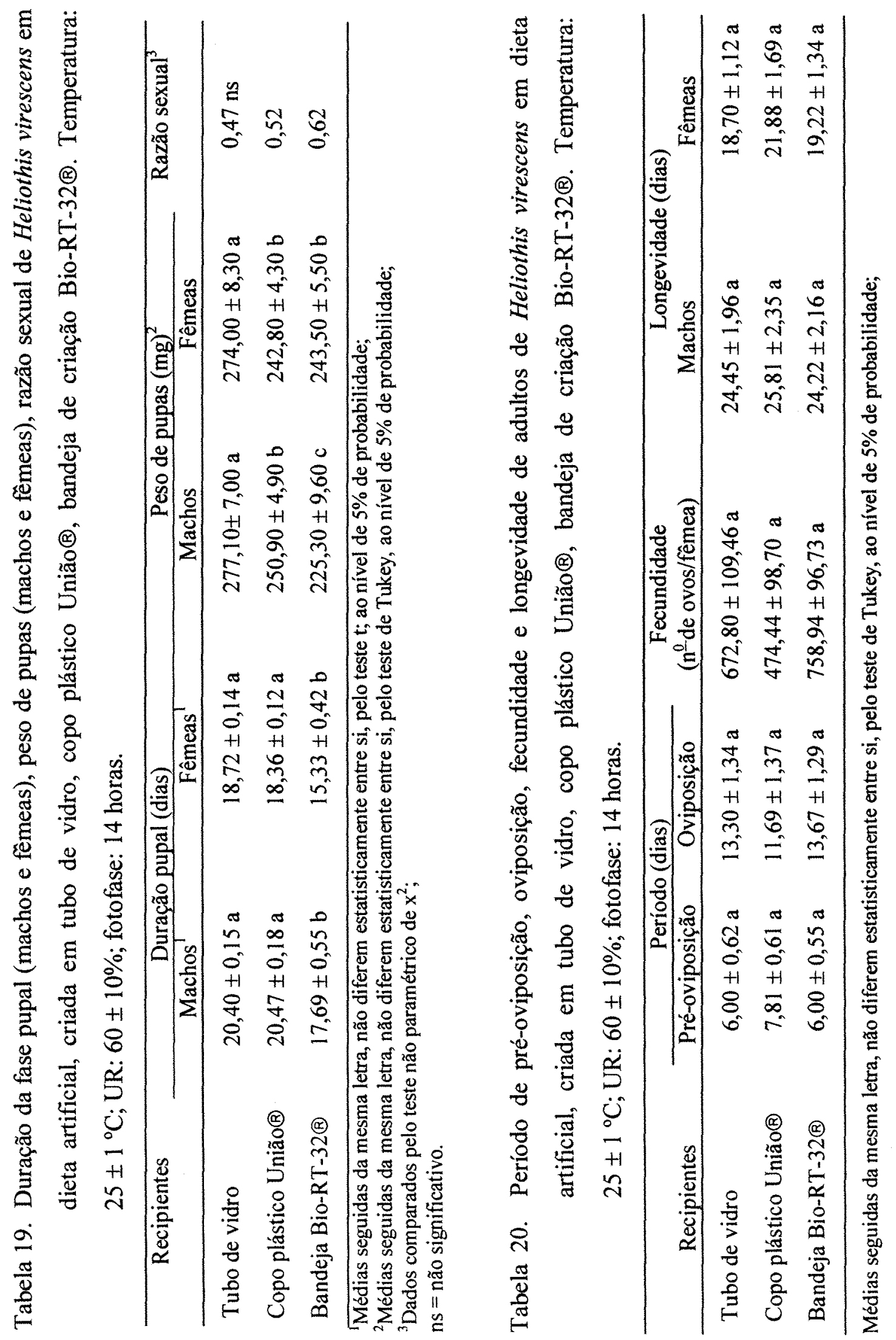




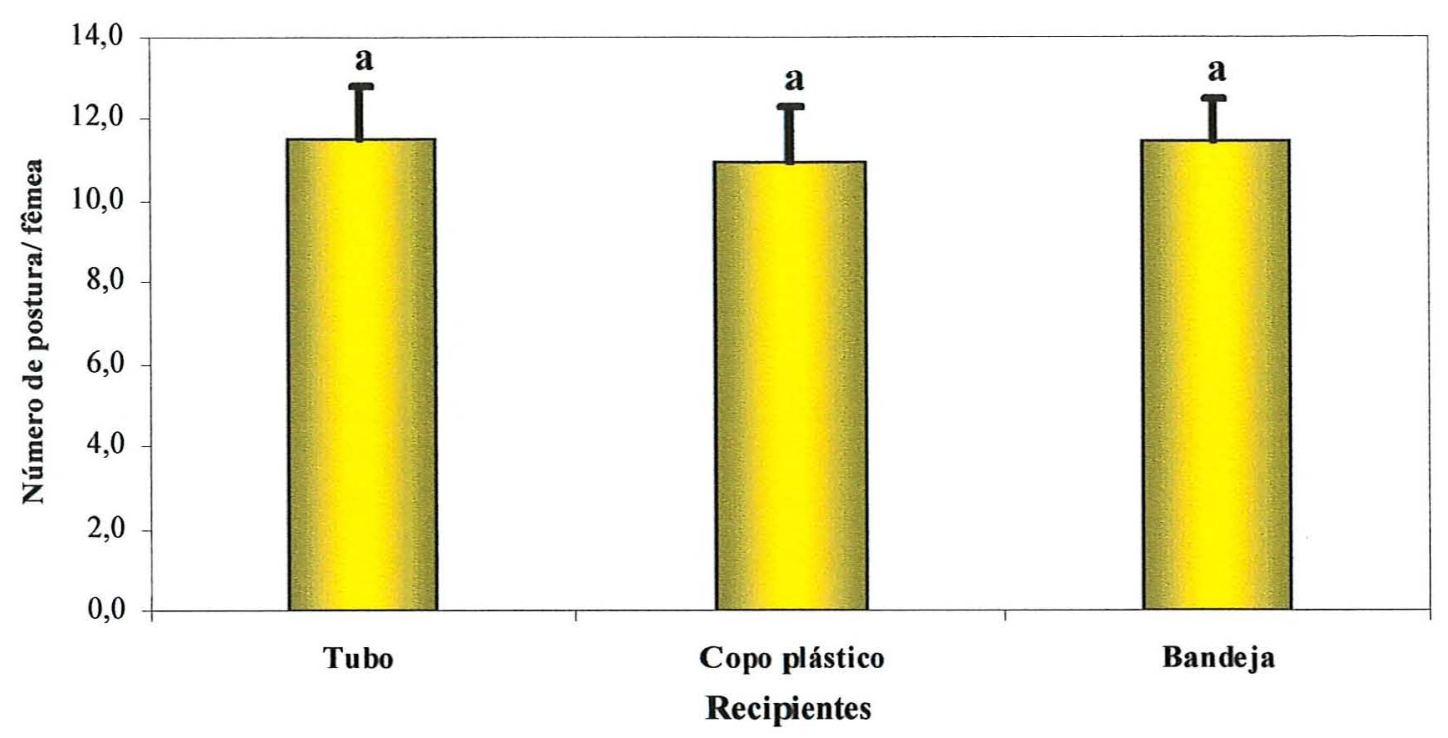

Figura 16. Número de posturas por fêmea de Heliothis virescens, criada em dieta artificial em tubo de vidro, copo plástico União®e bandeja de criação Bio-RT$32 \circledR$. Temperatura: $25 \pm 1{ }^{\circ} \mathrm{C}$; UR: $60 \pm 10 \%$; fotofase: 14 horas.

Médias seguidas da mesma letra, não diferem estatisticamente entre si, pelo teste de Tukey, ao nível de $5 \%$ de probabilidade.

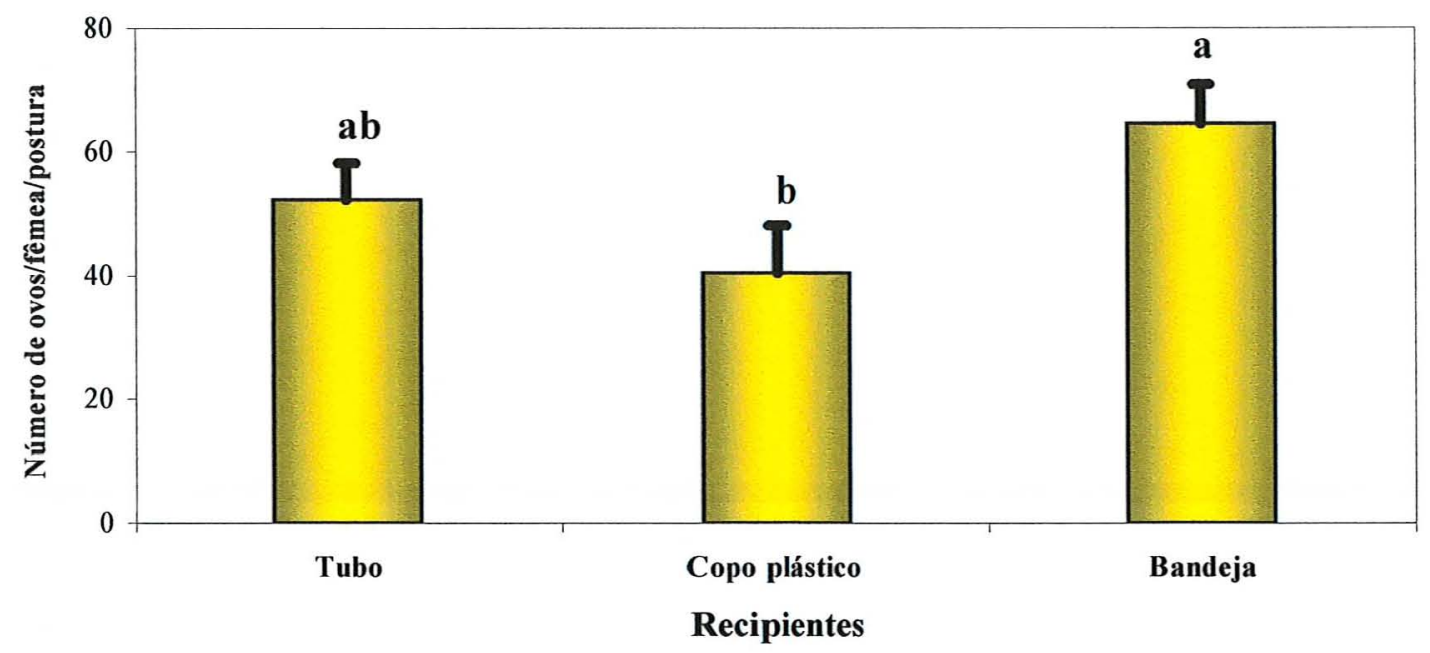

Figura 17. Número de ovos por postura de Heliothis virescens, criada em tubo de vidro, copo plástico União $\circledast$ e bandeja de criação Bio-RT-32®. Temperatura: $25 \pm 1$ ${ }^{\circ} \mathrm{C}$; UR: $60 \pm 10 \%$; fotofase: 14 horas.

Médias seguidas da mesma letra, não diferem estatisticamente entre si, pelo teste de Tukey, ao nível de $5 \%$ de probabilidade. 
Tabela 21. Porcentagem de recipientes que ocorreu deformação de pupa e adultos de Heliothis virescens em dieta artificial, criada em tubo de vidro, copo plástico União ${ }^{\circledR}$ e bandeja de criação Bio-RT-32®. Temperatura: $25 \pm 1{ }^{\circ} \mathrm{C}$; UR: 60 $\pm 10 \%$; fotofase: 14 horas.

\begin{tabular}{lcc}
\hline \multicolumn{1}{c}{ Recipientes } & \multicolumn{2}{c}{ Deformação (\%) } \\
\cline { 2 - 3 } & Pupas & Adultos $^{2}$ \\
\hline Tubo de vidro & $2,71 \pm 1,41 \mathrm{a}$ & $1,74 \pm 1,16 \mathrm{ab}$ \\
Copo plástico União@ & $4,00 \pm 0,99 \mathrm{a}$ & $2,77 \pm 0,78 \mathrm{a}$ \\
Bandeja Bio - RT -32 @ & $3,42 \pm 1,40 \mathrm{a}$ & $0,00 \pm 0,00 \mathrm{~b}$ \\
\hline
\end{tabular}

${ }^{1}$ Médias seguidas da mesma letra, não diferem estatisticamente entre si, pelo teste Tukey, ao nível de 5\% de probabilidade;

${ }^{2}$ Médias seguidas da mesma letra, não diferem estatisticamente entre si, pelo teste $t$, ao nível de $5 \%$ de probabilidade.

Tabela 22. Perda acumulada de água (g) de dieta artificial, em tubo de vidro, copo plástico União $\circledast$, bandeja de criação Bio-RT-32®. Análise realizada no período correspondente à $50 \%$ ( $\left.9^{\circ} \mathrm{dia}\right)$ do desenvolvimento larval e no final deste período ( $18^{\circ}$ dia) de Heliothis virescens Temperatura: $25 \pm 1{ }^{\circ} \mathrm{C}$; UR: $60 \pm 10 \%$; fotofase: 14 horas.

\begin{tabular}{lcc}
\hline \multicolumn{1}{c}{ Recipientes } & \multicolumn{2}{c}{ Perda d'água $(\mathrm{g})$} \\
\cline { 2 - 3 } & $\begin{array}{c}9 \text { dias } \\
(50 \% \text { do desenvolvimento larval })\end{array}$ & $\begin{array}{c}18 \text { dias (Final do } \\
\text { desenvolvimento larval })\end{array}$ \\
\hline Tubo de vidro & $0,0774 \pm 0,0009 \mathrm{a}$ & $0,1507 \pm 0,0018 \mathrm{a}$ \\
Copo plástico União® & $0,0433 \pm 0,0022 \mathrm{c}$ & $0,0827 \pm 0,0044 \mathrm{c}$ \\
Bandeja Bio-RT-32® & $0,0599 \pm 0,0038 \mathrm{~b}$ & $0,1123 \pm 0,0059 \mathrm{~b}$ \\
\hline
\end{tabular}

Médias seguidas da mesma letra, não diferem estatisticamente entre si, pelo teste $t$, ao nível de $5 \%$ de probabilidade. 


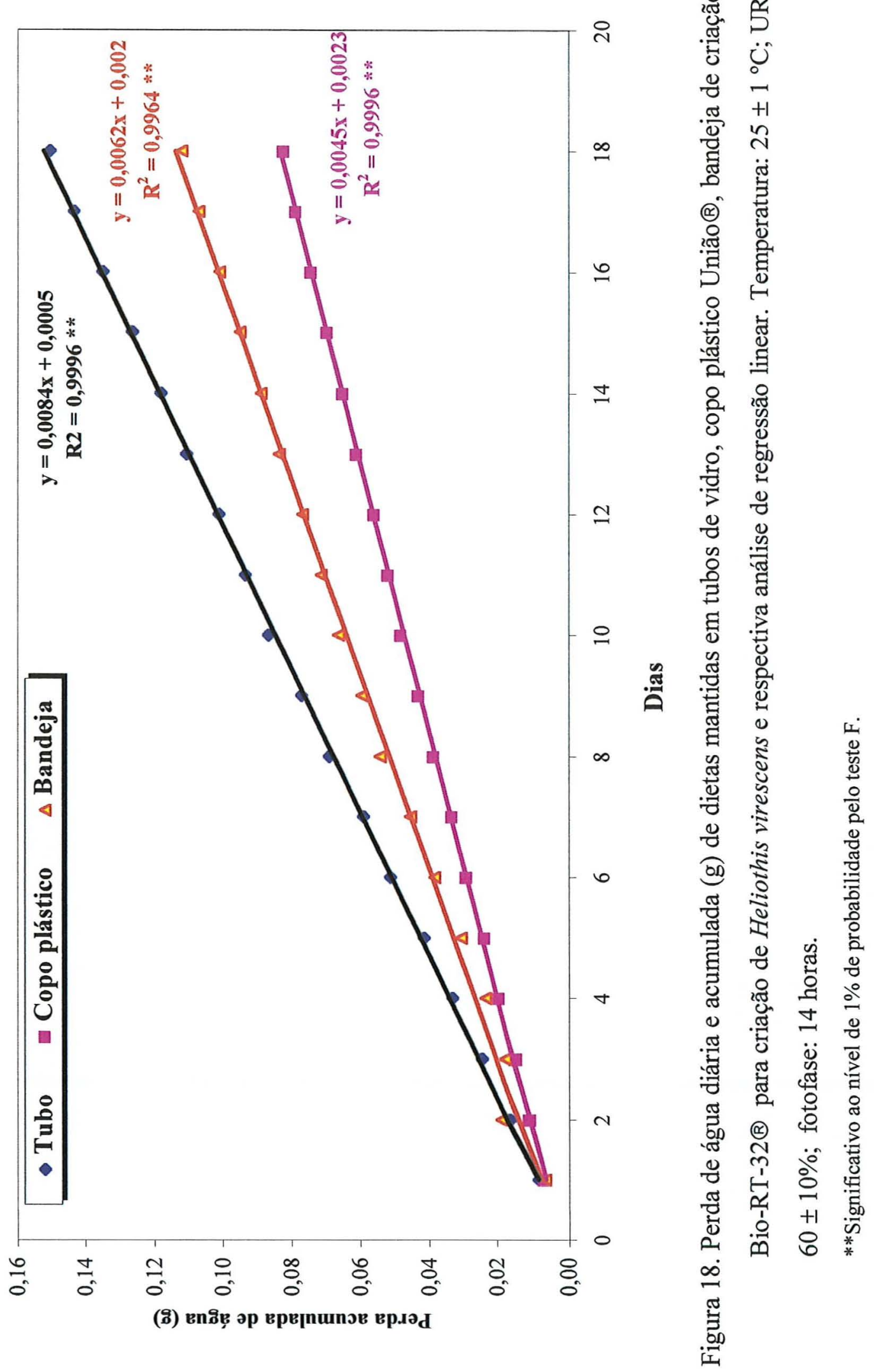




\subsection{Biologia comparada de Diatraea saccharalis em cinco tipos de recipientes de criação}

O "pegamento", ou viabilidade larval após sete dias de "inoculação" foi próximo a $100 \%$ para todos os tratamentos, não diferindo estatisticamente nos cinco recipientes utilizados para a criação de $D$. saccharalis (Tabela 23).

Tabela 23. Viabilidade no $7^{0}$ dia de Diatraea saccharalis em dieta artificial, criada em tubo de vidro, copo plástico União $\circledast$, bandeja de criação Bio-RT-32®, copo plástico translúcido da Arteplast ${ }^{\circledR}$ e caixa acrílica. Temperatura: $25 \pm 1{ }^{\circ} \mathrm{C}$; UR: $60 \pm 10 \%$; fotofase: 14 horas.

\begin{tabular}{ll}
\hline \multicolumn{1}{c}{ Recipientes } & Viabilidade (\%) ( ${ }^{\mathbf{0}}$ dia) \\
\hline Tubo de vidro & $98,80 \pm 1,00$ a \\
Copo plástico União $@$ & $99,86 \pm 0,14$ a \\
Bandeja Bio - RT -32 $®$ & $99,00 \pm 0,45$ a \\
Copo plástico Arteplast $®$ & $99,05 \pm 0,46$ a \\
Caixa acrílica & $99,83 \pm 0,17$ a \\
\hline
\end{tabular}

Médias seguidas da mesma letra, não diferem estatisticamente entre si, pelo teste de Tukey, ao nível de $5 \%$ de probabilidade;

${ }^{1}$ Dados transformados para arcsen $\sqrt{x / 100}$.

À semelhança do que ocorrera com S. frugiperda e H. virescens, também para $D$. saccharalis, houve um encurtamento do período larval em tubos de vidro (embora sem diferir dos valores registrados em copos plásticos e caixa acrilica) (Tabela 24). Por outro lado, também de forma análoga ao que ocorrera para as duas espécies citadas, houve um alongamento da fase pupal no tubo de vidro (Tabela 24). O resultado obtido em tubo de vidro foi semelhante ao valor obtido por Mélo (1984), que estudou a biologia da broca-da-cana-de-açúcar em dieta à base de germe-de-trigo e também por Mihsfeldt (1985), em dieta à base de milho "Nutrimaiz", ambos utilizando o mesmo tubo 


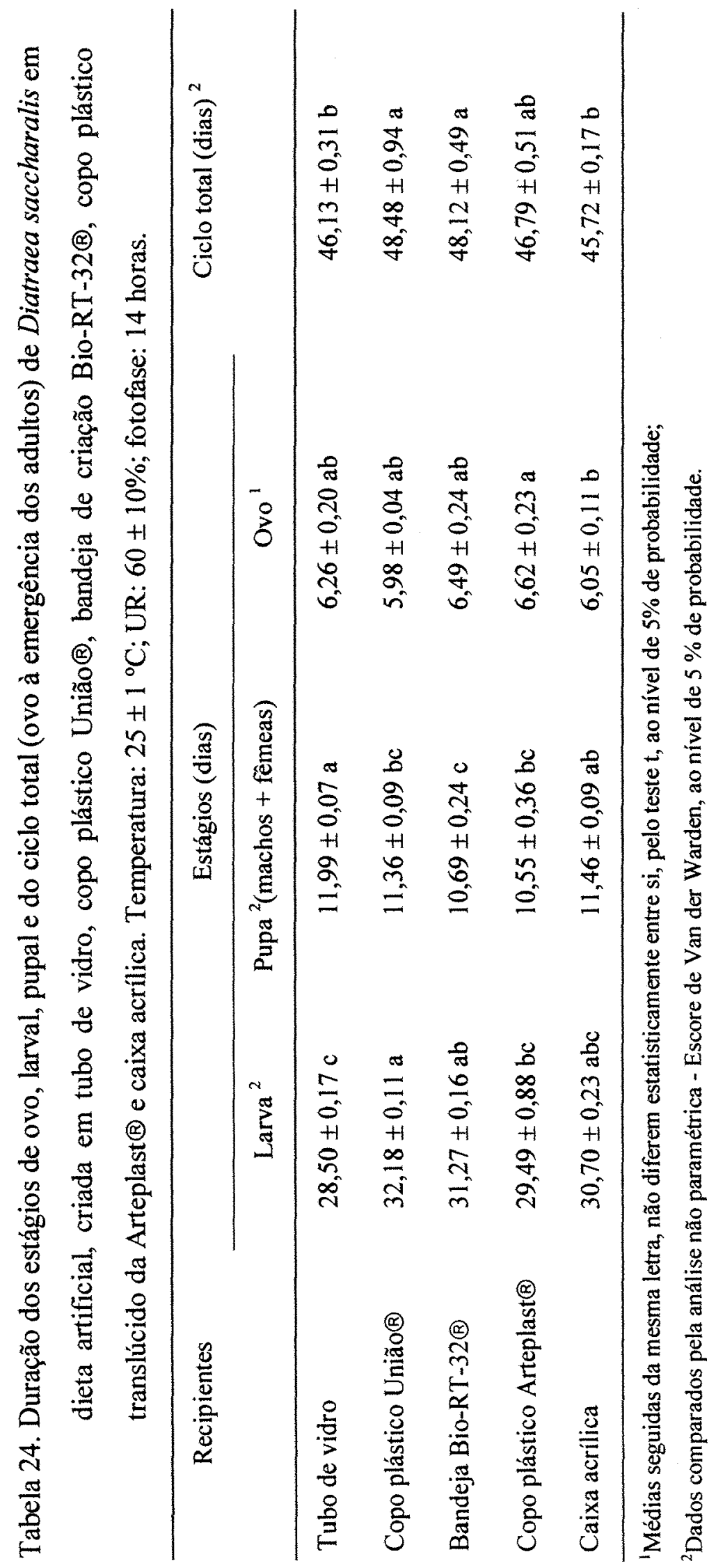




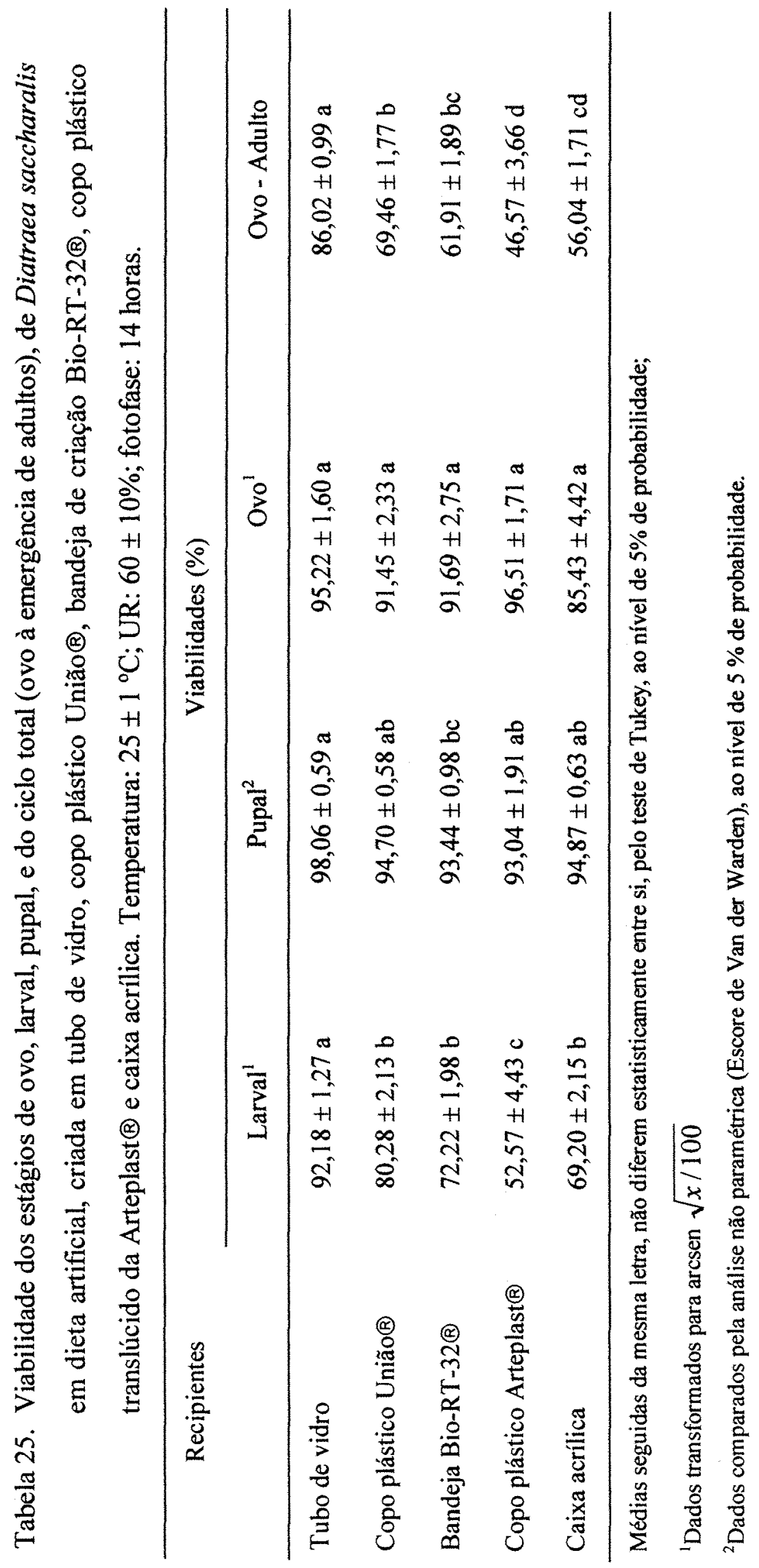


de vidro e mesma condição térmica. Embora o período embrionário de F1 tenha sido, numericamente, maior para insetos provenientes do copo plástico Arteplast $\circledast$, os valores nos cinco recipientes foram muito próximos (Tabela 24). O resultado verificado em copo plástico União@ (volume de $40 \mathrm{ml}$ ) foi semelhante ao valor constatado por King et al. (1975), que utilizaram copos plásticos de $30 \mathrm{ml}$, em dieta à base de soja e germe-detrigo, à $26^{\circ} \mathrm{C}$. Em termos gerais, o ciclo (ovo-adulto) foi menor nos tubos de vidro e nas caixas acrílicas, além do copo plástico Arteplast ${ }^{\circledR}$ (Tabela 24).

A viabilidade das diferentes fases de desenvolvimento foi elevada, se comparada com os valores registrados para $S$. frugiperda e $H$. virescens (4.3 e 4.4). Entretanto, apenas o tubo de vidro possibilitou viabilidade superior a $75 \%$, considerada adequada para criações em dietas artificiais em laboratório (Tabela 25). A viabilidade larval constatada em tubo de vidro está próxima ao valor verificado por Mihsfeldt (1985), em dieta à base de milho "Nutrimaiz" e também foi superior ao registrado por Mélo (1984), na mesma condição térmica. Da mesma forma, a viabilidade pupal observada em tubo de vidro foi maior à encontrada por Mélo (1984), na mesma temperatura. Já Mihsfeldt (1985), em dieta artificial à base de milho "Nutrimaiz", encontrou uma viabilidade de $94,38 \%$. O valor constatado para viabilidade dos ovos em tubo de vidro foi superior aos registrados por Mélo (1984) e por Mihsfeldt (1985). Além disso, o resultado observado em copo plástico União® está próximo daquele verificado também em copo plástico $(30 \mathrm{ml})$ por King et al. (1975).

A perda de água na dieta, maior em tubos de vidro, não foi suficiente para prejudicar o desenvolvimento de $D$. saccharalis (Tabela 26 e Figura 19).

Os dois sexos foram igualmente afetados nos cinco recipientes, pois a duração da fase pupal, de machos ou de fêmeas, (Tabela 27) seguiu a mesma tendência de análise conjunta (Tabela 24). Os valores verificados, em tubo de vidro, foram superiores aos resultados obtidos por Mélo (1984) e Mihsfeldt (1985).

Os pesos de pupas-fềmeas foram elevados em todos os recipientes, exceto no copo plástico Arteplast ${ }^{\circledR}$ (Tabela 27); em geral, os pesos de ambos os sexos foram superiores aos obtidos por Mihsfeldt (1985). Como consequiência, a postura de fềmeas 
Tabela 26. Perda acumulada de água (g) da dieta artificial, criada em tubo de vidro, copo plástico União $\circledast$, bandeja de criação Bio-RT- $32 \AA$, copo plástico translúcido da Arteplast $\circledast$ e caixa acrílica. Análise realizada no período correspondente à $50 \%\left(15^{\circ}\right.$ dia $)$ do desenvolvimento larval e no final ( $30^{\circ}$ dia), deste período de

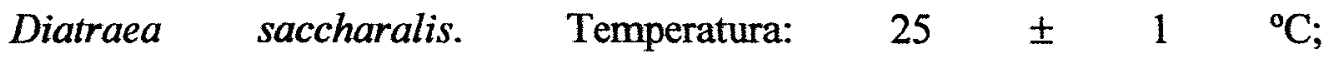
UR: $60 \pm 10 \%$; fotofase: 14 horas.

\begin{tabular}{|c|c|c|}
\hline \multirow[t]{2}{*}{ Recipientes } & \multicolumn{2}{|c|}{ Perda d'água (g) } \\
\hline & $\begin{array}{c}15 \text { dias } \\
\text { (50\% do desenvolvimento larval) }\end{array}$ & $\begin{array}{l}30 \text { dias } \\
\text { (Final do desenvolvimento larval) }\end{array}$ \\
\hline Tubo de vidro & $0,0941 \pm 0,0009 a$ & $0,1942 \pm 0,0020 a$ \\
\hline Copo plástico União® & $0,0385 \pm 0,0014 b c$ & $0,0795 \pm 0,0030 \mathrm{bc}$ \\
\hline Bandeja Bio - RT - $32 \AA$ & $0,0469 \pm 0,0023 b$ & $0,0979 \pm 0,0052 \mathrm{ab}$ \\
\hline Copo plástico Arteplast $\mathbb{B}$ & $0,0052 \pm 0,0007 \mathrm{c}$ & $0,0118 \pm 0,0012 \mathrm{c}$ \\
\hline Caixa acrílica & $0,0550 \pm 0,0047 \mathrm{ab}$ & $0,0977 \pm 0,0063 \mathrm{abc}$ \\
\hline
\end{tabular}

Médias seguidas da mesma letra, não diferem estatisticamente entre si, pela análise não paramétrica (Escore de Van der Warden), ao nível de $5 \%$ de probabilidade.

sobreviventes foi semelhante em todos os tratamentos (Tabela 28), bem como o número de posturas e o número de ovos por postura (Figuras 20 e 21), evidenciando que a redução do peso de fêmeas provenientes do copo plástico Arteplast ${ }^{\circledR}$ não foi suficiente para prejudicar a capacidade de postura do inseto.

Os demais parâmetros, quais sejam, razão sexual, longevidade (de machos e fềmeas), período de pré-oviposição e oviposição foram semelhantes quando as fases imaturas de $D$. saccharalis foram criadas nos diferentes recipientes (Tabelas $27 \mathrm{e}$ 28). O resultado observado em tubo de vidro para o período de pré-oviposição foi semelhante aos relatados por Mélo (1984), enquanto que o período de oviposição foi superior àqueles resultados. A longevidade de machos e fềmeas obtida nesta pesquisa foi superior ao referido por Mihsfeldt (1985), com um período de pré-oviposição semelhante. 


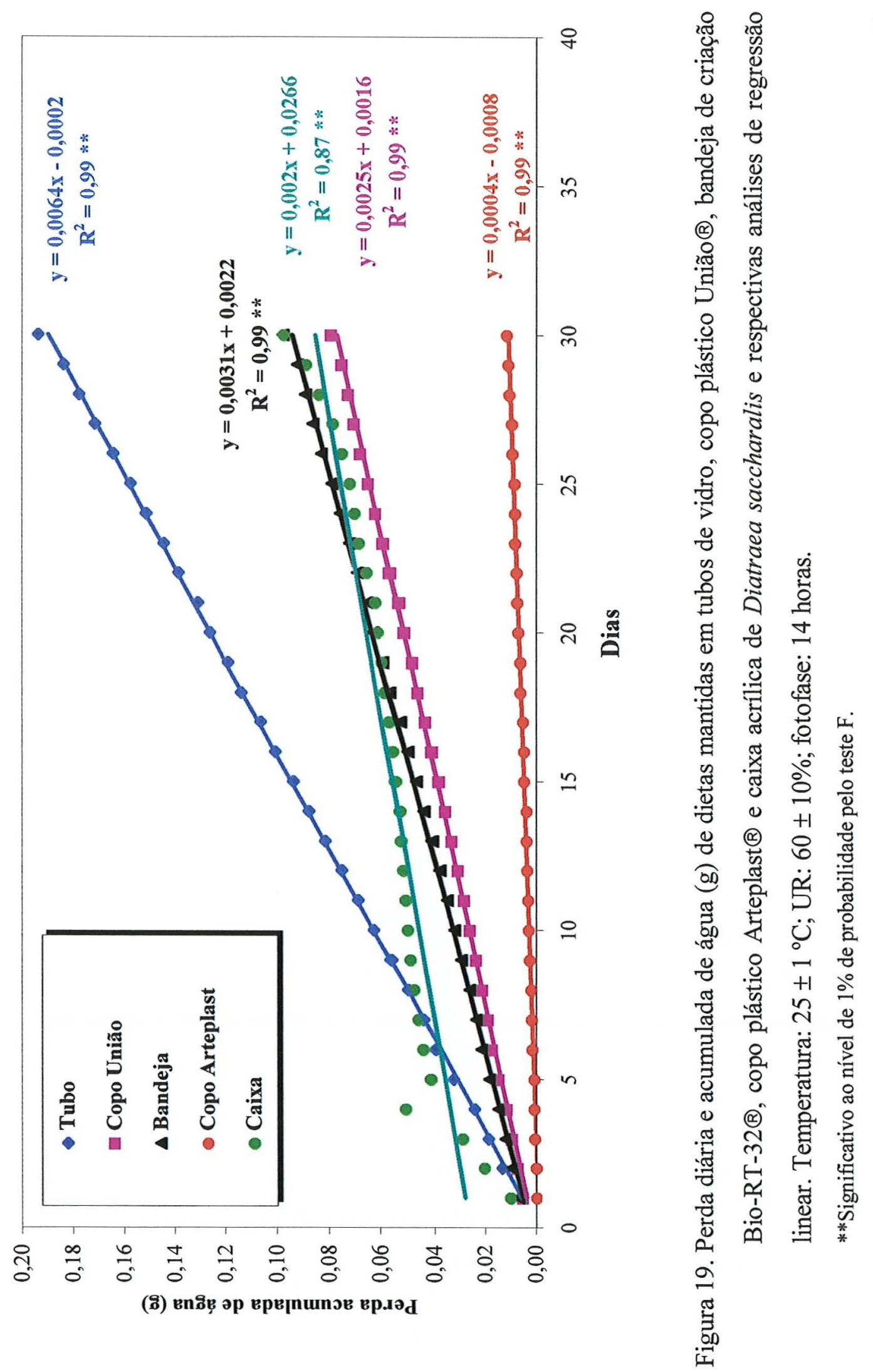









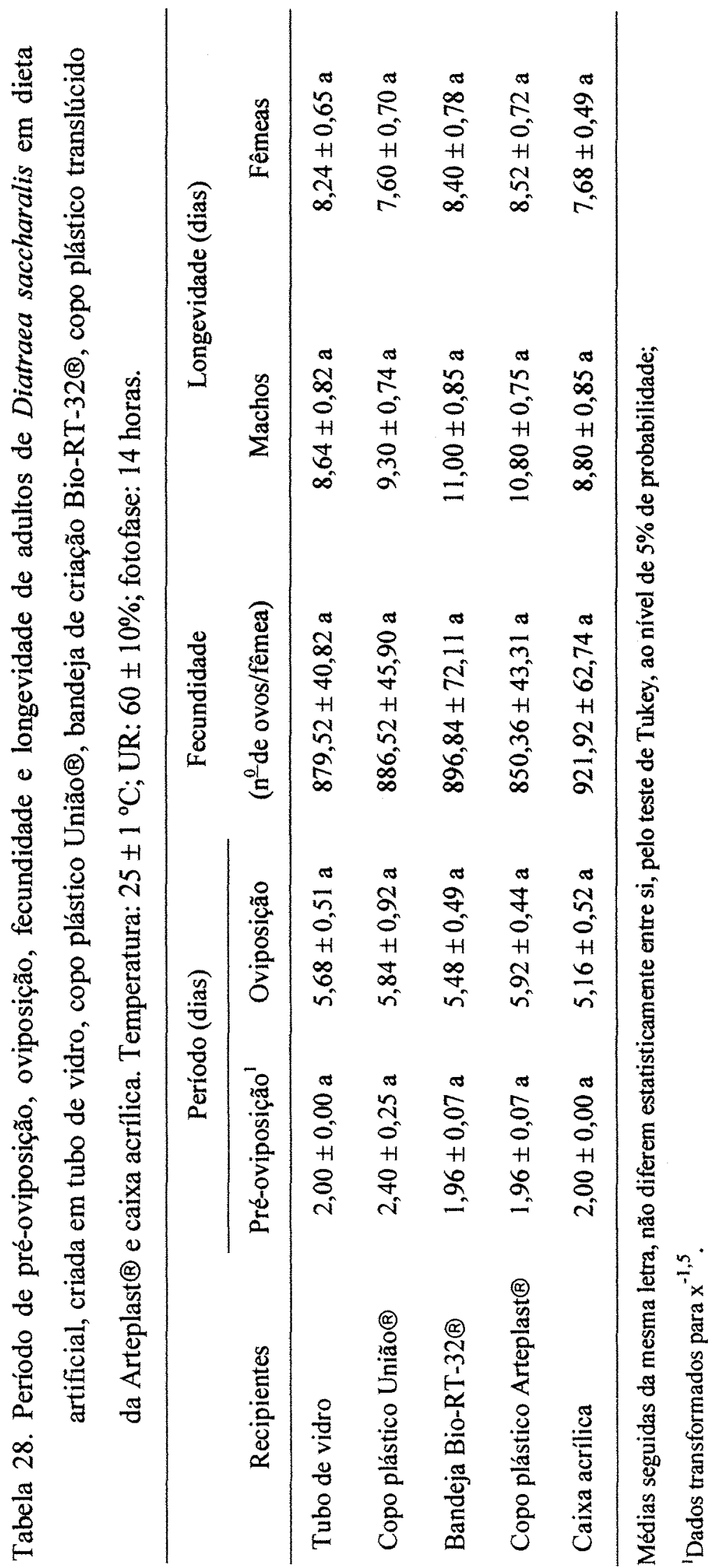




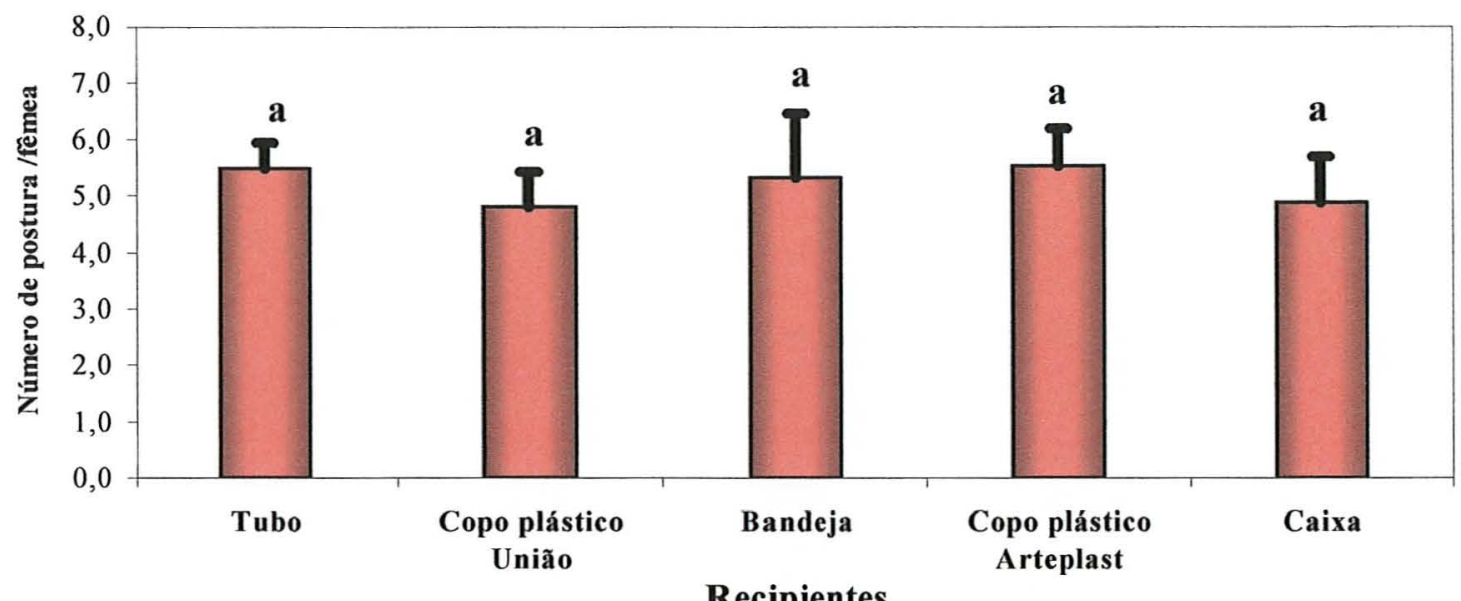

Figura 20. Número de posturas por fềmea de Diatraea saccharalis, criada em tubo de vidro, copo plástico União $\circledast$, bandeja de criação Bio-RT-32®, copo plástico Arteplast ${ }^{\circledR}$ e caixa acrílica. Temperatura: $25 \pm 1{ }^{\circ} \mathrm{C}$; UR; $60 \pm 10 \%$; fotofase: 14 horas.

Médias seguidas da mesma letra, não diferem estatisticamente entre si, pelo teste de Tukey, ao nível de $5 \%$ de probabilidade.

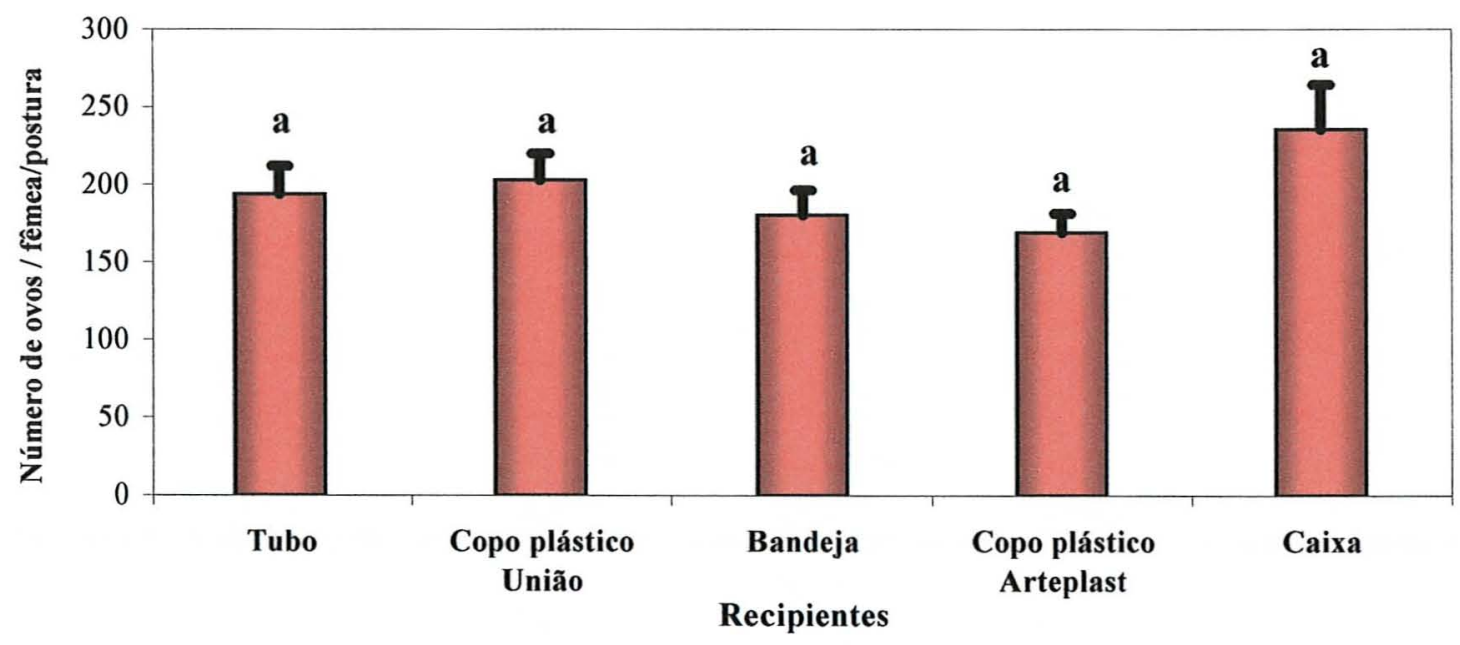

Figura 21. Número de ovos por postura de Diatraea saccharalis, criada em tubo de vidro, copo plástico União $\circledast$, bandeja de criação Bio-RT-32®, copo plástico Arteplast ${ }^{\circledR}$ e caixa acrílica. Temperatura: $25 \pm 1{ }^{\circ} \mathrm{C}$; UR: $60 \pm 10 \%$; fotofase: 14 horas.

Médias seguidas da mesma letra, não diferem estatisticamente entre si, pelo teste de Tukey, ao nível de $5 \%$ de probabilidade. 
As deformações de pupas e de adultos foram baixas e também semelhantes nos diversos tipos de recipientes (Tabela 29). A porcentagem de deformação de adultos obtida em tubo de vidro foi próxima ao valor referido por Mihsfeldt (1985), em dieta artificial à base de milho "Nutrimaiz".

A perfuração do recipiente (Tabela 30) e o canibalismo (Figura 22) podem ser limitantes à seleção do recipiente. No caso de $D$. saccharalis, como o canibalismo ocorre quando existem simultaneamente lagartas de últimos ínstares e pupas, e as perfurações também são resultantes da ação de lagartas maiores, é possível utilizarem-se recipientes que permitam a produção não homogênea de pupas, retirandose as lagartas quando elas se encontram no $4^{0}$ ínstar, para produção de parasitóides ou patógenos. Isto se aplica às bandejas Bio-RT-32@ ou caixas de acrílico, resultando numa significativa redução de custo de produção, pela diminuição da mão-de-obra. As observações de canibalismo confirmam as observações de Hensley \& Hammond, (1968) e King et al. (1975), que relataram que as lagartas maiores danificam as primeiras pupas formadas.

Tabela 29. Deformação (\%) de pupas e de adultos de Diatraea saccharalis criada, em dieta artificial em tubo de vidro, copo plástico União $\circledast$, bandeja de criação Bio-RT-32 $\circledast$, copo plástico translúcido da Arteplast $\AA^{\circledR}$ e caixa acrílica. Temperatura: $25 \pm 1{ }^{\circ} \mathrm{C}$; UR: $60 \pm 10 \%$; fotofase: 14 horas.

\begin{tabular}{lcc}
\hline \multicolumn{1}{c}{ Recipientes } & \multicolumn{2}{c}{ Deformação (\%) } \\
\cline { 2 - 3 } & $0,43 \pm 0,28 \mathrm{a}$ & Adultos \\
\hline Tubo de vidro & $1,41 \pm 0,36 \mathrm{a}$ & $1,58 \pm 0,77 \mathrm{a}$ \\
Copo plástico União ${ }^{8}$ & $1,16 \pm 0,48 \mathrm{a}$ & $3,02 \pm 0,63 \mathrm{a}$ \\
Bandeja Bio-RT-32® & $0,25 \pm 0,25 \mathrm{a}$ & $3,80 \pm 1,07 \mathrm{a}$ \\
Copo plástico Arteplast ${ }^{\circledR}$ & $0,99 \pm 0,37 \mathrm{a}$ & $1,72 \pm 0,66 \mathrm{a}$ \\
Caixa acrílica & & $1,73 \pm 0,44 \mathrm{a}$ \\
\hline
\end{tabular}

Médias seguidas da mesma letra, não diferem estatisticamente entre si, pelo teste de Tukey, ao nível de $5 \%$ de probabilidade. 
Tabela 30. Perfuração (\%) por Diatraea saccharalis nos recipientes: tubo de vidro, copo plástico União $\circledast$, bandeja de criação Bio-RT- $32 \circledast$, copo plástico translúcido da Arteplast ${ }^{\circledR}$ e caixa acrílica. Temperatura: $25 \pm 1{ }^{\circ} \mathrm{C}$; UR: $60 \pm 10 \%$; fotofase: 14 horas.

\begin{tabular}{lc}
\hline \multicolumn{1}{c}{ Recipientes } & Perfuração (\%) \\
\hline Tubo de vidro & $0,00 \pm 0,00 \mathrm{c}$ \\
Copo plástico União ${ }^{\circ}$ & $83,00 \pm 4,96 \mathrm{a}$ \\
Bandeja Bio-RT-32® & $49,00 \pm 6,90 \mathrm{~b}$ \\
Copo plástico Arteplast $\circledast$ & $0,00 \pm 0,00 \mathrm{c}$ \\
Caixa acrílica & $0,00 \pm 0,00 \mathrm{c}$ \\
\hline
\end{tabular}

Médias seguidas da mesma letra, não diferem entre si, pelo teste de t, ao nível de $5 \%$ de probabilidade

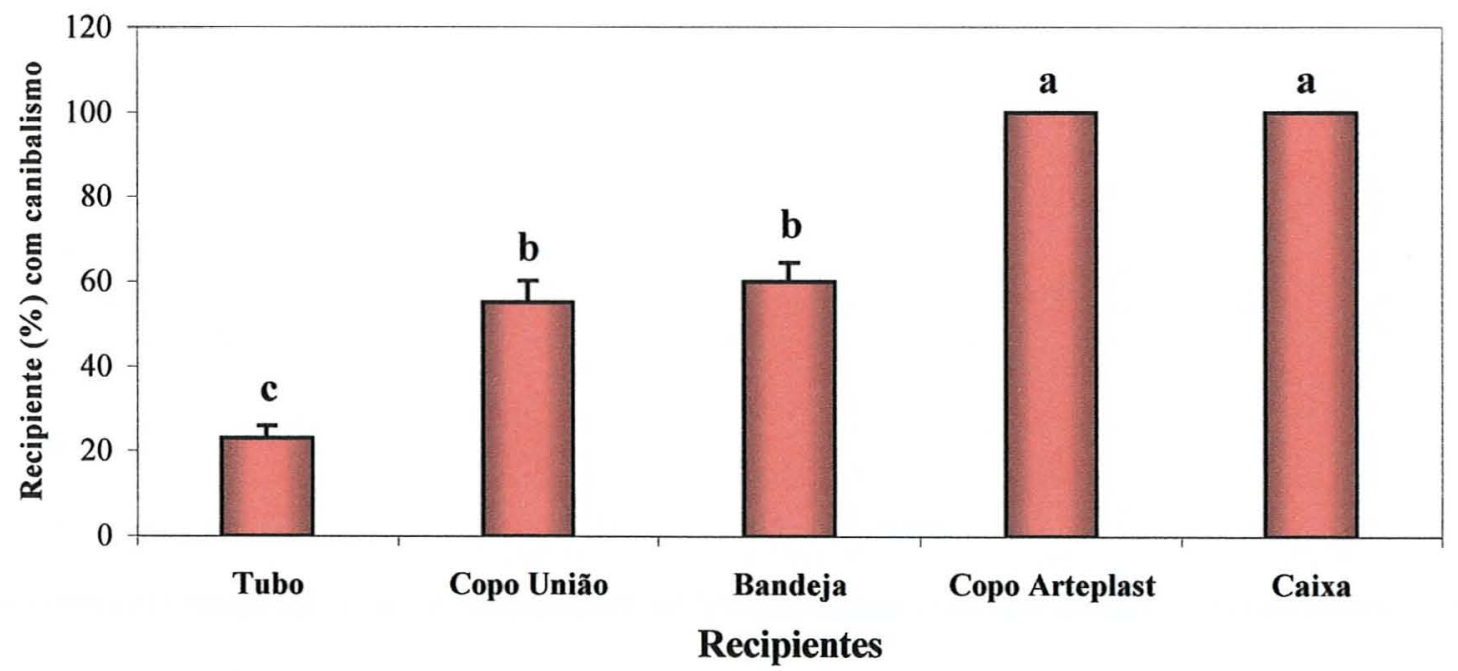

Figura 22. Porcentagem de recipientes em que ocorreu canibalismo na criação de Diatraea saccharalis em cinco tipos de recipientes. Temperatura: $25 \pm 1^{\circ} \mathrm{C}$; UR: $60 \pm 10 \%$; fotofase: 14 horas.

Médias seguidas da mesma letra, não diferem estatisticamente entre si, pelo teste $t$, ao nível de $5 \%$ de probabilidade. 


\subsection{Considerações Gerais}

Na primeira etapa da pesquisa, visando avaliar o consumo e utilização de alimento por Spodoptera frugiperda (J. E. Smith, 1797), Heliothis virescens (Fabricius, 1781) e Diatraea saccharalis (Fabricius, 1794), em duas temperaturas, objetivando definir a mais adequada para estudos da escolha de recipiente para as três espécies, com hábitos comportamentais diferentes, pôde-se constatar que o consumo e utilização da dieta artificial variaram com a espécie, temperatura, e posição em que a dieta foi oferecida aos insetos. Quando o alimento foi oferecido em recipientes mantidos na posição vertical, a maior eficiência de conversão se deu à $30^{\circ} \mathrm{C}$ para $S$. frugiperda, sendo, no entanto, semelhante à 25 e $30^{\circ} \mathrm{C}$ para $H$. virescens e $D$. saccharalis. Demonstrando esta variação mais característica, provavelmente ligada a fatores abióticos (luminosidade) ou mesmo bióticos (características morfológicas e comportamentais), S. frugiperda aproveitou melhor a alimento, à $25 \mathrm{C}$, quando o recipiente foi mantido na posição inclinada. Para espécies que devem ser criadas isoladamente durante todo o desenvolvimento, por serem canibais, caso de $S$. frugiperda que tem este hábito desde o $3^{\mathrm{o}}$ ínstar, nem sempre a quantidade correspondente ao consumo por um indivíduo é suficiente para o seu desenvolvimento normal. Assim, embora $S$. frugiperda consuma $5 \mathrm{ml}$, se esta quantidade for colocada em recipiente de criação na posição vertical, haverá problemas com relação à mortalidade inicial, duração e viabilidade larval e peso de pupas. Neste caso, deve ser colocado $60 \%$ a mais de dieta $(8 \mathrm{ml})$ para que o desenvolvimento do inseto seja adequado. Ficou demonstrado, baseando-se nos resultados da presente pesquisa, que, para seleção de recipientes, não há necessidade de observações relacionadas às fases adulta, desde que os insetos sobreviventes têm comportamentos semelhantes entre si. A perda de água, neste caso, afetará o normal desenvolvimento do inseto. Quando o recipiente for mantido na posição inclinada, pelo fato das fezes ficarem em contato com a dieta, a umidade é mantida, e a quantidade de dieta por tubo pode ser reduzida. Para as três espécies mencionadas pôde- 
se constatar que o tubo de vidro foi o melhor recipiente, independente do hábito do inseto, ou seja, canibal ( $S$. frugiperda), semi canibal ( $H$. virescens) ou não canibal $(D$. saccharalis).

Embora no tubo de vidro tenha ocorrido maior perda de água, ao longo do tempo em relação aos outros recipientes, tal perda não foi limitante para a escolha do tipo de recipiente, desde que se coloque uma quantidade de dieta superior àquilo que o inseto consome. Este recipiente propiciou, em geral, menor duração, maior viabilidade das fases larval e do ciclo total, bem como maior peso de pupas. Ao lado destas vantagens, não permitiu a perfuração dos recipientes, fator limitante para os copos plásticos e bandeja, no caso de $D$. saccharalis e em menor escala para copos plásticos e para $H$. virescens. Dadas às melhores condições microclimáticas proporcionadas, o canibalismo foi menor no tubo de vidro, especialmente para $S$. frugiperda.

Desta forma, considerando-se as características ideais de um recipiente de criação, ou seja: preço, transparência (para observações biológicas), facilidade de aquisição no mercado, que mantenha umidade suficiente para permitir o desenvolvimento do inseto, e que seja de material não tóxico (Parra, 1996), o tubo de vidro atende a estes requisitos, mesmo para produção massal de laboratório, embora tenha um custo adicional com mão-de-obra, por ser reutilizável. Considerando-se que alguns materiais são importados, como as bandejas Bio-RT-32®, poderia, neste caso, haver um custo adicional neste processo de importação. Os tubos de vidro são melhores para insetos canibais, pois no caso de $D$. saccharalis ou mesmo $H$. virescens podem ser usadas as caixas acrílicas ou copos plásticos, desde que as lagartas sejam destinadas à produção de parasitóides ou patógenos, procedendo-se à sua retirada antes de ocorrer o canibalismo (no caso de D. saccharalis, antes de se formarem as primeiras pupas).

Desta forma, para as condições brasileiras, em função do melhor desempenho biológico das três espécies, quando se pretende a criação contínua em laboratório, o tubo de vidro de fundo chato, pode-ser considerado o recipiente mais adequado. 


\section{CONCLUSÕES}

1. O consumo e utilização de alimento é variável, dependendo da espécie, da temperatura e da posição em que a dieta é oferecida.

2. Quando a dieta é oferecida em recipientes mantidos na posição vertical, a maior eficiência de conversão do alimento, ocorre à $30^{\circ} \mathrm{C}$ para Spodoptera frugiperda (J. E. Smith , 1797), sendo tal eficiência semelhante à 25 e $30^{\circ} \mathrm{C}$ para $H$. virescens e $D$. saccharalis.

3. A forma como a dieta é oferecida é mais importante para $S$. frugiperda, em relação às outras espécies.

4. A quantidade de alimento a ser colocada em um recipiente, determinada pelo consumo do alimento, pode não ser suficiente para o normal desenvolvimento da espécie, pois quando os insetos são criados isoladamente, a perda de água ao longo do tempo, pode afetar a mortalidade inicial, duração e viabilidade das fases imaturas e peso de pupas.

5. Para S. frugiperda, deve ser colocado $60 \%$ a mais de dieta para normal desenvolvimento das fases imaturas, quando o recipiente é mantido na posição vertical.

6. A maior perda de água, ao longo do tempo, não é suficiente para a escolha de um recipiente.

7. A qualidade do recipiente, permitindo a perfuração por lagartas, pode ser decisivo na escolha do recipiente de criação.

8. O tubo de vidro de fundo chato é o recipiente mais adequado para criação de $S$. frugiperda, $H$. virescens e $D$. saccharalis por permitir menor duração e maior viabilidade das fases imaturas e maior peso de pupas, além de impedir a perfuração pelas lagartas e diminuir sensivelmente o canibalismo. 


\section{REFERÊNCIAS BIBLIOGRÁFICAS}

ALMEIDA, R.M.S. Nutrição quantitativa e influência da densidade populacional no desenvolvimento e fecundidade de Diatraea saccharalis (Fabricius, 1794) (Lepidoptera - Pyralidae). Piracicaba, 1986. 68p. Dissertação (Mestrado) - Escola Superior de Agricultura "Luiz de Queiroz", Universidade de São Paulo.

BAILEY, D.L.; CHADA, H.L. Effects of natural (sorghum) and artificial (wheat germ) diets on development of the corn earworm, fall armyworm and southwestern corn borer. Journal of Economic Entomology, v.61, n.1, p.257-260, 1968.

BARFIELD, C.S.; MITCHELL, R.E.; POE, S.L. A temperature-dependent model for fall armyworm development. Annals of the Entomological Society of America, v.71, n.1, p.70-74, 1978.

BERGER, R.S. Laboratory techniques for rearing Heliothis species on artificial medium. Washington: USDA, Agricultural Research Service, 1963. 4p (ARS, 3384)

BOWLING, C.C. Rearing of the two lepidopterous pests of rice on a common artificial diet. Annals of the Entomological Society of America, v.60, n.6, p.1215-1216, 1967. 
BREWER, F.D. Development of Heliothis virescens and Diatraea saccharalis on a soyflour-corn oil diet. Annals of the Entomological Society of America, v.74, n.3, p.320-323, 1981.

BREWER, F.D. Evaluation of selected parameters as quality control criteria for mass producing a tobacco budworm (Lepidoptera: Noctuidae). Annals of the Entomological Society of America, v.76, n.3, p.339-342, 1983.

BURTON, R.L.; COX, H.C. An automated packaging machine for lepidopterous larval. Journal of Economic Entomology, v.59, n.4, p.907-909, 1966.

BURTON, R.L.; HARREL, E.A. Modification of a lepidopterous larvae dispenser for a packaging machine. Journal of Economic Entomology, v.59, n.6, p.1544-1545, 1966.

BURTON, R.L.; PERKINS, W.D. WSB, a new laboratory diet for the corn earworm and the fall armyworm. Journal of Economic Entomology, v.65, n.2, p.385-386, 1972.

BURTON, R.; PERKINS, D. Containerization for rearing insects. In: KING, E.G.; LEPPLA, N.C. (Ed.) Advances and challenges in insects rearing. New Orleans: (USDA), Agricultural Research Service (Southern Region), 1984. cap. 3, p.51-56.

BURTON, R.L.; HARREL, E.A.; COX, H.C.; HARE, W.W. Devices to facilitate rearing of lepidopterous larvae. Journal of Economic Entomology, v.59, n.3, p.594-596, 1966.

BUTT, B.A.; CANTU, E. Sex determination of lepidopterous pupae. Washington: USDA, 1962.7p. 
COMBS JR, R.L.; VALERIO, J.R. Biology of the fall armyworm on four varieties of bermudagrass when held at constant temperatures. Environmental Entomology, v.9, n.4, p.393-396, 1980.

CRÓCOMO, W.B.; PARRA, J.R.P. Consumo e utilização de milho, trigo e sorgo por Spodoptera frugiperda (J.E.Smith, 1797) (Lepidoptera, Noctuidae). Revista Brasileira de Entomologia, v.29, p. 225-260, 1985.

DAVIS, F. M. Mechanically removing southwestern corn borer pupae from plastic rearing cups. Journal of Economic Entomology, v.75, n.2, p.393-395, 1982.

DAVIS, F.M.; MALONE, S.; OSWALT, T.G.; JORDAN, W.C. Medium sized lepidopterous rearing system using multicellular rearing trays. Journal of Economic Entomology, v.83, n.4, p.1535-1540, 1990.

ESCALANTE, J.A.G. Contribuición al conocimiento de la biologia de Heliothis zea y Spodoptera frugiperda, en el Cusco. Revista Peruana de Entomologia, v.17, n.1, p.121-122, 1974.

FERRAZ, M.C.V.D. Determinação das exigências térmicas de Spodoptera frugiperda (J.E.Smith, 1797) (Lepidoptera, Noctuidae) em cultura de milho. Piracicaba, 1982. 81p. Dissertação (Mestrado) - Escola Superior de Agricultura "Luiz de Queiroz", Universidade de São Paulo.

FOX, L.R. Cannibalism in natural populations. Annual Review of Ecology and Systematies, v.6, p.87-106, 1975 a.

GALLO, D.; WIENDL, F. M.; WILLIAMS, R. N.; BERTI FILHO, E. Métodos de criação artificial da broca de cana-de-açúcar para emprego no seu controle. In: 
REUNIÃO ANUAL DE ENTOMOLOGIA, 2., Recife, 1969. Resumos. Recife: SEB, 1969. p.4-5.

GUERRA, A.A. Effect of biologically active substances in the diet on development and reproduction of Heliothis spp. Journal of Economic Entomology, v.63, n.5, p.1518-1521, 1970.

GUERRA, A.A. ; BHUTYA, A.D. Nutrition of the tobacco budworm: an economical larval diet for rearing. Journal of Economic Entomology, v.70, n.5, p.568-570, 1977.

HARE, W.W.; HARRELL, E.A.; PERKINS, W.D. Moisture removed from rearing cells during incubation of corn earworm on an artificial diet. Journal of Economic Entomology, v.66, n.1, p.284-285, 1973.

HARTLEY, G.C.; KING, E. G.; BREWER, F.D.; GANTT, C.W. Rearing of the Heliothis sterile hybrid with a multicellular larval rearing container and pupal harvesting. Journal of Economic Entomology, v.75, n.1, p.7-10, 1982.

HENDRICKS, D.E.; LEAL, M.P.; ROBINSON, S.H.; HERNANDEZ, N.S. Oil soluble black dye in larval diet marks adults and eggs of tobacco budworm and pink bollworm. Journal of Economic Entomology, v.64, n. 6, p.1399-1401, 1971.

HENSLEY, S.D.; HAMMOND, A. M. Laboratory techniques for rearing the sugarcane borer on an artificial diet. Journal of Economic Entomology, v.61, n.6, p. 1742$1743,1968$.

IGNOFFO, C.M.; BOENING, O.P. Compartmented disposable plastic trays for rearing insects. Journal of Economic Entomology, v.63, n.5, p.1696-1697, 1970. 
JOYNER, K.; GOULD, F. Developmental consequences of cannibalism in Heliothis zea (Lepidoptera: Noctuidae). Annals of the Entomological Society of America, v.78, n.1, p.24-28, 1985.

JOYNER, K.; GOULD, F. Conspecific tissues and secretions as sources of nutrition. In: SLANSKY Jr., F.; RODRIGUEZ, J.G. (Ed.) Nutritional ecology of insects, mites, spiders and related invertebrates. New York: John Willey, 1987. p.697-719.

KASTEN JUNIOR, P.; PRECETTI, A.A.C.M.; PARRA, J.R.P. Dados biológicos comparativos de Spodoptera frugiperda (J.E. Smith, 1797) em duas dietas artificiais e substrato natural. Revista de Agricultura, v.53, n.1/2, p.68-78, 1978.

KING, E.G.; HARTLEY, G.G. Diatraea saccharalis. In: SINGH, P.; MOORE, R.F. (Ed.). Handbook of insect rearing. New York: Elsevier, 1985. p.265-270.

KING, E.G.; BREWER, F.D.; MARTIN, D.F. Development of Diatraea saccharalis (Lep.: Pyralidae) at constant temperatures Entomophaga, v.20, n.3, p.301-316, 1975.

KOGAN, M. Criação de insetos: bases nutricionais e aplicação em programas de Manejo de Pragas. In: CONGRESSO BRASILEIRO DE ENTOMOLOGIA, 6., Campinas, 1980. Anais. Campinas: Fundação Cargill, 1980. p.45-75.

LEPPLA, N.C.; ADAMS, F. Insect mass-rearing technology, principles and applications. $1987.20 \mathrm{p}$.

LEPPLA, N.C.; CARLYLE, S.L.; PONS, W.S.;MITCHELL, E.R. Use of a rodent rearing container for culturing insects. Journal of Georgia Entomological Society, v.10, p.326-327, 1975. 
LEUCK, D.B.; PERKINS, W.D. A method of estimating fall armyworm progeny reduction when evaluating control achieved host-plant resistance. Journal of Economic Entomology, v.65, p.482-483, 1972.

LINGREN, P.D.; BRYAN, D.E. Dosage mortality data on the bollworm, Heliothis zea, and the tobacco budworm, Heliothis virescens, in Oklahoma. Journal of Economic Entomology, v.58, n.1, p.14-18, 1965.

MACEDO, N.; CAMPOS, M.B.S. Inovações tecnológicas na criação massal de Diatraea saccharalis para controle biológico. STAB, v.7, n.2, p.46-49, nov/dez. 1998.

MACEDO, N.; BOTELHO, P.S.M.; DEGASPARI, N.; ALMEIDA, L.C.; ARAÚJO, J.R.; MAGRINI, E.A. Controle biológico da broca da cana-de-açúcar: manual de instrução. Piracicaba: IAA, PLANALSUCAR, 1983. 22p.

MACHADO, L.A.; PARRA, J.R.P. Comparação de recipientes para criação de Spodoptera frugiperda (J.E. Smith, 1797) em dietas artificiais. In: CONGRESSO BRASILEIRO DE ENTOMOLOGIA, 11, Campinas, 1987. Resumos. Campinas: SEB, 1987. p.30.

MARQUEZ, S.A.; VILLARREAL, J.F.; SCHALLENMUELLER, D.E.; VEILLARD, J.M. Estudios biológicos del gusano cogollero. Informe Annual de Investigación, v.9, p.27-32, 1963/1964.

MÉLO, A.B.P. Biologia de Diatraea saccharalis (Fabricius, 1794) (LepidopteraPyralidae) em diferentes temperaturas para determinação das exigências térmicas. Piracicaba, 1984. 101p. Dissertação (Mestrado) - Escola Superior de Agricultura "Luiz de Queiroz", Universidade de São Paulo. 
MENDONÇA FILHO, A. Criação artificial em laboratório dos parasitos da broca da cana-de-açúcar (Diatraea spp.) (Lep., Crambidae) Brasil Açucareiro, v.81, p.4780, 1973.

MIELITZ, L.R., CORSEUIL, E.; SOARES, C.M.S. Efeito do germe-de-trigo e vitaminas em dieta artificial sobre Spodoptera frugiperda (J.E. Smith, 1797) (Lepidoptera, Noctuidae). Anais da Sociedade Entomológica do Brasil, v.15, p.105-115, 1986.

MIHSFELDT, L.H. Comparação de dietas artificiais para a criação de Diatraea saccharalis (Fabricius, 1794) (Lepidoptera-Pyralidae). Piracicaba, 1985. 120p. Dissertação (Mestrado) - Escola Superior de Agricultura "Luiz de Queiroz", Universidade de São Paulo.

MISKIMEN, G.N. Nonaseptic laboratory rearing of the sugarcane borer, Diatraea saccharalis. Annals of the Entomological Society of America, v.58, n.6, p.820823, 1965.

MONTEWKA, R.H.; PONGPONRATN, P.; FEARS, R.D. Rearing tobacco budworm in the Iaboratory. Wayside: Miss. Dow Chemical, 1976. 6p.

MORAES, G.J.; GALLO, D. Contribuição à metodologia de criação de Diatraea saccharalis. In: CONGRESSO BRASILEIRO DE ENTOMOLOGIA, 3., Maceió, 1976. Resumos. Maceió: SEB, 1976. p. 157.

MORETI, A.C.C.C Biologia comparada e controle de qualidade de Heliothis virescens (Fabr., 1781) (Lepidoptera - Noctuidae) em dietas natural e artificial. Piracicaba, 1980. 98p. Dissertação (Mestrado) - Escola Superior de Agricultura "Luiz de Queiroz", Universidade de São Paulo. 
MORETI, A.C.C.C.; PARRA, J.R.P. Biologia comparada e controle de qualidade de Heliothis virescens (Fabr., 1781) (Lepidoptera-Noctuidae) em dietas natural e artificial. Arquivos do Instituto Biológico, v.50, n.1/4, p.7-15, jan./dez. 1983.

MORRISON, R.K.; HOUSE, V.S.; RIDGWAY, R.L. Improved rearing unit for larvae of a common green lacewing. Journal of Economic Entomology, v.68, p.881-882, 1975.

NALIM, D.M. Biologia, nutrição quantitativa e controle de qualidade de populações de Spodoptera frugiperda (J.E.Smith, 1797) (Lepidoptera: Noctuidae) em duas dietas artificiais. Piracicaba, 1991. 150p. Tese (Doutorado) - Escola Superior de Agricultura "Luiz de Queiroz", Universidade de São Paulo.

NG, S.S.; DAVIS, F.M.; REESE, J.C. Southwestern corn borer (Lepidoptera: Pyralidae) and fall armyworm (Lepidoptera: Noctuidae): comparative developmental biology and food consumption and utilization Journal of Economic Entomology, v.86, n.2, p.394-400, 1993.

NOVARETTI, W.R.; TERAN, F.O. Melhorias introduzidas nas dietas usadas para criação de Diatraea saccharalis (Fabr., 1794). In: SEMINÁRIO COPERSUCAR DA AGROINDÚSTRIA AÇUCAREIRA, 4., São Paulo, 1976. Anais. São Paulo: COPERSUCAR, 1976. p.81-84.

OLIVEIRA, L.J. Biologia, nutrição quantitativa e danos causados por Spodoptera frugiperda (J.E.Smith, 1797) (Lepidoptera: Noctuidae) em milho cultivado em solo corrigido para três niveis de aluminio. Piracicaba, 1987. 125p. Dissertação (Mestrado) - Escola Superior de Agricultura "Luiz de Queiroz", Universidade de São Paulo. 
PAN, Y.S.; LONG, W.H.. Diets for rearing the sugarcane borer. Journal of Economic Entomology, v.54, n.2, p.257-261, 1961.

PANTOJA, A.; SMITH, C.M.; ROBINSON, J.F. Development of fall armyworm, Spodoptera frugiperda (J.E. Smith) (Lepidoptera: Noctuidae), strains from Louisiana and Puerto Rico. Environmental Entomology, v.16, n.1, p.116-119, Feb. 1987.

PARRA, J.R.P. A situação da criação de insetos, em meios artificiais, no Brasil. In: CONGRESSO BRASILEIRO DE ENTOMOLOGIA, 6., Campinas, 1980. Anais. Campinas: Fundação Cargill, 1980. p.193-212.

PARRA, J.R.P. Consumo e utilização de alimento por insetos. In: PANIZZI, A.R.; PARRA, J.R.P.(Ed.) Ecologia nutricional de insetos e suas implicações no manejo de pragas. São Paulo: Manole, 1991. p.9-65.

PARRA, J.R.P. Téenicas de criação de insetos para programas de controle biológico. 3.ed. Piracicaba: FEALQ, 1996. 137p.

PARRA, J.R.P.; CARVALHO, S.M. Biologia e nutrição quantitativa de Spodoptera frugiperda (J.E.Smith, 1797) em meios artificiais compostos de diferentes variedades de feijão. Anais da Sociedade Entomológica do Brasil, v.12, n.2, p.305-319, 1984.

PARRA, J.R.P.; MIHSFELDT, L.H. Comparison of artificial diets for rearing the sugarcane borer. In: ANDERSON, T. E.; LEPPLA, N.C. (Ed.) Advances in insect rearing for research $\&$ pest management. San Francisco: Westview Press, 1992. p.195-209. 
PARRA, J.R.P.; BOTELHO, P.S.M.; ALVES, S.B.; MAGRINI, E.A. Controle da lagarta-da-soja Anticarsia gemmatalis: projeto piloto para produção de Baculovirus anticarsia, visando o seu controle. Piracicaba: ESALQ; CENA,1993. (ESALQ.CENA. Boletim Técnico, 3). p.8.

PATANA, R. Rearing cotton insects in the laboratory. Washington: USDA, 1969. 7p. (USDA. Production Research Report, 108).

PENCOE, N.L.; MARTIN, P.M. Development and reproduction of fall armyworms on several wild grasses. Environmental Entomology, v.10, n.6, p.999-1002, 1981.

PENCOE, N.L.; MARTIN, P.B. Fall armyworm (Lepidoptera, Noctuidae) larval development and adult fecundity of five grass hosts. Environmental Entomology, v.11, n.3, p.720-723, 1982.

PETERSON, A. Entomological techniques: how to work with insects. Ann Arbor: Edwards Brother, 1964. 435 p.

PETTERSON, M.A.; DEBOLT, J.W. Rearing the beet armyworm in paraffined paper bags. Journal of the Georgia Entomological Society, v.10, n.2, p.166-168, 1975.

PETTERSON, M.A.; DEBOLT, J.W. Reusable plastic trays for rearing but armyworms and cabbage loopers. Journal of the Georgia Entomological Society, v.11, n.2, p.183-186, 1976.

POLIS, G.A. The evolution and dynamics of intraspecific predation. Annual Review of Ecology and Systematics, v.12, p.225-251, 1981. 
QUISENBERRY, S.S.; WITFORD, F. Evaluation of bermudagrass resistance to fall armyworm (Lepidoptera: Noctuidae): influence of host strain and dietary conditioning. Journal of Economic Entomology, v.81, n.5, p.1463-1468, 1988.

RAFFA, K.F. Effect of host plant on cannibalism rates by fall armyworm (Lepidoptera: Noctuidae) larvae. Environmental Entomology, v.16,n.3, p.672-675, 1987.

RAULSTON, J.R.; LINGREN, P.D. A technique for rearing larvae of the bollworm and tobacco budworm in large numbers. Journal of Economic Entomology, v.62, p.959-961, 1969.

RAULSTON, J.R.; LINGREN, P.D. Methods for large-escale rearing of the tobacco budworm.. Washington: USDA, 1972. 10p. (USDA. Production Research Report, 145).

REVELO, M.A.; RAUN, E.S. Rearing the fall armyworm under greenhouse conditions. Journal of Economic Entomology, v.57, n.6, p.1000, 1964.

RICHMOND, C.A.; MARTIN, D.F. Techniques for mass rearing of the pink bollworm by infesting diet medium with eggs. Journal of Economic Entomology, v.59, n.3, p.762-763, 1966.

RISCO, S.H.; MORALES, N.; AYQUIPA, C. Uma dieta para crianza masiva de orugas del borer de la caña de azúcar: Diatraea saccharalis (Fabr.) (Lep.: Crambidae) Saccharum, v.1, n.1, p. 27-42, 1973.

ROBERSON, J.L.; NOBLE, L.W. Rearing the tobacco budworm in honeycomb- like cells. Journal of Economic Entomology, v.61, n.1, p.331-332, 1968. 
ROE, R.M.; HAMMOND, A.M.; SPAKS, T.C. Growth of larval Diatraea saccharalis (Lepidoptera-Pyralidae) on an artificial diet and synchronization of the last larval stadium. Annals of the Entomological Society of America, v.75, n.4, p.421-429, 1982.

SANTA CRUZ, J.M.S.; MOSS, C.S.; RAYNAUD, G.G.; MONTALVO, C.G. Cria artificial de Diatraea saccharalis Fab. (Lepidoptera-Pyralidae) y su aplicación en la evolución de resistencia en maiz. Agrociencia, v.18, p.3-13, 1964.

SCRIBER, J.M.; SLANSKY Jr, F. The nutritional ecology of immature insects. Annual Review of Entomology, v.26, n.1, p.183-211, 1981.

SCRIBER, J.M.; SLANSKY Jr, F. Food consumption and utilization. In: KERKUT, G.A.; GILBERT, L.I. (Ed.) Comprehensive insect physiology, biochemistry and pharmacology. New YorK: Pergamon Press, 1985. p.87-163.

SGRILLO, R.B. Criação em laboratório da broca da cana-de-açúcar Diatraea saccharalis (Fabricius, 1794) visando o seu controle. Piracicaba, 1973. 98p Dissertação (Mestrado) - Escola Superior de Agricultura "Luiz de Queiroz", Universidade de São Paulo.

SGRILLO, R.B.; WALDER, J.M.M.; WIENDL, F.M. Progressos na criação da broca da cana de açúcar, Diatraea saccharalis (F.), realizados no Centro de Energia Nuclear da Agricultura-CENA. O Solo, v. 69, n.1, p. 58-60, 1976.

SHOREY, H.H.; HALE, R.L. Mass-rearing of the larvae of nine noctuid species on a simple artificial medium. Journal of Economic Entomology, v.58, n.3, p.522-524, 1965. 
SINGH, P. Artificial diets for insects, mites, and spiders. New York: IFI/ Plenum, 1977. 594p.

SINGH, P. A general purpose laboratory diet mixture for rearing insects. Insect Science and its Application, v.4, n.4, p.357-362, 1983.

SINGH, P.; JERRAM, E.M. Plastic damage by insects. The New Zealand Entomologist, v.6, n.2, p.1181, 1976.

SMTTH, C.N. Insect colonization and mass production. New York: Academic Press, 1966. 618p.

SOUZA, A.R.R. Biologia comparada de Heliothis virescens (Fabr., 1781) (LepidopteraNoctuidae) a diferentes temperaturas, em meios naturais e artificial. Piracicaba, 1981. 87p. Dissertação (Mestrado) - Escola Superior de Agricultura "Luiz de Queiroz", Universidade de São Paulo.

VAN DINTHER, J.B.M.; GOOSSENS, P.A. Rearing of Diatraea saccharalis on diets in Surinam. Entomologia Experimentalis et Applicata, v.13, p.320-326, 1970.

VÁZQUEZ, W.R.C. Biologia comparada de Pseudoplusia includens (Walker, 1857) (Lepidoptera: Noctuidae) em dietas naturais e artificiais e efeito de um vírus de poliedrose nuclear na sua mortalidade e no consumo da área foliar da soja. Piracicaba, 1988. 164p. Dissertação (Mestrado) - Escola Superior de Agricultura "Luiz de Queiroz", Universidade de São Paulo.

VILLACORTA, A.; MAGRO, J.A. Criação massal de Diatraea saccharalis (Lepidoptera: Pyralidae) em laboratório. Anais da Sociedade Entomológica do Brasil, v.4, n.1, p.43-48, 1975. 
WALDBAUER, G.P. The consumption and utilization of food by insects. Advances of Insect Physiology, v.5, n.1, p.229-288, 1968.

WALKER, D.W.; FIGUEROA, M. Biology of the sugarcane borer, Diatraea saccharalis (F.). III. Oviposition rate. Annals of the Entomological Society of America, v.57, n.4, p.515-516, 1966.

WISEMAN, B.R.; PITRE, H.N.; GOURLEY, L.; FALES, S.L. Differential growth responses of fall armyworm larval on developing sorghum seeds incorporated into a meridic diet. Florida Entomologist, v.67, n.3, p.357-367, Sept. 1984.

WONGSIRI, T.; RANDOLPH, N.M. A comparison of the biology of the sugarcane borer on artificial and natural diets. Journal of Economic Entomology, v.55, n.4, p.472-473, 1962.

WOOD, H.A.; HUGHES, P.R. Recombinant viral insecticides: delivery of environmentally safe and cost-effective products. Entomophaga, v.41, n.3/4, p.361$373,1996$. 